\title{
Applying Organic Compounds as Indicators in Innovative Monitoring Strategies
}

\author{
Dissertation \\ zur Erlangung des mathematisch-naturwissenschaftlichen Doktorgrades \\ „Doctor rerum naturalium“ \\ der Georg-August-Universität Göttingen \\ im Promotionsprogramm Geowissenschaften \\ der Georg-August University School of Science (GAUSS)
}

vorgelegt von

Wiebke Warner

aus Hannover

Göttingen 2019 


\title{
Betreuungsausschuss
}

\author{
apl. Prof. Dr. Tobias Licha
}

Georg-August-Universität Göttingen

\section{Dr. Karsten Nödler}

Technologiezentrum Wasser Karlsruhe

Mitglieder der Prüfungskommission

$\begin{array}{ll}\text { Referent } & \text { apl. Prof. Dr. Tobias Licha } \\ \text { Georg-August-Universität Göttingen }\end{array}$

Korreferenten Prof. Dr. Matthias Willbold

Georg-August-Universität Göttingen

Dr. Karsten Nödler

Technologiezentrum Wasser Karlsruhe

Weitere Mitglieder der Prüfungskommission

Prof. Dr. Joachim Reitner

Georg-August-Universität Göttingen

Dr. Christine Heim

Georg-August-Universität Göttingen

Dr. habil. Elke Bozau

Technische Universität Clausthal

Tag der mündlichen Prüfung: 08. Juli 2019 


\section{Abstract}

Today, demands on water quality are diverse and strongly differ by water use related criteria. Additionally, the complex topic of water quality is of increasing importance for citizens and is therefore often emotionally loaded by media. Surface waters are important ecosystems for biota. Additionally, they can serve as drinking water resources and have become increasingly important for recreational activities and tourism. Ground and surface waters hence deserve protection, which creates a need for reliable water quality monitoring that produces high resolution and information-rich water quality data.

Currently, European water quality is assessed under the water framework directive (WFD), which has shown that water quality needs to be improved in many catchments. Nowadays, water quality data are based on fixed stations with monitoring conducted on predetermined dates and focusing on a more historically relevant list of classic water quality indicators. This often generates a biased and insufficient picture of the water quality. Understanding system dynamics to meet the needs of divers demands on water quality between catchments and water bodies requires a more flexible approach, while producing more meaningful data.

Classic water quality indicators, such as inorganic ions, are often not source specific and too general as they have myriad different anthropogenic and natural origins. They are only to a minor extent suitable for reliable source apportionment, to understand system dynamics and risk assessment.

In contrast, sources of micropollutants such as pharmaceuticals, lifestyle and personal care products, pesticides, household chemicals etc., are strongly related to anthropogenic activities. These in turn are very source specific, bear neglectable natural background concentrations, and hence can act as powerful, reliable and unbiased indicators.

This thesis gives a comprehensive and systematic overview of (micro)pollutants used as indicators in the aquatic environment over the last decades. Successfully exploiting micropollutants as indictors starts with appropriate sampling procedures, sample storage and analysis. These are essential steps in providing reliable data. This review is structured into the qualitative, semi-quantitative and quantitative use of indicators and presents a guide on how to decide for a suitable set of indicators.

Besides suitable sets of indicators, a water quality monitoring strategy, adjusted to the catchment needs and producing reliable and information-rich data, is im- 
portant for water quality assessment. Even though micropollutants are powerful indicators, they require analysis in a laboratory environment and do not allow acquisition in real-time. Correlating micropollutants which indicate a water quality threat to a universal signal (proxy), e.g. electrical conductivity, enables real-time data. Proxy mapping permits detecting potential pollution hot spots with a high information density for consecutive sampling. These signals can be derived from cheap sensor arrays in real-time which can easily be installed on automated sampling boats or drones. The successful application of this innovative strategy is presented on the inflow of a small tributary into Lake Garda (Italy) with an EC anomaly.

Besides recent applications, micropollutants can also serve to reconstruct historic pollution when they are stored in environmental archives such as sediment cores. This transfer is presented by two age-dated sediment cores of Lake Süßer See (Mansfeld area, Germany) historically a region of high intensity copper shale mining. Released during combustion, polycyclic aromatic hydrocarbons (PAHs), and especially the ratios of them, allowed delineating aqueous particle-bond transport of PAHs into the lake from atmospheric deposition.

Furthermore, an outlook for possible changes and new possibilities in water quality monitoring is presented. Future water quality problems regarding highly polar persistent mobile organic compounds (PMOCs) breaking the barrier into drinking water and indicators for pristine non-anthropogenic influenced areas are discussed in the conclusions of this thesis. 


\section{Zusammenfassung}

Die Anforderungen an Gewässerqualität werden heutzutage immer komplexer und sind sehr verschieden je nach Art der Wassernutzung. Zusätzlich hat das Thema Gewässerqualität zunehmend eine gesteigerte Wichtigkeit in der Bevölkerung, maßgeblich auch durch die emotionale Berichterstattung in den Medien.

Dennoch sind Oberflächengewässer essentielle Ökosysteme, können der Trinkwassergewinnung dienen und werden immer wichtiger in Hinblick auf Freizeitaktivitäten wie Naherholung und Tourismus. Grund- und Oberflächengewässer benötigen aus diesem Grund besonderen Schutz und ein verlässliches Überwachungssystem.

Zur Zeit findet Gewässerqualitätsüberwachung unter dem Schirm der Europäischen Wasserrahmenrichtlinie (WRRL) statt und hat gezeigt, dass viele Gewässerkörper eine verbesserungswürdige Qualität haben. Gewässerqualitätsdaten werden dadurch erhoben, dass an definierten Standorten und festen Terminen Gewässerproben entnommen und hinsichtlich, einer, eher historisch relevanten, Liste an Gewässerqualitätsparametern bestimmt werden. Dies erzeugt häufig ein falsches und unvollständiges Abbild der realen Gewässerqualität. Um zusätzlich auch Informationen über die Dynamik eines Systems zu erlangen, die Gewässerqualität besser zu erfassen und um die verschieden Bedürfnisse mit einzubeziehen, brauchen wir einen flexibleren Ansatz mit dem bessere Datensätze erzeugt werden können. Klassische Gewässerqualitätsindikatoren, wie anorganische Ionen sind oft nicht spezifisch genug, da sie viele anthropogene, aber gleichzeitig auch natürliche Quellen haben. Sie sind somit nur in einem geringen Maße in der Lage Quellen zuzuordnen, Systemdynamiken zu verstehen oder Risiken abzuschätzen.

Im Gegensatz dazu sind Quellen von Mikroschadstoffen wie Pharmaka, Pestizide, Zusätze in Kosmetikprodukten etc. stark anthropogen korreliert und sehr quellspezifisch mit einem vernachlässigbaren natürlichen Hintergrund und können somit hervorragend als Indikatoren genutzt werden.

Diese Arbeit gibt einen systematischen und umfassenden Überblick über die Nutzung von Mikroschadstoffen als Indikatoren in der aquatischen Umwelt. Die Nutzung von Mikroschadstoffen erfordert gleichermaßen eine sorgfältige Probenahme, deren richtige Lagerung und Analyse. Diese Zusammenfassung ist gegliedert in die qualitative, semi-quantitative und quantitative Anwendung, was ein Novum in der internationalen Literatur darstellt. Darüber hinaus gibt es eine verständliche Hilfestellung zur Auswahl geeigneter Indikatoren hinsichtlich spezifischer Fragestellungen. 
Neben der Auswahl an Gewässerqualitätsindikatoren, ist eine an das Einzugsgebiet angepasste Gewässerüberwachungsstrategie, die verlässliche und informative Daten liefert, unerlässlich. Auch wenn Mikroschadstoffe hervorragende Indikatoren sind, benötigen diese eine Laboranalyse und können keine Echtzeitdaten liefern. Korreliert man aber Mikroschadstoffe mit Summenparametern wie Leitfähigkeit oder universellen Parametern wie Temperatur, kann dieser Proxy für Echtzeitdaten genutzt werden, da das Erfassen von Proxy-Daten häufig sehr viel kostengünstiger ist und im Feld durchgeführt werden kann. Eine Erfassung des Gewässerkörpers mit Hilfe dieser Proxies kann helfen potentielle Einträge zu detektieren, an welchen dann Proben zwecks Laboranalysen genommen werden können, was die Informationsdichte gegenüber herkömmlichen Probenahmestrategien signifikant erhöht. Dies konnte im Rahmen dieser Arbeit erfolgreich an einem Zufluss des Garda-Sees (Italien) mit einer Leitfähigkeitsanomalie demonstriert werden.

Neben aktuellen Fragestellungen können Mikroschadstoffe aber auch genutzt werden, um historische Belastungsereignisse zu rekonstruieren, wenn sie in Umweltarchive, wie Sedimentkerne eingelagert wurden. Dieser Transfer konnte erfolgreich anhand zweier altersdatierter Tiefenprofile des Süßen Sees (Mansfeld, Germany) gezeigt werden. Durch die Kupferschieferverhüttung in diesem Gebiet sind polyzyklische aromatische Kohlenwasserstoffe (PAKs) in die Umwelt und in den Wasserkörper gelangt. Das Verhältnis verschiedener PAKs zueinander gibt Aufschluss darüber ob diese durch atmosphärischen oder partikelgetragenen Transport in den See gelangt sind. Ferner konnte der industrielle PAK-Ausstoß von dem Brand einer nahegelegenen Fabrik abgegrenzt werden.

Schlussendlich wird ein Ausblick auf denkbare Veränderungen und Möglichkeiten hinsichtlich der Gewässerqualitätsüberwachung gegeben, sowie Möglichkeiten der Nutzung zukünftiger problematischer Stoffgruppen als Indikatoren aufgezeigt und Perspektiven für Indikatoren in menschenunbeeinflussten Gebieten gegeben. 


\section{Danksagung}

Zunächst möchte ich mich bei Prof. Dr. Tobias Licha und Dr. Karsten Nödler für die Betreuung meiner Arbeit, sowie umfangreiche Unterstützung bedanken. Bei Tobias möchte mich ganz besonders für das entgegen gebrachte Vertrauen, konstruktive Kritik und angeregte Diskussionen bedanken. Großer Dank gilt auch Karsten und dem Technologiezentrum Wasser (TZW) für die stets motivierende Unterstützung bei Methodenentwicklung, sowie kritischen Diskussionen und Anregungen. Selbstverständlich möchte mich auch bei allen weiteren Mitgliedern der Prüfungskommission, Prof. Dr. Joachim Reitner, Prof. Dr. Matthias Willbold, Dr. Christine Heim und Dr. habil. Elke Bozau bedanken.

Des Weiteren möchte ich mich bei den Mitgliedern des INTCATCH Projektes, besonders Nathalie Gilbert, Geoff Brighty, sowie Lesley und Ant Parsons, für die kollegiale Unterstützung und zahlreichen Impulse bedanken. Besonders bei Nathalie Gilbert möchte ich für die sprachliche Korrektur bedanken.

Mechthild Rittmeier gebührt ganz besonderer Dank für ihre großzügige Unterstützung, die weit über die Laborarbeit hinausging.

Der größte Dank gilt wohl meinen Eltern, die durch ihre liebevolle Erziehung schon früh die Neugierde und Interesse an den Naturwissenschaften und am Denken in mir geweckt und gefördert haben. Meiner Mutter danke ich besonders für ihr offenes Ohr und Zuspruch in besonders schwierigen Zeiten und die bedingungslose Unterstützung meiner Entscheidung zu promovieren.

Bei meinen Freunden und Bekannten möchte ich mich von ganzem Herzen für ihr Verständnis, die vielen schönen verbrachten Stunden und guten Gespräche bedanken. Für die sprachliche Korrektur dieser Arbeit, aber vor allem für unsere wunderbaren und inspirierenden Gespräche abseits der Naturwissenschaften gebührt Katrin Bensler großer Dank. Florian danke ich für die liebevolle Unterstützung auf der Zielgeraden und vor allem dafür, dass er die Zeit abseits der Promotion so wertvoll gemacht hat. 
Dem Problem der Toleranz

dürften Sie kaum gewachsen sein, Ingenieur.

Prägen Sie sich immerhin ein, daß Toleranz zum Verbrechen wird, wenn sie dem Bösen gilt.

Thomas Mann - Der Zauberberg 


\section{Contents}

$\begin{array}{ll}\text { 1. Motivation and background } & 16\end{array}$

1.1. Current state of water quality monitoring. . . . . . . . . . . . . . 16

1.2. Need for changes in monitoring strategies . . . . . . . . . . . . . . . . 18

1.3. Need for new water quality indicators . . . . . . . . . . . . . . . 20

1.4. Scope, objectives and further outline of the thesis . . . . . . . . . 21

2. Qualitative and quantitative use of micropollutants as source and $\begin{array}{ll}\text { process indicators. A review. } & 27\end{array}$

2.1. Introduction . . . . . . . . . . . . . . . . . . . . . . . 28

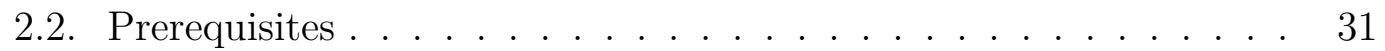

2.2.1. Potential, sources and environmental behaviour of micropollutants ............................... 31

2.2.2. Analytical requirements and recent developments . . . . . 34

2.2 .3 . Sampling and storage . . . . . . . . . . . . . 36

2.3. Obtaining qualitative and semi-quantitative information from in-

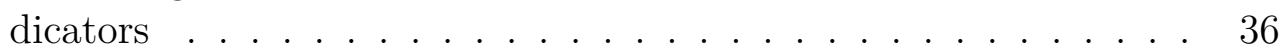

2.3.1. Persistent indicators for the detection of domestic wastewater 37

2.3.2. Indicators to identify the presence of untreated wastewater 39

2.3.3. Indicator sets to differentiate between treated and untreated wastewater .................. 40

2.3.4. Application of indicators with seasonal variations and defined application periods as chronomarkers . . . . . . . . . 41

2.3.5. Process indicators for changing boundary conditions. . . . 43

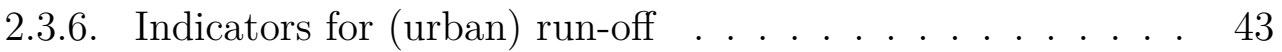

2.3.7. Verification of connectivity and exchange between water bodies ...................... 44

2.3.8. Using ratios of related compounds as indicators . . . . . . 45

2.4. Obtaining quantitative information from indicators . . . . . . . . 47

2.4.1. Wastewater-based epidemiology (WBE) . . . . . . . . . 47

2.5. Summary information - How to decide for a suitable set of indicators 49

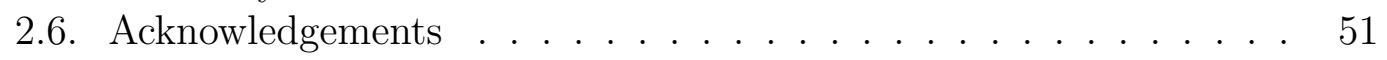

3. Integrated approach for innovative monitoring strategies of reser$\begin{array}{ll}\text { voirs and lakes } & 74\end{array}$

3.1. Abstract . . . . . . . . . . . . . . . . . . . . . . 75

3.2. Introduction . . . . . . . . . . . . . . . . 75 
3.3. Aspects of an innovative monitoring strategy . . . . . . . . . . . . 77

3.3.1. First step: Composing existing data and defining problems

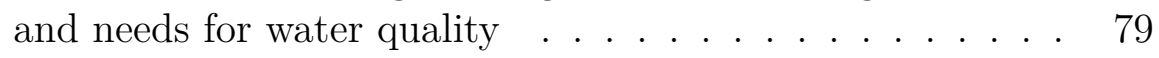

3.3.2. Second step: Investigative real-time water quality mapping, sampling and identification of an appropriate set of source and process specific indicators . . . . . . . . . . . 79

3.3.3. Third step: Real-time monitoring by using proxies . . . . . 83

3.4. Application of the investigative monitoring aspects within the in-

novative monitoring strategy . . . . . . . . . . . . . . . . . . 84

3.4.1. Field site . . . . . . . . . . . . . . . . . . . . . 84

3.4.2. Materials and methods . . . . . . . . . . . . . . 86

3.4.3. Results . . . . . . . . . . . . . . . . 86

3.5. Conclusions . . . . . . . . . . . . . . . . . . . . . . . . . . . . 88

3.6. Acknowledgments . . . . . . . . . . . . . . . . . . . . . . . . . . . . 89

4. Application of PAH concentration profiles in lake sediments as in$\begin{array}{ll}\text { dicators for smelting activity } & 94\end{array}$

4.1. Introduction . . . . . . . . . . . . . . . . . . . . . . 95

4.2. Materials and methods . . . . . . . . . . . . . . . . . . . 97

4.2.1. Description of sampling site . . . . . . . . . . . . . . . . 97

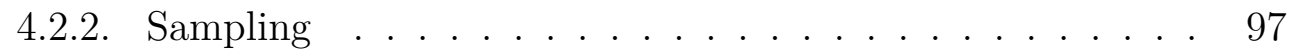

4.2.3. Chemicals . . . . . . . . . . . . . . . . . . . . . . . . . . . 98

4.2.4. Sample preparation and analysis . . . . . . . . . . . . . . 98

4.3. Results and discussion . . . . . . . . . . . . . . . . . 100

4.3.1. Time and space resolved correlation of heavy metals and

PAH fluxes . . . . . . . . . . . . . . . . . 100

4.3.2. Enrichment of heavy metals and PAHs connected to copper smelting activity . . . . . . . . . . . . . 103

4.4. Conclusion . . . . . . . . . . . . . . . . . . . 105

4.5. Acknowledgment . . . . . . . . . . . . . . . . . 106

\begin{tabular}{ll}
\hline 5. General conclusions and perspectives & 111
\end{tabular}

5.1. Implementation of integrated monitoring strategies . . . . . . . . 111

5.2. New indicators and future problems . . . . . . . . . . . . . . . . 113

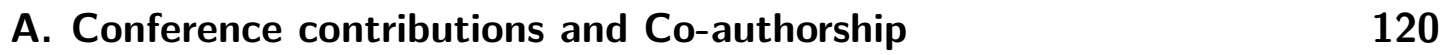




\section{List of Figures}

2.1. Universal overview based on compound groups for a successful decision process to find a suitable indicator for source apportionment and in investigative approaches. Specific compounds need to be selected according their application in the respective catchment. Micropollutants already applied as indicators and a summary of compound databases can be found in the text and in Table 2.1. . 52

3.1. All three figures show a potential plume (dotted line) originating from a hypothetic point source. The fixed number of twenty samples are marked as red dots. The proxy map (e. g., EC) is marked in red. By allocating all samples according to the mapped plume the information density increases remarkably and becomes independent from plume dynamics. In (a) all are samples distributed equally over the water body, in (b) they are distributed within the plume and in (c) accordingly to the drifted plume. . . . . . . . . . 80

3.2. Graphical overview over the different steps of the described innovative monitoring strategy. . . . . . . . . . . . . . . . 85

3.3. Picture of a proxy mapping campaign by using an automated boat during a mapping and sampling campaign in October 2017 in Italy / Lake Garda near Ronchi. As can be seen in: (a) on the first day the plume drifts southwards, while one day later the plume changed directions (b). . . . . . . . . . . . . . . . 87

4.1. Location of Lake Süßer See in Mansfeld area in the East of Germany (black point on the small map). A and B indicate the location of the sediment. The length of sediment core is $107 \mathrm{~cm}$ and the length of sediment core B is $74 \mathrm{~cm}$. Smelters were located in the river catchment and are closed today, for details see Wennrich et al. 2004. Maps from http://www.openstreetmap.de/ and http://www.d-maps.com/index.php?lang=de.] . . . . . . . . 97

4.2. Input of PAHs compared to input of $\mathrm{C}_{\text {org }}$ of sediment core $\mathrm{A}$ and B. The input of $\mathrm{C}_{\text {org }}$ is about 100 times higher than input of PAHs. The peak in 1980 indicates the maximum of smelter production. . 101

4.3. Distribution of PAHs and heavy metals in sediment core A and B with an additional maximum input of PAH in the early 1960s in absence of an elevated input of heavy metals. . . . . . . . . . . . 102 
4.4. Ratio of fluoranthene to pyrene stabilizes after 1960 and converges to 2. We assume an increasing influence for Theisen sluge beginning in 1960s in contrast to the direct influence of coppershale smelting process itself before 1960 indicated by ratio $>2 . \quad$. . . . 104

4.5. $\log \mathrm{K}_{\mathrm{OW}}<5.7 / \log \mathrm{K}_{\mathrm{OW}}>5.7$ compared with Theisen sludge (Th. s.) and Theisen sludge leachate calculated with data from Vrana, Paschke, and Popp 2001. The ratio of $\log \mathrm{K}_{\mathrm{OW}}<5.7 / \log \mathrm{K}_{\mathrm{OW}}$ $>5.7$ of both sediment cores converge to an even lower the value of Theisen: 1.5 over time, which represents a particulate input of Theisen sludge. . . . . . . . . . . . . . . . . . . 105 


\section{List of Tables}

2.1. Summary of applied and established indicators for quantitative and semiquantitative information. Detailed information and references can be found in the text. . . . . . . . . . . . . . 53

3.1. Examples of typical indicators used in the last decades. . . . . . . 82

4.1. Enrichment factors of core A and core B compared to the composition of a remote Lake in Sweden and of Loess, which are assumed

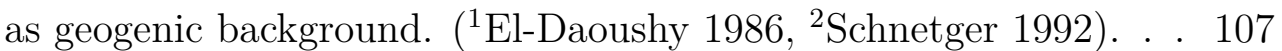

4.2. Enrichment factors of core A and B compared to data from other lakes, a peat bog and air with a remarkable enrichment of fluoranthene and pyrene in sediment cores from lake Süßer See. $\left({ }^{1}\right.$ Thuens, Blodau, and Radke 2013, ${ }^{2}$ Gschwend and Hites 1981, ${ }^{3}$ Stracquadanio, Apollo, and Trombini 2006, ${ }^{4}$ Mantis, Chaloulakou, and Samara 2005, ${ }^{5}$ Fernandez, Vilanova, and Grimalt 1999, ${ }^{6}$ Fernandez, Vilanova, and Grimalt 1999). . . . . . . . . . . . . . . . 107 


\section{Nomenclature}

BTEX ........ toluene, benzene, ethylbenzene and xylene isomers

CSO $\ldots \ldots \ldots$ combined sewage overflows

DDD ........ defined daily doses

DSS $\ldots \ldots \ldots$ decision support system

EC $\ldots \ldots \ldots$ electrical conductivity

EQS ......... environmental quality standards

EU $\ldots \ldots \ldots \ldots$ European Union

GC-MS ....... gas chromatography coupled with mass spectrometry

HILIC ........ hydrophilic interaction liquid chromatography

HRMS ....... high resolution mass spectrometry

LC-MS/MS .... liquid chromatography coupled with mass spectrometry

$\log \mathrm{K}_{\mathrm{OW}} \ldots \ldots$ octanol-water partition coefficient

LVI ......... large volume injection

MDA ....... 3,4-methylenedioxyamphetamine

MDMA ..... 3,4-methylendioxy- N-methylamphetamine

PAHs $\ldots \ldots \ldots$ polycyclic aromatic hydrocarbons

PMOCs $\ldots . .$. polar persistent mobile organic compounds

REACH ....... Registration, Evaluation, Authorisation and Restriction of Chemicals, Directive 1272/2008/EU

RMI ......... riverfly monitoring initiative

SCAP ........ short chained alkyl phenols

SFC $\ldots \ldots \ldots$ supercritical fluid chromatography 
SPE

solid phase extraction

$\mathrm{T}$

temperature

$\mathrm{TP} \ldots \ldots \ldots$ transformation product

UHPLC ....... ultra-high-performance liquid chromatography

WBE $\ldots . . \ldots$. waste water-based epidemiology

WFD ......... Water Framework Directive

WHO ........ World Health Organisation

WWTP ...... waste water treatment plant 


\section{Motivation and background}

\subsection{Current state of water quality monitoring}

Being a European citizen, safe and clean drinking water is part of our everyday life. Compared to many countries around the world this is an enormous privilege which we must protect against contamination and over abstraction. In particular, ground and surface waters are important sources for drinking water abstraction in many European countries and therefore require special protection and monitoring. Further, surface waters such as rivers and lakes are an essential part of our ecosystems, valuable habitats, and have socio-economic functions, e.g. recreational activities. Threats to water quality, for example caused by misconnection of domestic wastewater pipelines, run-off from fields or roads and industrial effluents, are predominantly caused by anthropogenic activity and hence are strongly correlated with population density and economic growth (Diamantini et al. 2018). The global population is predicted to grow rapidly, which may lead to a serious water quality deterioration in Future. Such deterioration will be due to an increase in anthropogenisation occurring simultaneously with a rising demand of safe water resources (UN-Water 2018). Although this is hard to quantify, most climate models predict that climate change will result in reduced surface water levels in many areas but also in extreme events as droughts and heavy rains which will further aggravate water stress (Gosling and Arnell 2016, Vörösmarty et al. 2000). This highlights that ensuring or restoring good water quality might be one of the major challenges in the 21 . Century.

Characterising, enforcing and obtaining clean and safe water resources, has a strong need for effective monitoring strategies to assess water quality. Effective management of water quality strongly requires information on the catchment and land use activities to asses sources of potential water quality threats (Chapman et al.2016). Rivers in particular often have multi-national catchments and the creation of an integrated multi-national monitoring network and strat- 
egy is desirable. For all European countries in the European Union (EU), the European Commission's Water Framework Directive (2000/60/EC) (WFD) is a multi-national water quality monitoring programme, comprising surface water such as running water, lakes, transitional and coastal waters, and also ground water. Aiming to be a sustainable and holistic approach, implementation of the WFD started in the year 2000 with a status assessment and with the development of water management plans in order to assess water quality and efficiency of water protection measures across borders.

The WFD distinguishes between an ecological status and a chemical status. The ecological status is, on the one hand, defined dependent on the presence or abundance of different species (fish fauna, benthic invertebrates, water body flora) which would inherently be present in the respective water body (further defined in WFD Annex V, 1.2 - Normative definitions of ecological status classifications). On the other hand, the status also dependents on hydromorphical quality elements, physicochemical quality and chemical quality elements. A good chemical status is defined as no concentration threshold of the defined priority substances, referred to as Environmental Quality Standards (EQS, (2008/105/EC)), is exceeded. For water quality assessment rivers are subdivided into their natural and hydrological units - river basin plans. The water quality status of the respective river basin is then categorised into very good, good, moderate, poor and bad. The current state of chemical water quality parameters is a combination of priority contaminant classes, but also nitrate, $\mathrm{pH}$ value, electrical conductivity (EC) and selected pesticides. According to the precautionary principle the WFD strongly follows the so-called one-out all-out rule: if only one criterium is classified as moderate, the whole water quality management unit can reach no better status than moderate.

Additionally, river basin specific compounds comprise substances, which may vary between catchments and can be defined by the country itself. They may further be used for reflecting the ecological status. The system is simple and also following the one-out all-out principle: If one threshold is exceeded, no good ecological status can be reached. Groundwater needs to achieve a good quantitative status and a good chemical status and hence can either be classified as good or poor.

Monitoring networks and sampling locations are selected by regional water 
managers and represent the respective water body. Today, more than 10,000 monitoring stations exist in running waters among European countries (Arle, Mohaupt, and Kirst 2016). To reduce costs, a tendency to reduce monitoring sites wherever possible can be observed. The WFD distinguishes between three different monitoring protocols: surveillance, operational and investigative monitoring (art. 7 WFD). Surveillance monitoring encompasses a larger hydrological unit to reflect large scaled and long-term trends. Consequently, the network is coarse-grid with up $2,500 \mathrm{~km}^{2}$ per site and the chemical status of water is tested, at minimum, once in 6 years. For water bodies that do not meet environmental objectives, an operational monitoring protocol is implemented with sampling occurring once in three years. Water bodies, which are not in a good or very good status are under investigative monitoring and are sampled twelve times per year to determine the cause of the failure in water quality.

The third and last river basin management plan period starts in 2021, whilst 2027 and is the final deadline for WFD implementation. The result of the first monitoring cycle is that only $8 \%$ of all water bodies have a very good or good status versus more than $90 \%$ do not meet good water quality status (Arle, Mohaupt, and Kirst 2016).

\subsection{Need for changes in monitoring strategies}

The overall bad status of the first monitoring cycle raised great concern, however, if mercury is omitted as a parameter for water quality classification, $81 \%$ of all monitored water bodies would achieve good water quality (European Environment Agency 2018). This clearly shows how ambiguous water quality assessment by following the one-out all-out principle can be.

The atmospheric mercury results from many industrial processes which includes coal and fossil fuel combustion and cement production, but also from natural sources such as emissions from volcanos, top soils and oceans (Pirrone et al. 2010). Naturally occurring compounds, such as mercury, derive often from numerous sources and it is often not possible to discern their origin with sufficient sensitivity to enable source apportionment, water quality assessment, or to quantify improvements or changes. Other legacy compounds to define the chemical water quality consist of a more historically relevant list of mainly lipophilic com- 
pounds such as polycyclic aromatic hydrocarbons (PAHs) or pesticides which are already banned. Compounds such as pharmaceuticals and transformation products, which are highly relevant for drinking water supply, are completely missing in the water quality assessment. Another problem to address is that some compounds, e.g. pharmaceutical residues or plasticizers, have strong effects to biota even if concentrations are low and guideline values are not exceeded (Keiter et al. 2012; Triebskorn et al. 2004). Furthermore, just using the exceedance of threshold values of priority substances does not exploit their full potential as indicators including source apportionment and understanding systems dynamics, flow paths or the efficiency of natural barriers.

Further, a representative sampling point is not defined in the WFD (Arle, Mohaupt, and Kirst 2016), but by local stakeholders without a universal scheme. Monitoring under the WFD is currently restricted to larger catchments $\left(>10 \mathrm{~km}^{2}\right)$ even if smaller water bodies often show significantly higher concentrations of pollutants, e.g. pesticides and metabolites. Nevertheless, neither small water bodies nor the majority of pesticides and their respective metabolites are included into routine monitoring under WFD (Brinke et al. 2017).

Statements regarding water quality are still ambiguous and show that the current monitoring strategy might be insufficient for the reliable determination of water quality. As water quality is hard to address and strongly differs with water use related criteria (Milano, Chèvre, and Reynard 2018), international monitoring programs often do not meet the need of solving national water quality problems (Walz 2000).

To solve this issue, a popular approach is to collect more samples and, more often to gather more data. Producing more time series would indeed probably lead to a better system understanding in certain areas, but does not inform about catchment dynamics. Sampling more points by random may provide a better picture about the catchment, but no system understanding. Both approaches increase costs of environmental monitoring as more samples need to be collected and processed, but budgets for environmental monitoring are already often very tight and are decreasing. Gathering more and more data without a significant gain of information is a long-known problem and already referred to as the data-rich but information-poor problem by Ward, Loftis, and McBride 1986 in the 1980s. Since then, technological progress has allowed faster analysis and 
an increasing automatisation of data processing (Sjerps et al. 2016) which has revolutionised and significantly simplified screening for water quality indicators, however, monitoring strategies remained still static: fixed sampling stations and sampling on predetermined dates.

With regards to the increasingly diverse demands on water quality (drinking water abstraction, recreational activities, irrigation, etc.) there is often no one size fits all solution (Behmel et al. 2016). Demands can vary significantly over time, so once a water quality monitoring strategy is implemented it should remain flexible and include stakeholder involvement (Behmel et al. 2016). With a paradigm shift towards holistic, systems thinking, there is a strong need for an effective, information dense and sustainable monitoring system (Voulvoulis, Arpon, and Giakoumis 2017).

\subsection{Need for new water quality indicators}

In order to robustly assess water quality, there also seems to be a strong need for reliable indicators which are highly source specific, following the polluter pays principle WFD art. 9 (Lindhout and Broek 2014) and allow quantifying the magnitude and extent of a water quality problem (Kahle et al. 2009). The definition of an indicator is simple: It should be able to describe the status of a system, facilitate the understanding the underlying processes, whilst having well-known, distinguishable source and is present in concentrations above the limit of quantitation (Jekel et al. 2015, Walz 2000). In context of this thesis an indicator is referred as an organic compound, dissolved in water, with a defined source and process allocation.

Even though anthropogenic activities are often correlated with inorganic ions, e.g. $\mathrm{K}^{+}$and domestic wastewater (Nödler et al. 2011), natural compounds are usually interfered with natural processes/sources and small concentration changes; or a distinct source is not detectable. In contrast, micropollutants such as pharmaceuticals, lifestyle products or pesticides and their transformation products/metabolites are very source specific and can be compounds of choice within the subject of reliable water quality indicators.

Micropollutants are used in large amounts. In Germany alone, more than 43,000 Mio DDDs pharmaceuticals were applied in 2017 (Häussler and Höer 
2018). On top of pesticides applied in agriculture and biocides in outdoor paintings, micropollutants include lifestyle products such as artificial sweeteners, but also additives in personal care products and industrial chemicals. Additionally, every compound often generates more than one transformation product, depending on the individual boundary conditions, and different environmental lifetimes. While some micropollutants do not or only partially undergo degradation during treatment and can enter the environment (Jiang, Zhou, and Sharma 2013; Lewandowski et al. 2011), others enter the environment directly via run-off (Davies and Neal 2007; Sidhu et al. 2013) or direct disposal. Their capability of detecing numerous processes together with their source specificity gives micropollutants a clear advantage over traditional indicators and enable them to be powerful and reliable water quality indicators.

\subsection{Scope, objectives and further outline of the thesis}

During the last decade advances in analytical LC-MS/MS techniques have facilitated the detection of more and more micropollutants. Analytical methods have become faster and now allow the development of multi methods comprising up to 2000 analytes or more (Wode et al. 2015). Micropollutants as water quality indicators are widely accepted by the scientific community and in research but are mostly not included into routine analytics for environmental monitoring and management (Deeb et al. 2017; Lapworth et al. 2012, Reemtsma et al. 2016). The large potential of micropollutants as indicators was already intensively elaborated in (Nödler 2013) and many others, while this thesis contributes to the topic by taking indicative micropollutants one crucial step forward in discussing their application by integrating them into innovative monitoring strategies and practical applications.

This thesis aims to condense previous work into universal concepts for the future implementation of micropollutants as water quality indicators in routine monitoring through an innovative risk-based monitoring strategy. Further it shows that an indicator concept can be transferred to media other than water, such as sediment cores which may function as environmental archives. 
Chapter 2 provides a detailed introduction into the qualitative and quantitative use of micropollutants in the aquatic environment. Starting with the technical requirements for a successful detection of micropollutants, but also appropriate sampling procedures and analytical trends, this review gives an extensive overview about the use of micropollutants for source apportionment. The semiquantitative and especially the quantitative use of micropollutants extent their application range to process identification and advanced application fields, such as waste water-based epidemiology (WBE). Reviewing more than two decades of micropollutant analysis and their application gives a comprehensive overview. Nevertheless, selecting the appropriate, catchment specific indicator set can be difficult because compounds can vary significantly between catchments. With the help of the decision process flow chart provided - based on compound groups rather than individual compounds - the selection of indicators for source apportionment or investigative applications is significantly simplified and applicable to a wide variety of problems.

In Chapter 3 a strategy for the development of new innovative and risk-based water quality monitoring is provided. As simple strategies which are universal and applicable to any catchment are still missing, this chapter gives a comprehensive guide for the implementation of a risk-based monitoring approach. Beginning with the investigative aspect of an innovative monitoring strategy starting with a catchment appraisal and review of already existing data - up to searching for potential water quality impairments and a suitable monitoring approach. The pivotal point is to create a relationship between the defined water quality indicators and an easily accessible and inexpensively analysable universal signal (proxy), e.g. temperature or EC. An indicator-proxy relationship allows data collection in real-time data which in turn enables easy deployment with tools such as automated boats or drones. Conducting proxy mapping to detect hot spots of poor water quality impairments helps to identify pollution hot spots and areas of higher potential risks where a sample can provide a high information density. Using proxies for real-time monitoring in areas with high potential risk could allow early warning systems and trigger limits to be implemented. For areas of lower potential risk a coarse-grid, long-term monitoring regime with occasional sampling might be sufficient. This keeps monitoring costs low, because 
fewer samples need to be processed, but significantly increases information density. This strategy was successfully tested at the inflow of a small tributary into Lake Garda (Italy) with an EC anomaly.

Chapter 4 shows the transferability of indicator concepts from recent problems, such as water quality impairments, towards environmental archives. Sediment cores from lakes can store anthropogenic pollution long-term when the respective indicators are deposited and incorporated in sediments where they are preserved from degradation. Depth profiles of two sediment cores from Lake Süßer See were age dated by $137-C s$ and sedimentation rates were reconstructed in order to assess the impact of copper shale mining in the Mansfeld area (Germany), using PAHs. As PAHs originate from nearly every combustion process, diagnostic ratios of PAHs based on their logKow were used to successfully differentiate between direct airborne transport of PAHs during mining activities versus transport in water phase after leaching of mining residues (Theißen sludge) and to differentiate this from the fire in a local factory in the 1960s. 


\section{References}

Arle, J., V. Mohaupt, and I. Kirst (2016). "Monitoring of Surface Waters in Germany under the Water Framework Directive - A Review of Approaches, Methods and Results". In: Water 8.6, p. 217. DOI: 10.3390/w8060217.

Behmel, S. et al. (2016). "Water quality monitoring strategies - A review and future perspectives". In: Science of the Total Environment 571, pp. 1312-1329. DOI: 10 . 1016/j.scitotenv.2016.06.235.

Brinke, M. et al. (2017). "Umsetzung des Nationalen Aktionsplans zur nachhaltigen Anwendung von Pestiziden Bestandsaufnahme zur Erhebung von Daten zur Belastung von Kleingewässern der Agrarlandschaft". In: p. 89.

Chapman, D. V. et al. (2016). "Developments in water quality monitoring and management in large river catchments using the Danube River as an example". In: Environmental Science and Policy 64, pp. 141-154. DOI: 10.1016/j.envsci.2016.06.015

Davies, H. and C. Neal (2007). "Estimating nutrient concentrations from catchment characteristics across the UK". In: Hydrology and Earth System Sciences 11, pp. 550558. DOI: 10.5194/hess-11-550-2007.

Deeb, A. A. et al. (2017). "Suspect screening of micropollutants and their transformation products in advanced wastewater treatment". In: Science of the Total Environment 601-602, pp. 1247-1253. DOI: 10.1016/j . scitotenv.2017.05.271.

Diamantini, E. et al. (2018). "Driver detection of water quality trends in three large European river basins". In: Science of the Total Environment 612, pp. 49-62. DOI: 10.1016/j.scitotenv.2017.08.172.

European Environment Agency (2018). Chemicals in European waters. 18. DOI: 10 . 2800/265080European.

Gosling, S. N. and N. W. Arnell (2016). "A global assessment of the impact of climate change on water scarcity". In: Climatic Change 134.3, pp. 371-385. DOI: 10.1007/ s10584-013-0853-x.

Häussler, B. and A. Höer (2018). Arzneimittel-Atlas 2018. Berlin: Medizinisch Wissenschaftliche Verlagsgesellschaft.

Jekel, M. et al. (2015). "Selection of organic process and source indicator substances for the anthropogenically influenced water cycle". In: Chemosphere 125, pp. 155-167. DOI: $10.1016 / \mathrm{j}$. chemosphere.2014.12.025.

Jiang, J., Z. Zhou, and V. Sharma (2013). "Occurrence, transportation, monitoring and treatment of emerging micro-pollutants in waste water - a review from global views". In: Microchemical Journal 110, pp. 292-300.

Kahle, M. et al. (2009). "Hydrophilic anthropogenic markers for quantification of wastewater contamination in ground-and surface WATERS". In: Environmental toxicology and chemistry 28.12, pp. 2528-2536.

Keiter, S. et al. (2012). "Long-term effects of a binary mixture of perfluorooctane sulfonate (PFOS) and bisphenol A (BPA) in zebrafish (Danio rerio)". In: Aquatic Toxicology 118-119, pp. 116-129. DOI: $10.1016 / \mathrm{j}$.aquatox.2012.04.003.

Lapworth, D. J. et al. (2012). "Emerging organic contaminants in groundwater: A review of sources, fate and occurrence". In: Environmental Pollution 163, pp. 287303. DOI: $10.1016 / \mathrm{j}$. envpol.2011.12.034. 
Lewandowski, J. et al. (2011). "Fate of organic micropollutants in the hyporheic zone of a eutrophic lowland stream: Results of a preliminary field study". In: Science of the Total Environment 409.10, pp. 1824-1835. DOI: 10.1016/j.scitotenv.2011. 01.028 .

Lindhout, P. E. and B. den Broek (2014). "The polluter pays principle: Guidelines for cost recovery and burden sharing in the case law of the European court of justice". In: Utrecht L. Rev. 10, p. 46.

Milano, M., N. Chèvre, and E. Reynard (2018). "Assessing watercourse quality: challenges in implementing European and Swiss legal frameworks". In: Environmental Science and Pollution Research 25.1, pp. 805-823.

Nödler, K. et al. (2011). "A case study on the correlation of micro-contaminants and potassium in the Leine River (Germany)". In: Applied Geochemistry 26, pp. 21722180. DOI: $10.1016 / \mathrm{j}$. apgeochem.2011.08.001.

Nödler, K. (2013). "Testing selected micro-contaminants for their applicability as water quality indicators". Dissertation. Georg-August-Universität Göttingen.

Pirrone, N. et al. (2010). "Global mercury emissions to the atmosphere from anthropogenic and natural sources". In: Atmospheric Chemistry and Physics 10.13, pp. 5951-5964. DOI: 10.5194/acp-10-5951-2010.

Reemtsma, T. et al. (2016). "Mind the Gap: Persistent and Mobile Organic Compounds - Water Contaminants That Slip Through". In: Environmental Science and Technology 50.19, pp. 10308-10315. DOI: 10.1021/acs.est.6b03338.

Sidhu, J. et al. (2013). "Sewage pollution in urban stormwater runoff as evident from the widespread presence of multiple microbial and chemical source tracking markers". In: Science of the Total Environment 463-464, pp. 488-496. DOI: 10.1016/j . scitotenv. 2013.06 .020

Sjerps, R. M. et al. (2016). "Data-driven prioritization of chemicals for various water types using suspect screening LC-HRMS". In: Water Research 93, pp. 254-264. DOI: $10.1016 / j$. watres.2016.02.034.

Triebskorn, R. et al. (2004). "Toxic effects of the non-steroidal anti-inflammatory drug diclofenac". In: Aquatic Toxicology 68.2, pp. 141-150. DOI: $10.1016 / \mathrm{j}$. aquatox . 2004.03 .015 .

Vörösmarty, C. J. et al. (2000). "Global Water Resources : Vulnerability from Climate Change and Population Growth Contemporary Population Relative to Demand per Discharge". In: Science 289.5477, pp. 284-288. DOI: 10.1126 /science.289.5477. 284.

Voulvoulis, N., K. D. Arpon, and T. Giakoumis (2017). "The EU Water Framework Directive: From great expectations to problems with implementation". In: Science of the Total Environment 575, pp. 358-366. DOI: 10.1016/j.scitotenv.2016.09.228

Walz, R. (2000). "Development of environmental indicator systems: Experiences from Germany". In: Environmental Management 25.6, pp. 613-623.

Ward, R. C., J. C. Loftis, and G. B. McBride (1986). "The "data-rich but informationpoor" syndrome in water quality monitoring". In: Environmental Management 10.3, pp. 291-297. DOI: 10.1007/BF01867251.

UN-Water (2018). The United Nations World Water Development Report 2018. Naturebased solutions for water. Paris, France. 
Wode, F. et al. (2015). "Search for over 2000 current and legacy micropollutants on a wastewater infiltration site with a UPLC-high resolution MS target screening method". In: Water Research 69, pp. 274-283. DOI: 10.1016/j . watres . 2014 . 11.034 


\section{Qualitative and quantitative use of micropollutants as source and process indicators. A review.}

Wiebke Warner ${ }^{1}$, Tobias Licha ${ }^{1}$, Karsten Nödler ${ }^{2}$

${ }^{1}$ Geoscience Centre, Department of Applied Geology, Hydrochemistry Group, University of Göttingen, Goldschmidtstr. 3, 37077 Göttingen, Germany

${ }^{2}$ Water Technology Center Karlsruhe (TZW), Karlsruher Straße 84, 76139 Karlsruhe, Germany

Citation: W. Warner, T. Licha, and K. Nödler (2019). "Qualitative and quantitative use of micropollutants as source and process indicators. A review". In: Science of The Total Environment 686, pp. 75-89

https://doi.org/10.1016/j.scitotenv.2019.05.385 


\section{Abstract}

Nowadays, micropollutants such as pharmaceuticals, pesticides and personal care products can be found ubiquitously in the anthropogenically influenced water cycle. As micropollutants have virtually no natural background concentrations they are significantly more sensitive in detecting processes and flow paths than classic inorganic tracers and indicators and at the same time they are often highly source specific. Therefore, using micropollutants as environmental indicators for anthropogenic activities is a common and frequently applied method today. As they interact in many ways with environmental matrices they can be used for source apportionment as well as to estimate flow paths and residence times in waterbodies. This review gives a systematic overview over the large variety of micropollutants used as indicators in the aquatic environment over the last decades together with the prerequisites on their use. Their application is subdivided into their qualitative (compound presence or absence) and quantitative (volume flows) use and shows the numerous possibilities from gaining basic information on the water regime up to advanced applications such as wastewater-based epidemiology.

Keywords: micropollutants, indicators, process information, source apportionment, environmental forensics

\subsection{Introduction}

Today, most surface water bodies show significant loads of anthropogenically produced compounds and only $10 \%$ of the European rivers are classified as "very clean" with respect to their chemical status (Loos et al. 2009). As water contamination can cause numerous issues including the demising of aquatic species, decreased biodiversity or pathogenic outbreaks (Khan et al. 2017; Kurissery et al. 2012; Voutsa et al. 2001) and can harm aquatic species even at low concentrations (Triebskorn et al. 2004), improving water quality is one of the most upcoming environmental topics for the next decades and future generations. Water quality can be effectively and sustainably improved by identifying and eliminating pollution sources. Especially for identifying and tracking sources unique indicators 
are required in a risk-based monitoring approach. Integrating the whole catchment into water quality monitoring, indicators allow detecting hot spots of water quality deterioration and areas of elevated risk. Consequently, an ideal indicator allows the unambiguous recognition of the source and the quantification of the magnitude of a pollution (Kahle et al. 2009) also known as source apportionment. Main requirement for indicators beside well-known and distinguishable sources is that their concentrations are above the limit of quantitation (Jekel et al. 2015).

In the past, classical indicators such as wastewater-associated inorganic ions like sodium, chloride, potassium, gadolinium or boron were used to detect the anthropogenic impact on water bodies (Bassett et al. 1995; Vengosh et al. 1994; Verplanck et al. 2005). In contrast to the comparably limited number of inorganic ions, there is a huge spectrum of (organic) compounds resulting from anthropogenic activities such as pesticides, pharmaceuticals and personal care products (Khazaei and Milne-Home 2017), which are often summarised as micropollutants. Even if some organic compounds can originate from natural processes, e.g. polycyclic aromatic hydrocarbons (PAHs) resulting from natural fires or volcanic activities (Wild and K. C. Jones 1995), natural concentrations are low compared to the anthropogenically induced pollution (Ravindra et al. 2008). For most of the aforementioned compounds the natural background is negligible or even absent as they have no non-anthropogenic sources. This leads to significantly higher sensitivities or rather significance and is an advantage when using them as environmental indicators compared to, e.g. major ions, which usually have a substantial natural, non-anthropogenic background. As early as in the late 1960s the use of coprostanol was introduced, as one of the earliest organic indicators for tracking faecal pollution. As coprostanol can be found in the faeces of warm-blooded animals but also in birds, it does not enable to differentiate between human and non-human origin (Murtaugh and Bunch 1967).

As analytical procedures improved significantly, lifestyle products, such as artificial sweeteners and nicotine, and human pharmaceuticals mostly replaced inorganic ions to detect and quantify wastewater-derived pollution. Some wellestablished examples for the replacement of these early-stage-indicators by anthropogenic micropollutants are the antiepileptic carbamazepine as a source indicator for wastewater instead of chloride or boron, elevated concentrations of PAHs instead of heavy metals to track the influence of smelting activities asso- 
ciated with mining, and corrosion inhibitors instead of boron isotope ratios to estimate the amount of detergents used in the catchment (Barth 1998. Clara, Strenn, and Kreuzinger 2004; Gäbler and Bahr 1999, Gasser et al. 2010, Hai et al. 2018; Janna et al. 2011; Kunkel and Radke 2012; Nödler, Licha, Fischer, et al. 2011; Warner, Ruppert, and Licha 2016).

Qualitative information from micropollutants can be gathered by the simple presence or absence of the indicator, while for deriving semi-quantitative information it needs a concentration ratio and its development within time and space. Quantitative information can only be gained if an input function such as compound specific application schedules, e.g. for pesticides, or discharges, is available. Beyond that, micropollutants are a powerful tool which can give important information about aquatic systems, e.g. changes in a catchment and processes such as degradation. However, most publications in this research field focus on the occurrence and concentration of selected micropollutants and discuss their sources (Barbosa et al. 2016; Lapworth et al. 2012, Lim, Ong, and $\mathrm{Hu} 2017$ ). Until publication more than 144,000,000 compounds are registered in the European CAS database $\mathrm{C}^{1}$. More than 100,000 compounds are relevant for the aquatic environment (Franco et al. 2010) and more than 1000 compounds are already reported to occur in aquatic systems (T. Schmidt 2018). Using them as indicators to gain qualitative and even quantitative information by using simple tools such as concentration ratios opens a wide spectrum of potential approaches. By using meaningful indicators for water quality monitoring we can shift the traditional and mainly static "information-poor but data-rich" monitoring system into an innovative, flexible, cost-effective and information-rich approach not solely but particularly with respect to the European water framework directive (Kahl, Nivala, et al. 2017).

This publication aims to give a reasonable summary over the work from the last decades structured into indicators used in a qualitative and quantitative manner. Breaking them down into well-established sets of indicators simplifies the selection process for specific questions regarding the monitoring of water quality, its decline and improvement.

\footnotetext{
${ }^{1}$ http://www.cas.org
} 


\subsection{Prerequisites}

Many micropollutants show low removal rates during conventional wastewater treatment such as the activated sludge process or biofiltration. This results in a broad spectrum of compounds entering the aquatic environment (Jiang, Zhou, and Sharma 2013; Lewandowski et al. 2011). Having great potential to be used as indicators for source apportionment and process identification, such as mixing and changes in redox conditions, micropollutants might close the currently existing gap in information-rich characterisation methods for the aquatic environment. Besides a profound understanding of the environmental behaviour of micropollutants, a sensitive detection method and appropriate sampling methods are the base for their successful use as indicators for source apportionment and process understanding.

\subsubsection{Potential, sources and environmental behaviour of micropollutants}

Pharmaceuticals, personal care products, hormones, pesticides and industrial chemicals are ubiquitous in modern society. A large number of compounds are metabolised in the human/animal body or transformed during wastewater treatment or in the environment resulting often in very specific reaction products. In this work, compounds such as, e.g. paraxanthine (a caffeine metabolite) are solely human metabolites (G. Schmidt and Schoyerer 1966) and defined as such, while transformation products (TPs) originating from physicochemical processes or microbial activities in wastewater treatment plants and in the environment are herein referred to as environmental TPs regardless of the underlying process(es), unless otherwise noted. Furthermore, there are compounds, which do not offer a clear differentiation between human and environmental origin (Barbieri et al. 2012; Godbillon and Duval 1984). Assignments were made to the best of the authors' knowledge. Micropollutants and their metabolites/TPs possess a wide range of physicochemical properties allowing them to interact in numerous ways within the biotic and abiotic environment. This interaction can be used to gain information, e.g. about the flow paths and boundary conditions, such as coexisting redox conditions or temperature fields and gradients. A profound knowledge of environmental fate and/or pharmacokinetics is necessary for selecting valuable 
single compounds or compound sets (e.g. specific ratios of parent/transformation compound) as environmental indicators.

The large variety of parent compounds and metabolites/TPs further fosters a detailed and reliable source apportionment. However, the use of metabolites/TPs for source apportionments is yet in its early stages. The use and approval of pharmaceuticals and pesticides may vary over time and space. This opens the opportunity to combine selected information on the application (e.g. the complete replacement/ban of a compound in a certain area, a changing prescription practice due to medical-technological progress) with monitoring data to derive meaningful interpretations on a spatiotemporal level. Nevertheless, most micropollutants are not included into routine monitoring for surface and drinking water yet (Deeb et al. 2017; Lapworth et al. 2012; Reemtsma, Berger, et al. 2016). Lots of compounds of emerging concern belong to the compound class of the so-called persistent mobile organic compounds (PMOCs). These compounds may easily pass selected barriers or even originate from WWTPs resulting in a potential risk for drinking water and they are only recently discussed to be regulated and integrated into routine monitoring (Reemtsma, Berger, et al. 2016, Scheurer et al. 2017; Solomon et al. 2016; Tröger et al. 2018). As many micropollutants are not only event-based released but consistently emitted (Zahn, Frömel, and Knepper 2016) they can be found in water bodies all over the populated world and even in remote areas such as arctic ecosystems (Jiang, Zhou, and Sharma 2013; O. Jones, Voulvoulis, and Lester 2001; Kallenborn et al. 2017; Loos et al. 2009; Luo et al. 2014; Petrie, Barden, and Kasprzyk-Hordern 2014; Schwarzenbach et al. 2010. Sorensen et al. 2015. Y. Yang, Liu, et al. 2017).

Sources of micropollutants in the aquatic environment can either be point sources such as WWTP effluents, spillage or the leaching from dumps or landfills (Deblonde, Cossu-Leguille, and Hartemann 2011; Hai et al. 2018) or diffusive ones such as runoff, e.g. from fields or roads (Davies and Neal 2007; Sidhu et al. 2013). Micropollutants mainly enter aquifers via surface waters (Sui et al. 2015) through infiltration and hyporheic interaction (Engelhardt, Piepenbrink, et al. 2011; Engelhardt, Prommer, et al. 2014, Schaper et al. 2018). Other pathways of micropollutants into groundwater are artificial recharge of treated wastewater (Clara, Strenn, and Kreuzinger 2004), direct exfiltration from leaky pipes or sewer systems (Wolf, Held, et al. 2004; Wolf, Zwiener, and Zemann 2012), as well 
as single-event contaminations such as spillages, accidents and leakages (Wolf, Eiswirth, and Hötzl 2006). This is problematic as groundwater is often the main source of drinking water supply. Especially for karst groundwater reservoirs intrusion of wastewater can be a serious threat as highly permeable flow pathways may lead to very rapid transport (Hillebrand, Nödler, Licha, et al. 2012, Reh, Hillebrand, et al. 2014, Reh, Licha, Geyer, et al. 2013, Reh, Licha, Nödler, et al. 2015). An important parameter is the chemical and biological stability of these compounds which defines the lifetime of a compound in the environment and in wastewater treatment plants (WWTP). Attenuation can be caused by biodegradation or non-biological degradation process including chemical degradation such as hydrolysis or photolysis (Jekel et al.2015). Abiotic degradation in the water via photolysis seems to be relevant only for a few micropollutants such as diclofenac, sotalol and sulfamethoxazole (Kunkel and Radke 2011; Kunkel and Radke 2012. Lee, Shon, and Cho 2014 Radke et al. 2010) and strongly depends on the system characteristics (Bartels and Tümpling 2007). Microbial transformation in the sediment phase or biodegradation within WWTPs is assumed to be the dominating attenuation process for many micropollutants (Kunkel and Radke 2012; Y. Yang, Ok, et al. 2017). Recent studies indicate that degradation capabilities of ecosystems may change over time or space in/along surface water bodies (Nödler, Tsakiri, and Licha 2014). Acesulfame, an artificial sweetener, was assumed to be persistent during wastewater treatment for the last two decades, but now shows a remarkable degradation to its TP sulfamic acid (Castronovo et al. 2017; Kahl, Kleinsteuber, et al. 2018, Y. Yang, Liu, et al. 2017). Pronounced degradation due to more advanced treatment techniques seems to be unlikely as a relationship between the removal of acesulfame and WWTP characteristics could not be observed (Castronovo et al. 2017). Changes in degradation patterns can be caused by, e.g. adaption of microconsortia to new compounds or by changes induced by altered redox conditions (Bertelkamp et al. 2014). Other studies showed that degradation can strongly depend on the presence of specific microorganisms or fungal species (Hai et al. 2018). This emphasises the strong need for continuous method adaptations according to the compound list respective to local characteristics and to specific questions when using micropollutants as indicators (Nödler, Licha, and Voutsa 2013). Anthropogenically established boundary conditions, e.g. WWTPs and other treatment techniques (Rivera-Utrilla et al. 2013) and 
natural boundary conditions can change within the geo- and/or ecosystem. Mixing, dilution, changes in redox conditions, $\mathrm{pH}$ value, temperature and sorption capacity limit the occurrence of the respective compound in the environment.

\subsubsection{Analytical requirements and recent developments}

Liquid-chromatography coupled with mass spectrometry (LC-MS/MS) is often the method of choice for detecting micropollutants in environmental samples. This is because analytics using modern LC-MS/MS instruments are often much faster, less expensive than traditional assays and enable multi-methods, allowing the detection of several hundred analytes quasi-simultaneously (Reemtsma, Alder, and Banasiak 2013). Even if classical assays can already be replaced by biosensors which are much faster (Farré et al. 2012. Proll, Tschmelak, and Gauglitz 2005) they are not as selective and sensitive as LC-MS/MS or GC-MS and many compounds cannot be detected with other techniques than LC-MS/MS. Recent developments such as higher scan rates and fast polarity switching lead to a significant increase in the total number of analytes per analysis and notably shortened the run times of analytical cycles. Decreasing column diameters $(<$ $2 \mathrm{~mm}$ ID) and particles sizes of the stationary phase (sub $\mu \mathrm{m}$ particles), coreshell techniques, monolithic columns, high-temperature LC and fast electronics enable ultra-high-performance liquid chromatography (UPLC or UHPLC) with high sample throughputs (Holčapek, Jirásko, and Lísa 2012). Developments in ion mobility spectroscopy (IMS), two-dimensional or even three-dimensional LCMS techniques allow for a better separation and a higher spectrum of identified compounds (Holčapek, Jirásko, and Lísa 2012, Stephan et al. 2016). Techniques such as hydrophilic interaction liquid chromatography (HILIC) and supercritical fluid chromatography (SFC) extend the polarity range for detectable compounds (Bieber et al. 2017; Reemtsma, Berger, et al. 2016). As the trend shifts from parent compound analysis to the analysis of TPs and metabolites (Farré et al. 2012) which are often more polar than their parent compounds (Boxall 2004) this might gain even more analytical relevance in the future. However, although there have been great advances in analytical techniques in the last decades there is still a lack of suitable routine analytical methods for the detection of highly polar compound classes and small molecules.

Technical developments in ionization techniques and ion optics sensitivity, en- 
able direct monitoring via direct injection as large volume injection (LVI) without any sample preconcentration (Holčapek, Jirásko, and Lísa 2012; Oliveira et al. 2015). This can be an advantage because preconcentration of samples, often performed by solid phase extraction (SPE), can be time consuming, cost intensive, and can result in poor recovery rates. However, direct injection of environmental water samples is challenging when high concentrations of inorganic salts are involved. SPE can be mandatory to reduce matrix effects, but also to stabilise samples, especially when immediate sample analysis is difficult (Hillebrand, Musallam, et al. 2013). An important weak point of direct injection is that particle-bound analytes in the native sample are not sufficiently accessible via direct injection. Due to their octanol-water partition coefficient log $\mathrm{K}_{\mathrm{OW}}$ (or $\log \mathrm{D}$ for ionisable compounds) some micropollutants, e.g. hormones such as testosterone (Qi, T. C. Zhang, and Ren 2014) tend to be particle-associated and transported as colloids enhancing their mobility in the environment (S. B. Roy and Dzombak 1997; Sen and Khilar 2006; P. Wang and Keller 2008). Accessing these compounds (at least partially) via SPE is a noteworthy advantage of this technique. Developments such as online SPE significantly speed up and automatise the analytical procedure (Farré et al. 2012). Applications with high resolution mass spectrometry (HRMS) allow to extend target screening with suspect and non-target screening to identify yet unknown but often environmentally relevant compounds (Čelić et al. 2017; Richardson and T. A. Ternes 2018. T. Schmidt 2018). Recent suspect screening workflows include growing databases and in silico fragmentation programs allowing substance lists up to several thousand compounds (Gago-Ferrero et al. 2018; Sjerps et al. 2016; Stephan et al. 2016; Wode, Baar, et al. 2015). An increasing number of analytes and shorter run times lead to an enormous increase in data, especially, in non-target analysis and automatisation of data evaluation is a challenging but promising subject for the future (Sjerps et al. 2016).

Even if analytical methods and instruments improved significantly, the complexity of sampling, sample preparation and preservation can be a challenging task, as the use of inappropriate procedures affect the overall quality of the results (Čizmić, Babić, and Kaštelan-Macan 2017; Nödler, Licha, Bester, et al. 2010; Wode, Reilich, et al. 2012). 


\subsubsection{Sampling and storage}

Sampling materials and sample containers made of inappropriate materials as well as filtration of the sample can result in significant losses of microcontaminants and should be critically tested before analysis (Hebig et al. 2014). Storage conditions are also relevant especially for readily degradable compounds such as caffeine, ibuprofen and paracetamol (Hillebrand, Musallam, et al. 2013). Short term storage and low storage temperatures should be aspired, as Gawlik et al. (2012) suggests analysing samples within six weeks at storage temperatures of about $4{ }^{\circ} \mathrm{C}$. However, higher temperatures and longer storage time as well as mixed and variable sample matrices within a time series of samples can lead to significant and, foremost, unpredictable losses of analytes (Hillebrand, Musallam, et al. 2013). Freezing of aqueous samples may result in matrix-dependent transformation of analytes (e.g. the formation of nitrophenols from phenolic micropollutants (Jewell, Wick, and T. Ternes 2014, Sun et al. 2017)) and should be applied with caution.

\subsection{Obtaining qualitative and semi-quantitative information from indicators}

Micropollutants are a powerful tool for source apportionment by simply monitoring their presence or absence. Building sets of different compounds from different origins can be useful for complex applications with numerous potential sources and can contribute to an improved risk management in susceptible or vulnerable areas. A sophisticated tool is using them in a semi-quantitative way, i.e. concentration ratios, also called diagnostic ratios, of two or more indicator compounds. Joint transport of compounds leads to concentration ratio changes along the flow path, e.g. due to sorption or degradation. This enables to track transport processes and gain information about the flow path or transit and residence times (Nödler, Tsakiri, Aloupi, et al. 2016). For gaining semi-quantitative information, these compounds need to be present simultaneously at any point in the aquatic system and their common transport direction needs to be known. They should show similar retardation along the flow path, i.e. relative transport velocity of compounds compared to the respective water phase, but different stabilities or 
vice versa as processes cannot always be differentiated from each other (Schaffer and Licha 2015). If compounds are affected by both, the derived information remains ambiguous. Further it is a useful tool for comparison of data sets gathered by different methods or sampling locations, for which dilution needs to be taken into account. Temporarily unstable ratios are problematic in surface water but less problematic in porous aquifers because of signal attenuation (Nödler, Licha, Fischer, et al. 2011). Using micropollutants as process indicators is a relatively new and yet unexploited field. Redox states, $\mathrm{pH}$ or temperature are always integral signals comprising several processes. As especially the fate micropollutants can be highly dependent on the boundary conditions, they can be used where the classical parameters are not accessible, e.g. in situ measurements in the hyporheic zone (Schaffer, Warner, et al. 2017; Valhondo et al. 2015) or they might help to differentiate processes more precisely.

A summary of all discussed indicators from the next sections and suggestions for suitable sets can be found in Table 2.1.

\subsubsection{Persistent indicators for the detection of domestic wastewater}

The precise detection of even low levels of wastewater in surface or groundwater and especially in sources for drinking water is mandatory and requires reliable methods. Especially residues of pharmaceuticals can have detrimental effects on exposed organisms (Hernando et al. 2006). For example even low concentrations of diclofenac lead to alternations and necrosis in the gill and kidney of trouts (Triebskorn et al. 2004) and antibiotics in aquatic environments are suspected to trigger resistances in bacteria (Baquero, Martínez, and Cantón 2008; Gothwal and Thatikonda 2017; Kümmerer 2009). This emphasises the need for reliable and sensitive indicators to qualify and quantify wastewater. Therefore, a series of studies have focused on the identification and usage of specific indicators for this application. Some compounds experience nearly complete mineralisation in the WWTP, while others undergo only little degradation/transformation. Detailed requirements for an ideal wastewater indicator can be found in (Oppenheimer et al. 2011).

For tracing treated wastewater, indicators need to be resistant to degradation in WWTPs. A very popular indicator is the anticonvulsant carbamazepine (Fenz 
et al. 2005, Gasser et al. 2010, Hai et al. 2018). It is assumed to be persistent in the environment (Clara, Strenn, and Kreuzinger 2004 Löffler et al. 2005, Y. Zhang, Geißen, and Gal 2008) and is often used as a comparative indicator, e.g. to gain insights into the attenuation of other micropollutants in the specific environment (Hillebrand, Nödler, Sauter, et al. 2015; Kunkel and Radke 2012) and the evaluation of co-occurring compounds with unknown persistence (Nödler, Hillebrand, et al. 2013). In most studies carbamazepine is successfully used to detect treated or untreated wastewater, such as tracking leaky sewer networks (Doummar et al. 2014, Fenz et al. 2005; James et al. 2016; Wolf, Eiswirth, and Hötzl 2006). Iodinated X-ray contrast media such as amidotrizoic acid, iothalamic acid, iomeprol and iopamidol were successfully applied to identify the influence of leaky sewers to groundwater, especially if the wastewater comes from hospitals (Wolf, Held, et al. 2004).

The anticonvulsant primidone is with its persistency a good indicator for wastewater especially to detect wastewater-influenced groundwater and a good tracer for wastewater plumes in groundwater (Müller et al. 2012; Oppenheimer et al. 2011 Van Stempvoort et al. 2013). The widely prescribed anti-gout drug allopurinol is extensively metabolised to oxypurinol in the human body (Day et al. 2007). Remaining allopurinol is transformed to oxypurinol (80\%) passing the WWTP. Oxypurinol shows high biological stability and can be found in high concentrations in surface waters. Thus, it can be used as an indicator for domestic wastewater (Funke et al. 2015). Valsartan acid is a microbial TP and formed during wastewater treatment but also in the environment (lower transformation kinetics), thus, providing a unique tracer for treated wastewater (Nödler, Hillebrand, et al. 2013 Nödler, Tsakiri, Aloupi, et al. 2016; Schaffer, Kröger, et al. 2015).

Artificial sweeteners are highly water soluble and together with their large consumption among the population, acesulfame, sucralose, cyclamate and saccharin, are also often applied for wastewater detection (Y.-Y. Yang et al. 2018). Aspartam is rarely used as indicator, because it is nearly completely metabolised in the human body (Renwick 1986). Sucralose was successfully used to evaluate the wastewater burden in surface and groundwater (Y.-Y. Yang et al. 2018). Acesulfame is also often used to identify the impact of treated wastewater (Blackstock, Wawryk, et al. 2018; Buerge, Buser, et al. 2009; Jekel et al. 2015, Lange, 
Scheurer, and Brauch 2012), but a recent publication showed significant degradation of acesulfame into sulfamic acid (Castronovo et al. 2017). Besides being a $\mathrm{TP}$, sulfamic acid can originate from most cleaning and descaling products. Thus, it will occur in high concentrations in surface waters not indicating acesulfame degradation alone (Castronovo et al. 2017). Nevertheless, acesulfame can also be used to trace contamination of urine in swimming pools (Blackstock, W. Wang, et al. 2017) and due to its occurrence in solid waste, it also can be used as a tracer for municipal landfill leachate (J. Roy, Van Stempvoort, and Bickerton 2014).

\subsubsection{Indicators to identify the presence of untreated wastewater}

Especially untreated wastewater respectively faecal contamination is well correlated with the presence of pathogens (S. E. Hrudey and E. J. Hrudey 2014; Leclerc et al. 2001; Sauvé et al. 2012). Untreated wastewater reaches the environment via intrusion into water bodies, e.g. of cross-connected sewers, leaky pipes and septic tanks, as well as misconnected households (Sauvé et al. 2012).

Caffeine is the earliest micropollutant used as indicator to identify untreated wastewater contamination (Buerge, Poiger, et al. 2003, 2006. Kurissery et al. 2012; Sheldon and Hites 1978; Sievers et al. 1977), as it is eliminated up to $99 \%$ during wastewater treatment (Buerge, Poiger, et al. 2006). Even if only $3 \%$ of caffeine is excreted unmetabolised after consumption (Tang-Liu, Williams, and Riegelman 1983), large amounts of caffeine are released by direct disposal of caffeinated drinks and residues such as coffee ground or may originate from washing dishes/rinsing cups (Seiler et al. 1999) and reach significant concentrations in untreated wastewater (Sauvé et al. 2012). It should be noted that in the potential case of natural sources of caffeine such as tea or coffee plantations, caffeine as an indicator should be applied with caution.Hillebrand, Nödler, Licha, et al. (2012) show that a correlation of caffeine with paraxanthine is a more reliable way for detecting wastewater. Together with other wastewater contaminants such as selected pharmaceuticals it can be used to detect the anthropogenic impact and pressure to open sea environments, e.g. from ferries and cruising ships, as they often discharge untreated wastewater directly to the sea (Arpin-Pont et al. 2016, Brumovský et al. 2017). Caffeine is also successfully used to reflect combined sewage overflows (CSO) (Cantwell et al. 2016, Viviano et al. 2017). 
As ibuprofen and paracetamol are efficiently eliminated in most WWTPs, they can also be applied as indictors for untreated wastewater (Heberer 2002). Cyclamate and saccharin undergo significant degradation during WWTP treatment, which qualifies them as further useful indicators for untreated effluent (Buerge, Buser, et al. 2009, Lange, Scheurer, and Brauch 2012, Oppenheimer et al. 2011, Zirlewagen et al. 2016).

\subsubsection{Indicator sets to differentiate between treated and untreated wastewater}

Even if the absence or presence of an indicative compound can give important information for source apportionment, for some applications semi-quantitative system information is needed. Indicator sets of two or more compounds indicating different sources can be useful for highly susceptible areas and can simplify the monitoring. A set based on elimination rates during wastewater treatment to distinguish between the influence of untreated wastewater (cyclamate, ibuprofen) and treated wastewater (acesulfame, iomeprol, benzotriazole) and a third compound group for runoff water from roads (tolyltriazole, hexamethoxymethylmelamine, 2-hydroxybenzothiazole, 2-mercaptobenzothiazole) was successfully applied to monitor water protection areas (Seitz and Winzenbacher 2017). It should be noted that the proposed set of indicators is not applicable for combined sewer systems, as sewage and rainwater (run-off) is collected and treated together. Based on their removal during conventional wastewater treatment, compounds with a high removal (> 80\%) such as ibuprofen and naproxen compared to compounds with low removal $(<20 \%)$ such as carbamazepine can be used to distinguish between treated and untreated effluent in a more reliable way than monitoring a single compound. As removal depends on various factors such as redox conditions and especially microbial diversity, this method should be adapted to the individual treatment techniques and application sites (Suárez et al. 2012). The indicator functionality of different degradabilities can also be used to understand the performance of WWTPs or related processes as flow treatment systems such as wetlands. Kahl, Nivala, et al. (2017) suggest caffeine and ibuprofen as readily degradable compounds, naproxen, $1 \mathrm{H}$-benzotriazole, acesulfame and diclofenac as moderately biodegradable compounds and as the endmember carbamazepine, which is assumed to be persistent, to assess the performance of 
wastewater treatment systems.

Nödler, Tsakiri, Aloupi, et al. (2016) suggest an indicator quartet of acesulfame, caffeine, valsartan and valsartan acid to detect point sources and contamination hot spots of treated and untreated wastewater. Further they suggest the ratio of valsartan to valsartan acid $>>1$ being diagnostic for fresh and untreated wastewater, while a ratio $\leq 1$ indicates wastewater with a higher treatment stage and/or residence time. For intrusions of wastewater into groundwater McCance et al. (2018) suggest a set of pharmaceuticals (carbamazepine, crotamiton, primidone, atenolol, sulfamethoxazole), artificial sweeteners (acesulfame, sucralose, saccharin, cyclamate) and pesticides (atrazine, simazine).

\subsubsection{Application of indicators with seasonal variations and defined application periods as chronomarkers}

Micropollutants with seasonal variations include selected pesticides, personal care products and pharmaceuticals. The concentrations of some pharmaceuticals show strong seasonal variations as they are specific to conditions, which occur more frequently in one season than in another, e.g. diseases of the respiratory tract or allergic reactions such as hay fever. Further, the application of personal care products such as UV blockers often correlate with seasons, weather conditions and can be connected to tourism. A seasonally variant input signal can be used to estimate travel times, touristic burden of regions and can help to adapt monitoring strategies accordingly. An increase of antihistamines, which are used to treat allergies, including compounds like cetirizine, acrivastine, fexofenadine, (excreted as parent compounds) as well as loratadine and ebastine (mainly excreted as their metabolites desloratadine and carebastine) (Parfitt 1999) show increased concentrations in WWTP effluents during maximum pollen production from March to

mid-May (Harman, Reid, and Thomas 2011; Kosonen and Kronberg 2009). This correlates well with the significantly higher prescription rates during that period (Petrie, Barden, and Kasprzyk-Hordern 2014). Higher concentrations of pharmaceuticals to treat cold symptoms and bronchitis such as pseudoephedrine and ephedrine (used in nasal decongestants) or pholcodine (cough medication) can be found in elevated concentrations in wastewater during winter months (KasprzykHordern and D. Baker 2012, Kasprzyk-Hordern and Baker 2012). Not only more prescriptions and larger consumptions can cause higher concentrations in surface 
water bodies but also removal rates in WWTPs can decrease due to decreased microbial activities in winter. Nödler, Licha, Fischer, et al. (2011) found the everyday chemicals $1 \mathrm{H}$-benzotriazole and tolyltriazole as well as pharmaceuticals, which have seasonally unaffected prescription schemes such as metoprolol and sotalol, in higher loads in river water during winter months. This is probably due to lower removal rates caused by lower temperatures (Burke et al. 2014. Herzog et al. 2014). (Gardarsdottir et al. 2010) report generally more prescriptions for antidepressants in winter month which could be confirmed for citalopram by Nödler, Licha, Fischer, et al. (2011) in river water. Lower removal rates and hence higher loads in winter months were also found for 4-nonylphenol (Musolff et al. 2009). In warmer months, UV Blockers such as octocrylene (Wode, Baar, et al. 2015) found in the sunscreen for dermal applications (Rodil et al. 2008) have higher concentrations under sunny weather conditions, which often correlates with an increased number of tourists (Loraine and Pettigrove 2006). Even if concentrations were low, Orlikowska, Fisch, and Schulz-Bull (2015) observed a seasonal pattern of the UV filter 2-phenylbenzimidazole-5-sulfonic acid in marine waters and benzophenone-4 in estuaries.

N,N-diethyl-m-toluamide (DEET), a widely used dermal insect repellent, can be ubiquitously detected in the environment at low concentrations (Costanzo et al. 2007; Sorensen et al. 2015; Stuart et al. 2012 Tran et al. 2014) and strong seasonal variations can be observed (Sodré et al. 2018) in the Western hemisphere. Knepper (2004) even showed a concentration increase of DEET in WWTP influent during vacation times in Germany.

Another compound group which shows strong seasonal variations in their concentrations are pesticides, e.g. atrazine, chloridazon and metolachlor. They show a sharp concentration increase after application in spring fading out until late summer (Buttiglieri et al. 2009; Byer et al. 2011). 1H-benzotriazole can be found in most de-icing agents and, thus, elevated concentrations may be found in winter, especially near airports where large amounts are applied (Alotaibi et al. 2015; Giger, Schaffner, and Kohler 2006; Kiss and Fries 2009, 2012).

Another application is the use of pharmaceutical products as unique stratigraphic markers for dating the anthropogenic impact in sediments of rivers and lakes. Market launches can be set as chronomarkers and sorption preserves them from degradation (Thiebault et al. 2017). Thiebault et al. (2017) dated sedi- 
mentation rates of a sediment core influenced by WWTP effluents and found a good correlation with the market authorization of metoprolol, acetaminophen, trimethoprim and sulfamethoxazole and their occurrence in the core. The ratio of acesulfame to sucralose can be applied for age dating of contaminated groundwater as sucralose was introduced significantly later to the market (US:1998, EU:2003) compared to acesulfame (Robertson, Van Stempvoort, Spoelstra, et al. 2016).

\subsubsection{Process indicators for changing boundary conditions}

Changes in boundary conditions such as redox potential, $\mathrm{pH}$, temperature or the presence of competitive ions can have a significant influence on the (re)mobilization or the degradation of pollutants (Burke et al. 2014 Schaffer, Börnick, et al. 2012). Massmann et al. (2006) investigated the redox-dependent degradation of phenazone beneath an artificial recharge pond. In winter $\left(\mathrm{T}<14^{\circ} \mathrm{C}\right)$, phenazone is completely eliminated from the sediment during prevailing aerobic conditions. In contrast, phenazone is not fully eliminated at warmer temperatures ( $\mathrm{T}>$ $14{ }^{\circ} \mathrm{C}$ ), when anaerobic conditions establish. Similar results for phenazone, but also for metoprolol, iopromide, diclofenac, acesulfame and tolyltriazole where shown by Burke et al. (2014). Redox-depend degradation could be caused by different microbial communities, which develop at different redox conditions. So, biodegradability of compounds can be used as an indirect indicator of redox conditions (Kahl, Nivala, et al. 2017).

\subsubsection{Indicators for (urban) run-off}

In urbanized areas application and sources of micropollutants are concentrated and diverse (Bucheli et al. 1998). Due to a large proportion of impermeable surfaces such as roads, sidewalks, roofs and facades, micropollutants are predominately released by wash-off during rain events as urban run-off. Reaching significant concentrations, micropollutants enter the aquatic environment, e.g. through infiltration into groundwater, or when collected via combined sewer systems after treatment directly in WWTP effluent (Wittmer, Scheidegger, et al. 2011).

Nicotine is widely consumed around the world and cigarette butts are ubiqui- 
tous litter in urban areas. Often accumulated in hotspots, they release significant amounts of nicotine when in contact with water, which enables nicotine to be a powerful indicator for urban run-off (L., Putschew, and Nehls 2014).

Besides their agricultural application, pesticides/biocides are also often used in urban areas and can also be used as indicator for urban run-off (Wittmer, Scheidegger, et al. 2011). Hanke et al. (2010) showed that peak concentrations of glyphosate are not necessarily coinciding with peaks from agricultural fields and result from applications in private gardens and their use by professional gardeners. A similar pattern was observed for diuron and mecoprop, which are used as biocides in bitumen layers of flat roofs and antifouling paints on facades (Wittmer, Bader, et al. 2010). Atrazine and its degradation products desethylatrazine and desisopropylatrazine were used in a karst system to delineate rural areas from urban areas (Reh, Hillebrand, et al. 2014). High fractions of desethylatrazine compared to desisopropylatrazine may be characteristic for agricultural areas, where the source is often runoff from fields. Elevated fractions of desisopropylatrazine may indicate the influence of urban areas, where it originates mostly from point sources as former landfills. However, this might be highly specific for the studied area.

\subsubsection{Verification of connectivity and exchange between water bodies}

Connectivity and exchange between water bodies can cause transfer of undesired substances or pathogens from one reservoir to another (Snider et al. 2017). Especially the infiltration of wastewater into groundwater is of great concern because groundwater is often used as a drinking water resource. Detailed knowledge on the aquatic system and pollutant dynamics, especially in urban watersheds, can contribute to a successful water management (Robertson, Van Stempvoort, Roy, et al. 2016). Micropollutants, which undergo no transformation during soil passage, e.g. carbamazepine, galaxolide and bisphenol A can be used to verify the exchange between surface and groundwater (Banzhaf, Krein, and Scheytt 2013. Osenbrück et al. 2007). Buser, Poiger, and Muller (1999) applied a ratio of the readily biodegradable ibuprofen and the persistent clofibric acid for estimating water residence time after wastewater leakage. For tracking leakage of wastewater also a set of artificial sweeteners can be used. 
A set of four artificial sweeteners can be used to distinguish fresh intrusions of wastewater (saccharin and cyclamate, readily degradable) from older intrusions (acesulfame and sucralose, absence of saccharin and cyclamate) (Snider et al. 2017). In general, sucralose, carbamazepine, and sulfamethoxazole are relatively resistant against biodegradation, which enables them to be used as a suitable set for even older intrusions (Y. Yang, Liu, et al. 2017). Wolf, Zwiener, and Zemann (2012) included the iodinated X-ray contrast medium amidotrizoic acid into a set of carbamazepine and acesulfame to identify and monitor leaky sewers in urban groundwater regimes. As nitrate in drinking water is an evolving issue of concern, Robertson, Van Stempvoort, Roy, et al. (2016) suggests the ratio of nitrogen to acesulfame and chloride to acesulfame to decide if the dominating source of nitrate in groundwater are leaky sewers or residues from fertilisers. Micropollutants also allow verifying the exchange on a regional or even global scale. Atrazine is banned in the EU since 2004 but still detected in the Mediterranean Sea intruding via the Dardanelles by the exchange with the Black Sea where atrazine is still used as a pesticide within its basin (Nödler, Licha, and Voutsa 2013).

\subsubsection{Using ratios of related compounds as indicators}

As homologues and isomers have similar structures, they often behave in a related, predictable way but often different enough for using them as a set of indicators. Ideally these compounds differ in retardation behaviour but not in chemical or biological behaviour. Often these are "classical contaminants" such as toluene and the three xylene isomers (BTEX), polycyclic aromatic hydrocarbons (PAHs), polychlorinated biphenyls (PCBs), and short chained alkyl phenols (SCAPs) (Fischer, Licha, and Markelova 2014. Licha, Herfort, and Sauter 2001). This can be an advantage for specific questions based on compound classes, e.g. after a spillage or a specific point source to track and define the flow path or its properties. Concentration ratios of PAHs, released in most combustion processes based also on their log $\mathrm{K}_{\mathrm{OW}}$ can be used to distinguish between the contamination by the direct residue of smelting activities associated with mining and its leachate as the ratio changes during transport (Warner, Ruppert, and Licha 2016).

Isomers are a series of compounds with equal molecular formulas but differently positioned functional groups (substituents). Isomers often do not show different 
retardation in the aquatic environment but can differ in chemical and biological degradation rates. Tolyltriazole, a corrosion inhibitor, has two positional isomers. While 5-methyl-1H-benzotriazol shows good degradation rates during wastewater treatment 4-methyl-1H-benzotrizol is only poorly removed (Herrero et al. 2014. Herzog et al. 2014). Enantiomers are isomers with their molecular structures being mirror images of each other. Abiotic processes usually have no effect on enantiomeric ratios but in most biotic processes one enantiomer is usually degraded faster than the other (Hühnerfuss and Shah 2009; C. S. Wong 2006). This means that enantiomers are ideal indicators for microbial activity and biotic transformation processes, to differentiate between biological and physicochemical degradation (Kohler et al. 1997). The analytical procedure to separate enantiomers is still challenging but made progress in the last years. Ibuprofen is a racemate of $\mathrm{S}$ - and $\mathrm{R}$-enantiomers but only the S-enantiomers has a pharmacological effect and is faster degraded in WWTPs than the R-enantiomer (Buser, Poiger, and Muller 1999). None of the propranolol enantiomers are metabolized preferentially in humans but by microconsortia in WWTP. After treatment the $\mathrm{R}(+)$-enantiomer is dominating (MacLeod, Sudhir, and C. Wong 2007). Atenolol shows a modest stereoselectivity and the $\mathrm{S}(-)$-atenolol is enriched in both, human urine and untreated wastewater. The psychoactive synthetic drugs 3,4-methylendioxy-N-methylamphetamine (MDMA) and its metabolite 3,4-methylenedioxyamphetamine (MDA), which is also available on the illicit market, are both racemates. The $\mathrm{S}(+)$-enantiomer of MDMA is preferably metabolised in the human body leading to an enrichment of the $\mathrm{R}(-)$-enantiomer and $\mathrm{S}(+)-\mathrm{MDA}$ in raw wastewater. For direct consumption of MDA also the $\mathrm{S}(+)$-enantiomer is metabolised preferably and the $\mathrm{R}(-)$-enantiomer is enriched in wastewater. Screening for both enantiomers enables to decide whether consumption of MDMA or MDA is dominating (Kasprzyk-Hordern 2010 KasprzykHordern and D. Baker 2012). Enantiomeric profiling of wastewater also enables to distinguish the consummation of MDMA and amphetamine or direct disposal, by the relative proportion of the enantiomers to each other. If they are equal they are most likely disposed directly (Emke et al. 2014). The ratio of S- and R-enantiomers of mecoprop can be used as an indicator for in situ biodegradation processes in aquifers as S-mecoprop is preferentially degraded by microorganisms (Kohler et al. 1997; Zipper et al. 1998). 


\subsection{Obtaining quantitative information from indicators}

Besides qualitative and semi-quantitative information micropollutants can be used to estimate volumes flows. However, this approach requires knowledge about the input function of the respective compounds, which can be constructed using hydrodynamic models. Further input functions may be derived based on the daily consumption ("defined daily doses", DDD) or site-specific application schedules of pesticides. DDDs were already used to quantify the proportion of wastewater in water bodies.

Carbamazepine was recognised to be useful for quantifying the proportion of sewage in groundwater, e.g. caused by leaky sewer networks (Fenz et al. 2005). In regions where scabies is a substantial issue the scabicide crotamiton works well together with carbamazepine to estimate the percentage of sewage in groundwater (Nakada et al., 2008). As the artificial sweetener acesulfame is assumed to be persistent in the environment (Lange, Scheurer, and Brauch 2012), it is successfully used to estimate the percentage of wastewater in groundwater (Buerge, Buser, et al. 2009, Spoelstra, Senger, and Schiff 2017). As during the last years a significant transformation of acesulfame into sulfamic acid was observed, it should be applied with caution (Castronovo et al. 2017; Kahl, Kleinsteuber, et al. 2018). Knowing the input function cyclamate was used as a tracer for transport modelling to quantify the impact of a CSO on the quality of spring water of a karst spring (Zirlewagen et al. 2016).

A mass balance of caffeine was successfully used to determine the fraction of combined sewer overflows into groundwater (Buerge, Poiger, et al. 2006; Viviano et al. 2017). Caffeine and its metabolite paraxanthine can also be used to quantify untreated wastewater in karst systems (Hillebrand, Nödler, Licha, et al. 2012).

\subsubsection{Wastewater-based epidemiology (WBE)}

Another evolving field is wastewater-based epidemiology (WBE), which can be used to estimate population size, intake and exposure to environmental and food toxicants, (illicit) drug consumption and other lifestyle factors. Further micropollutants often reflect socio-economic factors such as migration of younger people from rural areas to urban centres (Nödler, Licha, Fischer, et al. 2011). 
In general the overall occurrence of micropollutants can be correlated with the degree of industrialisation (Sorensen et al. 2015). Micropollutants applied and emitted by humans can be used to gain relevant information about lifestyle habits, public health, wellbeing and often population size (Andrés-Costa, Andreu, and Picó 2017; Choi et al. 2018, Gracia-Lor, Rousis, et al. 2017). Specifically, the analysis of illicit drugs in wastewater can provide a non-intrusive, impartial and cost-effective way compared to surveys to estimate drug mass loads and doses (Castiglioni et al. 2006; Gatidou et al. 2016; Lai et al. 2013, Van Nuijs et al. 2009). A suitable biomarker for WBE should be excreted by humans only via urine/faeces in the range of $\mu \mathrm{g} / \mathrm{L}$ to ensure detection in raw wastewater and should be stable during transport, sampling and storage (Chen et al. 2014). As elimination during wastewater treatment can be substantial (Postigo, López de Alda, and Barceló 2010) untreated wastewater should be analysed for WBE. As many pharmaceuticals and drugs for recreational purposes undergo extensive metabolism in the human body, human excretion rates of metabolites need to be known for estimating the total consumption. However, further research is needed in this field as literature reports wide ranges of excretion rates for some compounds leading to uncertainties in calculations (Evgenidou, Konstantinou, and Lambropoulou 2015; Nuijs et al. 2011).

Caffeine consumption of a population can be calculated from the human exclusive metabolite 1,7-dimethyluric acid (Gracia-Lor, Rousis, et al. 2017). Antibiotic loads in wastewater can reflect the general health status of a population with respect to bacterial infections (Castiglioni et al. 2006. Huang et al. 2011). O'Brien et al. (2014) used a set of compounds (acesulfame, atenolol, caffeine, carbamazepine, codeine, furosemide, gabapentin, hydrochlorothiazide, ibuprofen, iopromide, naproxen, norfloxacin, paracetamol and salicylic acid) in raw wastewater to successfully estimate the population size within a catchment. Conducting the sampling campaign on a national Census Day allowed a verification with population data and showed that this compound set serves good estimations for population size. Lai et al. (2013) estimated population sizes using acesulfame, cyclamate, saccharin and sucrose. Especially for illicit drugs WBE seems promising to estimate consumption and objectively estimate the extent of drug use in a population (Been et al. 2016, Feng, W. Zhang, and Li 2018; Gracia-Lor, Zuccato, and Castiglioni 2016). Benzoylecgonine (a human metabolite of cocaine) 
was successfully applied to calculate the consumption of the parent compound, as well as 6-monoacetylmorphine (6-MAM) and norketamine for the consumption of heroin and ketamine, respectively (Plósz et al. 2013 Postigo, López de Alda, and Barceló 2010). Most frequently applied for the estimation of drug use are benzoylecgonine, amphetamine, methamphetamine, MDMA, and THC-COOH (Lai et al. 2013, K. Thomas et al. 2012). To estimate the community wide alcohol consumption the ethanol metabolite ethyl sulfate was successfully applied and correlates well with sales statistics (Andrés-Costa, Escrivá, et al. 2016, Boogaerts et al. 2016, Halter et al. 2009, Mastroianni, Lopez de Alda, and Barcelo 2014. Reid et al. 2011; Ryu et al. 2016). Cocaine and alcohol co-consumption leads to the specific co-metabolite cocaethylene and can be estimated by using the ratio of cocaethylene to benzoylecgonine (Mastroianni, Lopez de Alda, and Barcelo 2014. Rodríguez-Álvarez et al. 2015). Besides alcohol, nicotine is a legal and widely used drug. As a rise in nicotine concentrations was observed during rain events due to wash off of cigarette butts for WBE the human nicotine metabolites cotinine and trans-3'-hydroxycontinine is preferable and even spatial differences in a country are observable. Thomaidis et al. (2016) showed that even socioeconomic changes are reflected in the patterns of licit and illicit drugs. During the economic crisis in Greece from 2010 until 2014 they found significantly increased loads of benzodiazepines, antidepressants and antipsychotics, but also antihypertensives, antiepileptics, diuretics and antiepileptics in wastewater, reflecting an increase in stress-related diseases caused by the crisis.

\subsection{Summary information - How to decide for a suitable set of indicators}

The possibilities of using micropollutants as indicators are as manifold as questions to be solved in modern society. However, deciding for a suitable indicator among the huge variety of micropollutants possibly released into the environment is still challenging. Knowing your catchment as well as including possible sources for water quality impairments, defining problems to be solved and assigning susceptible areas to be monitored are crucial steps in preselecting a range of possible micropollutants to be applied as indicators. In addition to this, defining a meaningful set of indicators meeting the individual needs of a catchment and water 
quality requirements is a cost-effective and investigative monitoring approach for water quality, its decline or improvement.

The increasing number of industrial chemicals, pharmaceuticals, personal care products and associated metabolites/TPs makes the decision for suitable indicators a challenging task. However, the huge variety of compounds allows to answer many and even complex questions in a highly reliable and smart way. Figure 2.1 gives a comprehensive and universal overview to guide the reader through the selection processes on the way to find suitable indicators for source apportionment and investigative approaches based on compound groups. Micropollutants from different classes (pharmaceuticals, pesticides, personal care products, industrial process chemicals etc.) are listed in several databases: e.g. in the European Union industrial chemicals are registered in the REACH (Registration, Evaluation, Authorisation and Restriction of Chemical, Directive 1272/2008/EU) database (https://echa.europa.eu/regulations/reach), for Australia the Australian Inventory of Chemical Substances (AICS), for Canada domestic substance in the DSL and non-domestic in the NDSL databases, for the USA via the Toxic Substances Control Act (TSCA) and for China the Inventory of Existing Chemical Substances Produced or Imported in China (IECSC). Pesticides approved in the European Union can be found in a separate database (http://ec.europa. eu/food/plant/pesticides/eu-pesticides-database), also available for the USA (https://iaspub.epa.gov/apex/pesticides/f?p=chemicalsearch:1).

Human and veterinary pharmaceuticals with EU-wide use can be found in the MRI database (http://mri.cts-mrp.eu/). Personal care products can often be found in annexes of legislative texts, e.g. approved ingredients of cosmetics in Annex VI of European Regulation (EC) No. 1223/2009. Specific compounds need to be chosen according to their use and application in the respective Catchment. A more detailed overview is given in Table 2.1, showing compounds, which have already been successfully applied as indicators. Using a meaningful selection of indicators increases information density and utilising them for source apportionment allows for detecting the source of water quality impairments in a much smarter way. 


\subsection{Acknowledgements}

This study was funded by the European Commission (contract number 689341, INTCATCH, "Development and application of Novel, Integrated Tools for monitoring and managing Catchments") and by the German Federal Ministry of Education and Research (BMBF) (promotional reference No. 02WGW1460, "Grundwasser - Projekt GW-Analytik: Erarbeitung methodischer Grundlagen für die Charakterisierung der Beeinflussung von Grundwasservorkommen mittels modernster Analyseverfahren"), which are gratefully acknowledged. 


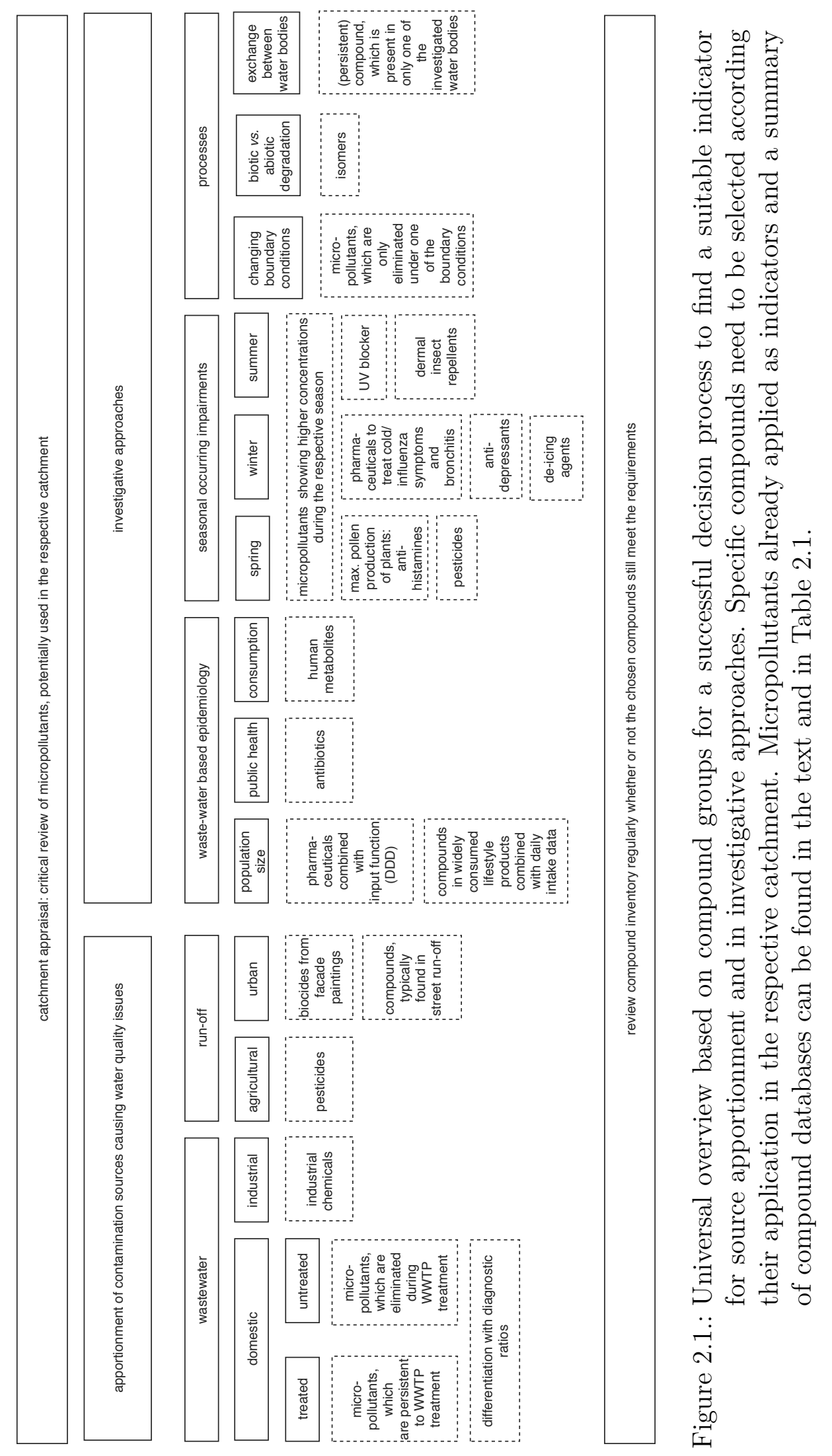




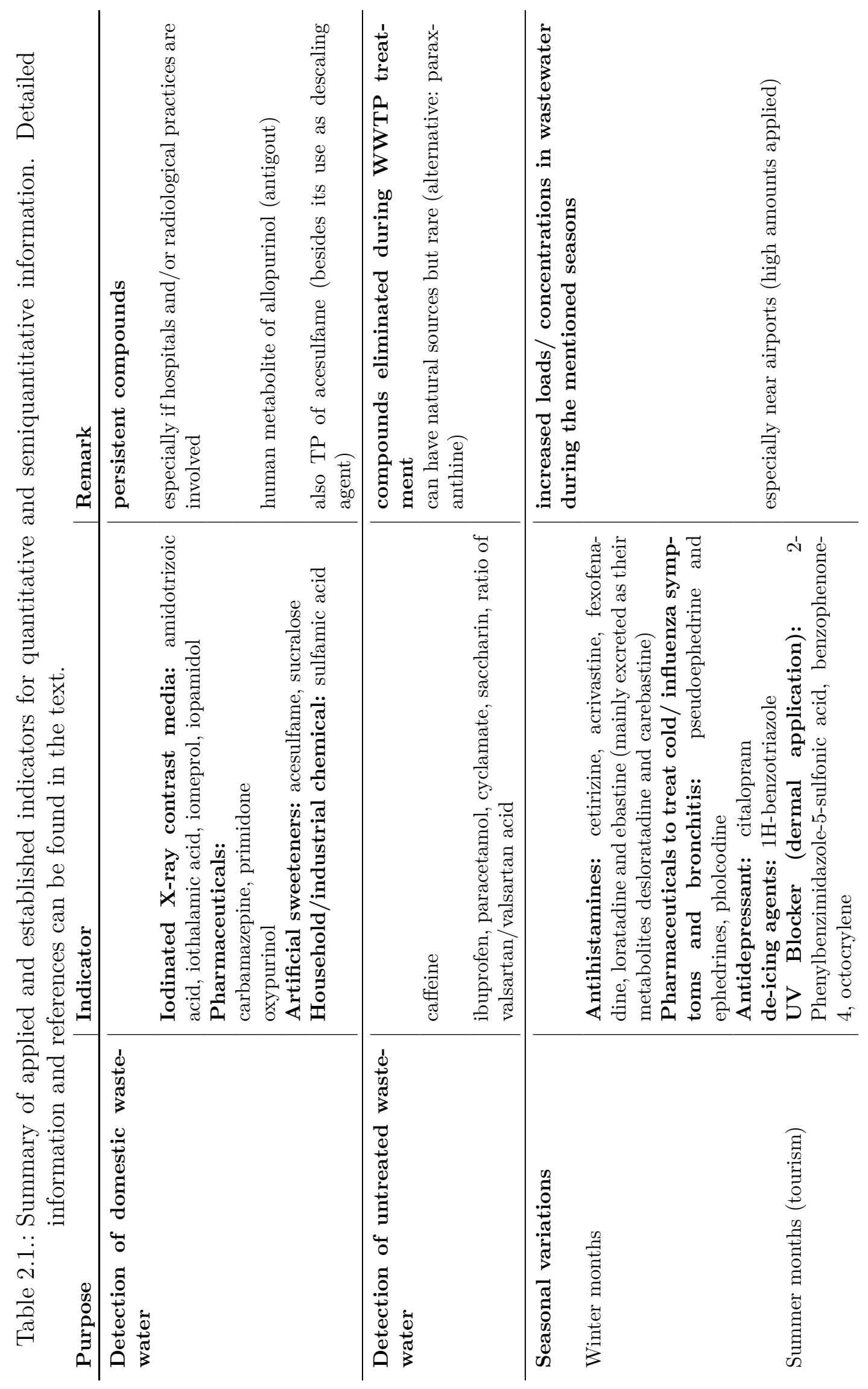




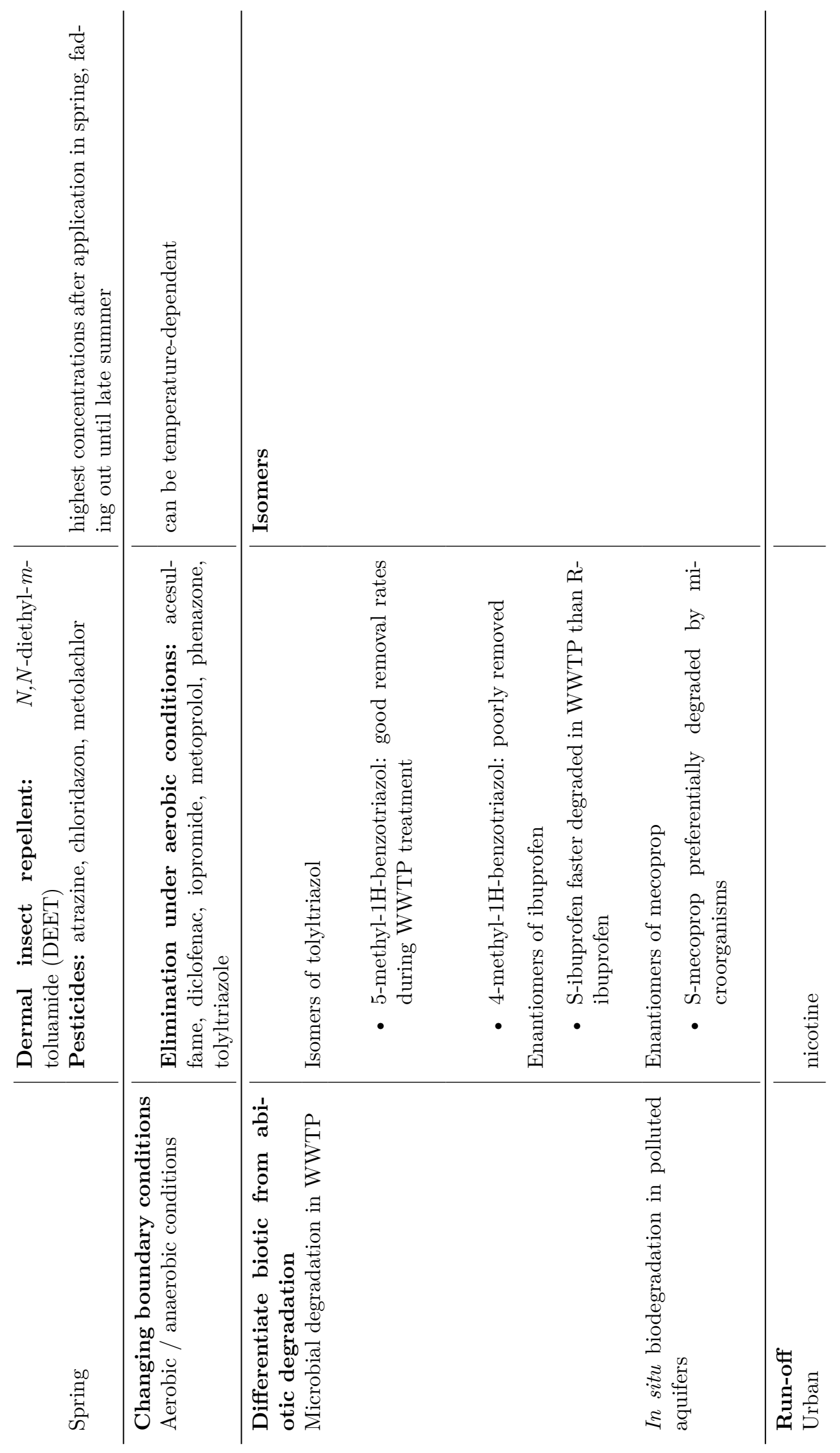




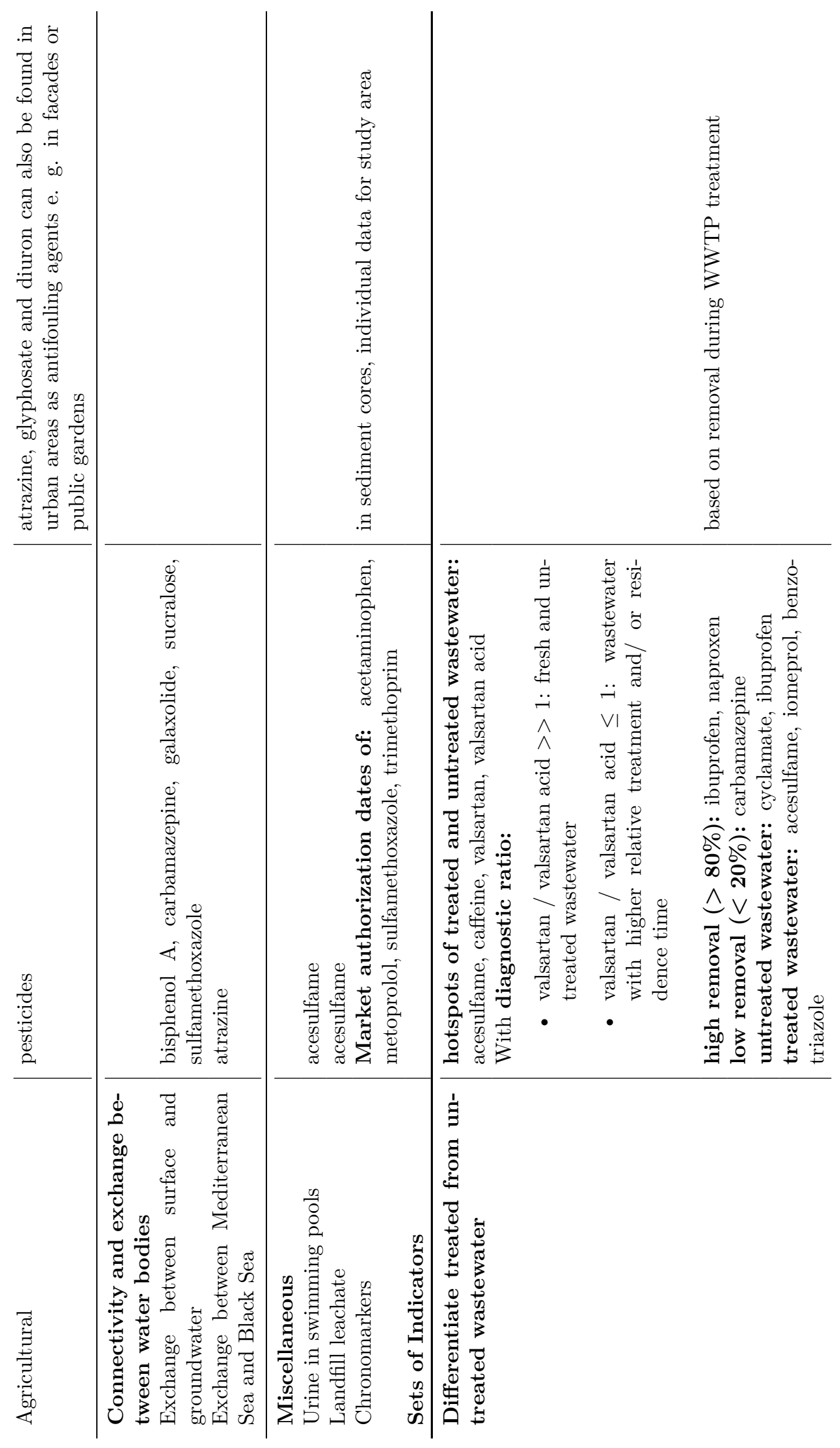




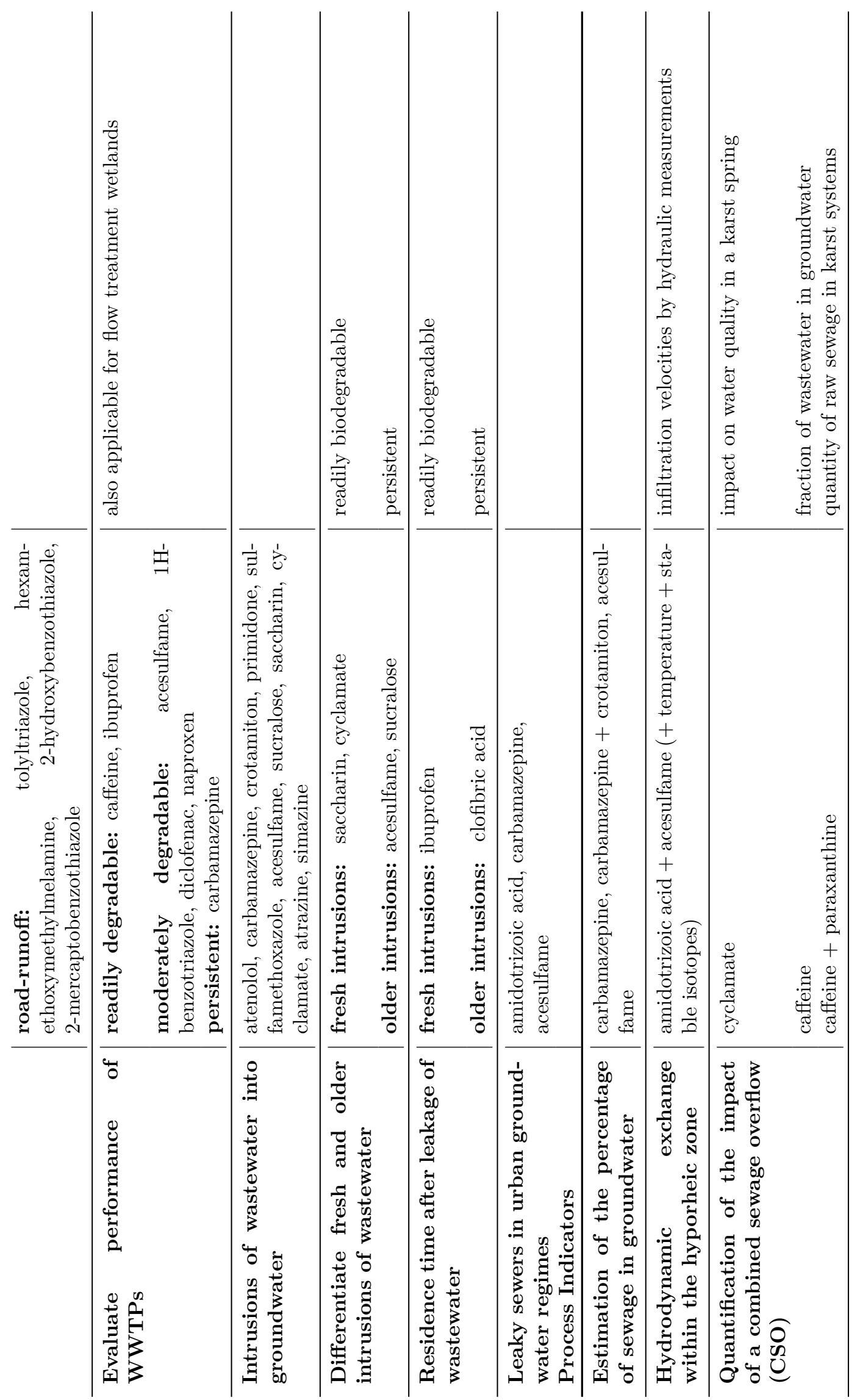




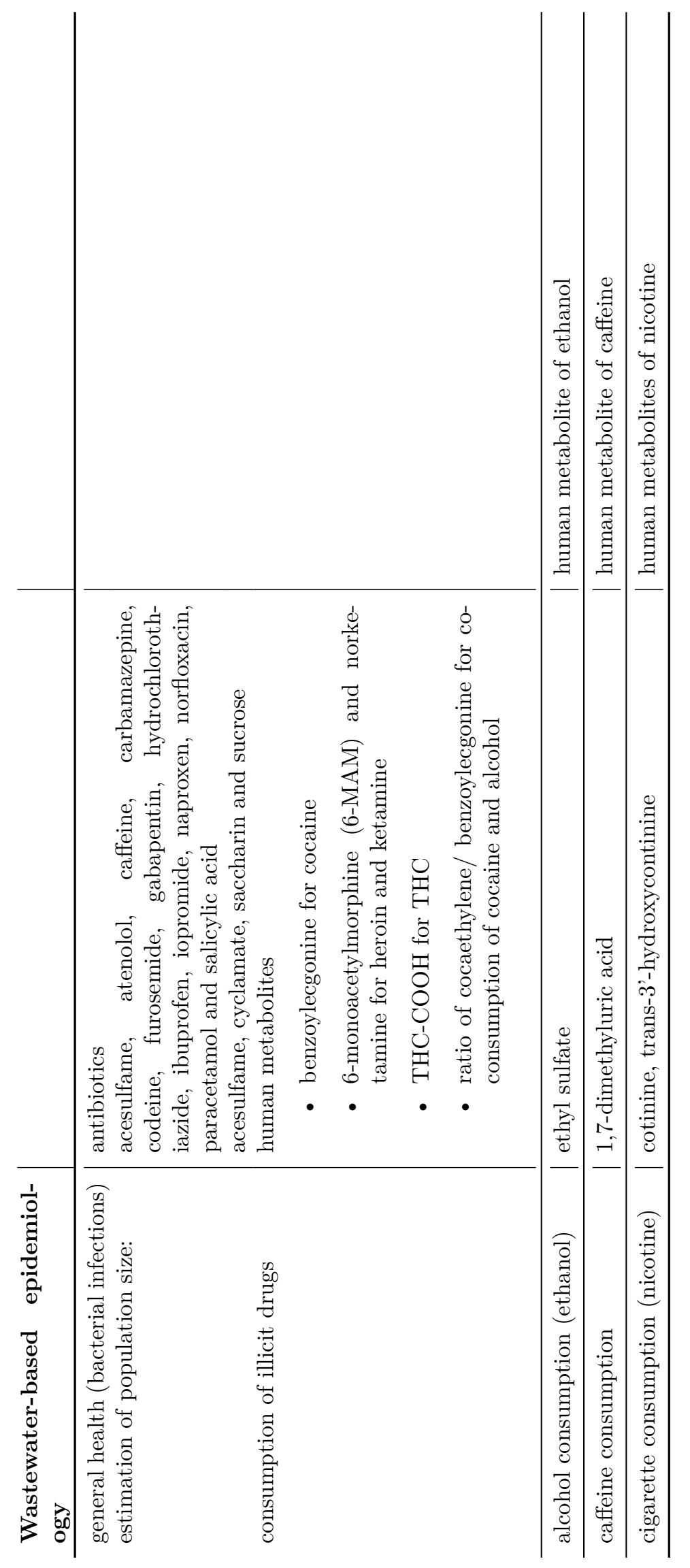




\section{References}

Alotaibi, M. D. et al. (2015). "Benzotriazoles in the Aquatic Environment: A Review of Their Occurrence, Toxicity, Degradation and Analysis". In: Water, Air, and Soil Pollution 226.7. DOI: $10.1007 /$ s11270-015-2469-4.

Andrés-Costa, M. J., V. Andreu, and Y. Picó (2017). "Liquid chromatography-mass spectrometry as a tool for wastewater-based epidemiology: Assessing new psychoactive substances and other human biomarkers". In: TrAC - Trends in Analytical Chemistry 94, pp. 21-38. DOI: 10.1016/j.trac.2017.06.012.

Andrés-Costa, M. J., Ú. Escrivá, et al. (2016). "Estimation of alcohol consumption during "Fallas" festivity in the wastewater of Valencia city (Spain) using ethyl sulfate as a biomarker". In: Science of the Total Environment 541, pp. 616-622. DOI: 10. 1016/j.scitotenv.2015.09.126.

Arpin-Pont, L. et al. (2016). "Occurrence of PPCPs in the marine environment: a review". In: Environmental Science and Pollution Research 23.6, pp. 4978-4991. DOI: $10.1007 / \mathrm{s} 11356-014-3617-\mathrm{x}$.

Banzhaf, S., A. Krein, and T. Scheytt (2013). "Using selected pharmaceutical compounds as indicators for surface water and groundwater interaction in the hyporheic zone of a low permeability riverbank". In: Hydrological Processes 27.20, pp. 28922902. DOI: 10.1002/hyp.9435.

Baquero, F., J. L. Martínez, and R. Cantón (2008). "Antibiotics and antibiotic resistance in water environments". In: Current Opinion in Biotechnology 19.3, pp. 260265. DOI: 10.1016/j.copbio.2008.05.006 arXiv: arXiv:1011.1669v3.

Barbieri, M. et al. (2012). "Fate of $\beta$-blockers in aquifer material under nitrate reducing conditions: Batch experiments". In: Chemosphere 89, pp. 1272-1277. DOI: 10.1016/ j.chemosphere.2012.05.019.

Barbosa, M. et al. (2016). "Occurrence and removal of organic micropollutants: An overview of the watch list of EU Decision 2015/495". In: Water Research 94, pp. 257279. DOI: $10.1016 / j$.watres.2016.02.047.

Bartels, P. and W. von Tümpling (2007). "Solar radiation influence on the decomposition process of diclofenac in surface waters". In: Science of the Total Environment 374.1, pp. 143-155. DOI: $10.1016 /$ j.scitotenv.2006.11.039

Barth, S. (1998). "Application of boron isotopes for tracing sources of anthropogenic contamination in groundwater". In: Water Research 32.3, pp. 685-690. DOI: 10 . 1016/S0043-1354(97)00251-0.

Bassett, R. L. et al. (1995). "Identification of Groundwater Solute Sources Using Boron Isotopic Composition". In: Environmental Science and Technology 29.12, pp. 29152922. DOI: 10.1021/es00012a005.

Been, F. et al. (2016). "Assessing geographical differences in illicit drug consumptionA comparison of results from epidemiological and wastewater data in germany and switzerland". In: Drug and Alcohol Dependence 161, pp. 189-199. DOI: 10.1016/j. drugalcdep.2016.02.002.

Bertelkamp, C. et al. (2014). "Sorption and biodegradation of organic micropollutants during river bank filtration: A laboratory column study". In: Water Research 52, pp. 231-241. DOI: $10.1016 /$ j.watres.2013.10.068. 
Bieber, S. et al. (2017). "RPLC-HILIC and SFC with mass spectrometry: Polarityextended organic molecule screening in environmental (water) samples". In: Analytical Chemistry, acs.analchem.7b00859. DOI: 10.1021/acs.analchem.7b00859.

Blackstock, L., N. J. P. Wawryk, et al. (2018). "Recent Applications and Critical Evaluation of Using Artificial Sweeteners to Assess Wastewater Impact". In: Current Opinion in Environmental Science $\&$ Health.

Blackstock, L., W. Wang, et al. (2017). "Sweetened swimming pools and hot tubs". In: Environmental Science \& Technology Letters 4.4, pp. 149-153.

Boogaerts, T. et al. (2016). "Spatial and temporal trends in alcohol consumption in Belgian cities: A wastewater-based approach". In: Drug and Alcohol Dependence 160, pp. 170-176. DOI: $10.1016 / \mathrm{j}$.drugalcdep.2016.01.002.

Boxall, A. (2004). "The environmental side effects of medication". In: EMBO reports 5.12, pp. 1110-1116. DOI: 10.1038/sj .embor. 7400307 .

Brumovský, M. et al. (2017). "Contaminants of emerging concern in the open sea waters of the Western Mediterranean". In: Environmental Pollution 229, pp. 976-983. DOI: 10.1016/j .envpol.2017.07.082.

Bucheli, T. D. et al. (1998). "Occurrence and behavior of pesticides in rainwater, roof runoff, and artificial stormwater infiltration". In: Environmental Science and Technology 32.22, pp. 3457-3464. DOI: 10.1021/es980317n.

Buerge, I., T. Poiger, et al. (2003). "Caffeine, an anthropogenic marker for wastewater contamination of surface waters". In: Environmental Science and Technology 37.4, pp. 691-700. DOI: $10.1021 /$ es020125z

- (2006). "Combined sewer overflows to surface waters detected by the anthropogenic marker caffeine". In: Environmental Science and Technology 40.13, pp. 4096-4102. DOI: 10.1021/es0525531.

Buerge, I., H. Buser, et al. (2009). "Ubiquitous occurrence of the artificial sweetener acesulfame in the aquatic environment: An ideal chemical marker of domestic wastewater in groundwater". In: Environmental Science and Technology 43.12, pp. 4381-4385. DOI: $10.1021 /$ es $900126 \mathrm{x}$.

Burke, V. et al. (2014). "Temperature dependent redox zonation and attenuation of wastewater-derived organic micropollutants in the hyporheic zone". In: Science of the Total Environment 482-483.1, pp. 53-61. DOI: 10.1016/j.scitotenv.2014.02.098.

Buser, H., T. Poiger, and M. Muller (1999). "Occurrence and environmental behavior of the chiral pharmaceutical drug ibuprofen in surface waters and in wastewater". In: Environmental Science and Technology 33.15, pp. 2529-2535. DOI: $10.1021 /$ es981014w.

Buttiglieri, G. et al. (2009). "Environmental occurrence and degradation of the herbicide n-chloridazon". In: Water Research 43.11, pp. 2865-2873. DOI: 10.1016/j . watres.2009.03.035

Byer, J. D. et al. (2011). "Spatial and seasonal variations in atrazine and metolachlor surface water concentrations in Ontario (Canada) using ELISA". In: Chemosphere 82.8, pp. 1155-1160. DOI: 10.1016/j.chemosphere.2010.12.054

Cantwell, M. G. et al. (2016). "Caffeine in Boston Harbor past and present, assessing its utility as a tracer of wastewater contamination in an urban estuary". In: Marine Pollution Bulletin 108.1-2, pp. 321-324. DOI: 10.1016/j.marpolbul.2016.04.006. 
Castiglioni, S. et al. (2006). "Identification and measurement of illicit drugs and their metabolites in urban wastewater by liquid chromatography-tandem mass spectrometry". In: Analytical Chemistry 78.24, pp. 8421-8429. DOI: 10.1021/ac061095b.

Castronovo, S. et al. (2017). "Biodegradation of the artificial sweetener acesulfame in biological wastewater treatment and sandfilters". In: Water Research 110, pp. 342353. DOI: $10.1016 / \mathrm{j}$.watres.2016.11.041.

Čelić, M. et al. (2017). "Environmental analysis: Emerging pollutants". In: Liquid Chromatography: Applications: Second Edition 2, pp. 451-477. DOI: 10.1016/B978-012-805392-8.00015-3.

Chen, C. et al. (2014). "Towards finding a population biomarker for wastewater epidemiology studies". In: Science of the Total Environment 487.1, pp. 621-628. DOI: 10.1016/j.scitotenv.2013.11.075.

Choi, P. M. et al. (2018). "Wastewater-based epidemiology biomarkers: Past, present and future". In: TrAC - Trends in Analytical Chemistry 105, pp. 453-469. DOI: 10. 1016/j.trac.2018.06.004.

Čizmić, M., S. Babić, and M. Kaštelan-Macan (2017). "Multi-class determination of pharmaceuticals in wastewaters by solid-phase extraction and liquid chromatography tandem mass spectrometry with matrix effect study". In: Environmental Science and Pollution Research. DOI: 10.1007/s11356-017-9660-7.

Clara, M., B. Strenn, and N. Kreuzinger (2004). "Carbamazepine as a possible anthropogenic marker in the aquatic environment: Investigations on the behaviour of Carbamazepine in wastewater treatment and during groundwater infiltration". In: Water Research 38.4, pp. 947-954. DOI: 10.1016/j .watres.2003.10.058.

Costanzo, S. D. et al. (2007). "Is there a risk associated with the insect repellent DEET (N,N-diethyl-m-toluamide) commonly found in aquatic environments?" In: Science of the Total Environment 384.1-3, pp. 214-220. DOI: 10.1016/j. scitotenv. 2007. 05.036 .

Davies, H. and C. Neal (2007). "Estimating nutrient concentrations from catchment characteristics across the UK". In: Hydrology and Earth System Sciences 11, pp. 550558. DOI: 10.5194/hess-11-550-2007.

Day, R. O. et al. (2007). "Clinical pharmacokinetics and pharmacodynamics of allopurinol and oxypurinol". In: Clinical Pharmacokinetics 46.8, pp. 623-644. DOI: 10.2165/00003088-200746080-00001.

Deblonde, T., C. Cossu-Leguille, and P. Hartemann (2011). "Emerging pollutants in wastewater: A review of the literature". In: International Journal of Hygiene and Environmental Health 214.6, pp. 442-448. DOI: 10.1016/j.ijheh.2011.08.002.

Deeb, A. A. et al. (2017). "Suspect screening of micropollutants and their transformation products in advanced wastewater treatment". In: Science of the Total Environment 601-602, pp. 1247-1253. DOI: 10.1016/j.scitotenv.2017.05.271.

Doummar, J. et al. (2014). "Carbamazepine breakthrough as indicator for specific vulnerability of karst springs: Application on the jeita spring, lebanon". In: Applied Geochemistry 47, pp. 150-156. DOI: 10.1016/j.apgeochem.2014.06.004.

Emke, E. et al. (2014). "Enantiomer profiling of high loads of amphetamine and MDMA in communal sewage: A Dutch perspective". In: Science of the Total Environment 487.1, pp. 666-672. DOI: 10.1016/j.scitotenv.2013.11.043. 
Engelhardt, I., M. Piepenbrink, et al. (2011). "Comparison of tracer methods to quantify hydrodynamic exchange within the hyporheic zone". In: Journal of Hydrology 400.1-2, pp. 255-266. DOI: 10.1016/j.jhydrol.2011.01.033.

Engelhardt, I., H. Prommer, et al. (2014). "Reactive transport of iomeprol during stream-groundwater interactions". In: Environmental Science and Technology 48.1, pp. 199-207. DOI: 10.1021/es403194r

Evgenidou, E. N., I. K. Konstantinou, and D. A. Lambropoulou (2015). "Occurrence and removal of transformation products of PPCPs and illicit drugs in wastewaters: A review". In: Science of the Total Environment 505, pp. 905-926. DOI: 10.1016/j. scitotenv.2014.10.021, arXiv: arXiv:1011.1669v3,

Farré, M. et al. (2012). "Achievements and future trends in the analysis of emerging organic contaminants in environmental samples by mass spectrometry and bioanalytical techniques". In: Journal of Chromatography A 1259, pp. 86-99. Dor: 10.1016/ j.chroma.2012.07.024.

Feng, L., W. Zhang, and X. Li (2018). "Monitoring of regional drug abuse through wastewater-based epidemiology-A critical review". In: Science China Earth Sciences 61.3, pp. 239-255. DOI: $10.1007 / \mathrm{s} 11430-017-9129-\mathrm{x}$.

Fenz, R. et al. (2005). "Quantification of sewer exfiltration using the anti-epileptic drug carbamazepine as marker species for wastewater". In: Water Science and Technology 52.9 , pp. 209-217.

Fischer, S., T. Licha, and E. Markelova (2014). "Transportverhalten kurzkettiger Alkylphenole (SCAP) im Grundwasser und in der Umwelt". In: Grundwasser 19.2, pp. 119126. DOI: $10.1007 / \mathrm{s} 00767-013-0233-5$.

Franco, A. et al. (2010). "An unexpected challenge: Ionizable compounds in the REACH chemical space". In: International Journal of Life Cycle Assessment 15.4, pp. 321325. DOI: $10.1007 / \mathrm{s} 11367-010-0165-6$.

Funke, J. et al. (2015). "Oxypurinol - A novel marker for wastewater contamination of the aquatic environment". In: Water Research 74, pp. 257-265. DOI: 10.1016/j. watres.2015.02.007

Gäbler, H.-E. and A. Bahr (1999). "Boron isotope ratio measurements with a doublefocusing magnetic sector ICP mass spectrometer for tracing anthropogenic input into surface and ground water". In: Chemical Geology 156.1, pp. 323-330. DOI: https: //doi.org/10.1016/S0009-2541(98)00181-8.

Gago-Ferrero, P. et al. (2018). "Suspect Screening and Regulatory Databases: A Powerful Combination to Identify Emerging Micropollutants". In: Environmental Science and Technology 52.12, pp. 6881-6894. DOI: 10.1021/acs.est.7b06598.

Gardarsdottir, H. et al. (2010). "Seasonal patterns of initiating antidepressant therapy in general practice in the Netherlands during 2002-2007". In: Journal of Affective Disorders 122.3 , pp. 208-212. DOI: $10.1016 / \mathrm{j} \cdot \mathrm{jad} .2009 .06 .033$.

Gasser, G. et al. (2010). "Quantitative evaluation of tracers for quantification of wastewater contamination of potable water sources". In: Environmental Science and Technology 44.10, pp. 3919-3925. DOI: 10.1021/es100604c.

Gatidou, G. et al. (2016). "Drugs of abuse and alcohol consumption among different groups of population on the Greek Island of Lesvos through sewage-based epidemi- 
ology". In: Science of the Total Environment 563-564, pp. 633-640. DOI: 10.1016/ j.scitotenv.2016.04.130.

Gawlik, B. et al. (2012). "Testing sample stability in short-term isochronous stability studies for EU-wide monitoring surveys of polar organic contaminants in water". In: TrAC - Trends in Analytical Chemistry 36, pp. 36-46. DOI: 10.1016/j.trac. 2012. 04.001 .

Giger, W., C. Schaffner, and H. P. Kohler (2006). "Benzotriazole and tolyltriazole as aquatic contaminants. 1. Input and occurrence in rivers and lakes". In: Environmental Science and Technology 40.23, pp. 7186-7192. DOI: 10.1021/es061565j.

Godbillon, J. and M. Duval (1984). "Determination of two metoprolol metabolises in human urine by high-performance liquid chromatography". In: Journal of Chromatography B: Biomedical Sciences and Applications 309.C, pp. 198-202. DOI: 10 . 1016/0378-4347(84)80025-0.

Gothwal, R. and S. Thatikonda (2017). "Role of environmental pollution in prevalence of antibiotic resistant bacteria in aquatic environment of river: case of Musi river, South India". In: Water and Environment Journal 31.4, pp. 456-462. DOI: 10.1111/ wej.12263.

Gracia-Lor, E., N. I. Rousis, et al. (2017). "Estimation of caffeine intake from analysis of caffeine metabolites in wastewater". In: Science of the Total Environment 609.July, pp. 1582-1588. DOI: $10.1016 /$ j.scitotenv.2017.07.258.

Gracia-Lor, E., E. Zuccato, and S. Castiglioni (2016). "Refining correction factors for back-calculation of illicit drug use". In: Science of the Total Environment 573, pp. 1648-1659. DOI: 10.1016/j.scitotenv.2016.09.179.

Hai, F. et al. (2018). "Carbamazepine as a Possible Anthropogenic Marker in Water: Occurrences, Toxicological Effects, Regulations and Removal by Wastewater Treatment Technologies". In: Water 10.2, p. 107. DoI: 10.3390/w10020107.

Halter, C. C. et al. (2009). "Assessment of the stability of the ethanol metabolite ethyl sulfate in standardised degradation tests". In: Forensic Science International 186.1-3, pp. 52-55. DOI: 10.1016/j.forsciint.2009.01.009.

Hanke, I. et al. (2010). "Relevance of urban glyphosate use for surface water quality". In: Chemosphere 81.3, pp. 422-429. DOI: 10.1016/j . chemosphere.2010.06.067.

Harman, C., Reid, and Thomas (2011). "In situ calibration of a passive sampling device for selected illicit drugs and their metabolites in wastewater, and subsequent yearlong assessment of community drug usage". In: Environmental Science and Technology 45.13, pp. 5676-5682. DOI: $10.1021 /$ es201124j.

Heberer, T. (2002). "Occurrence, fate, and removal of pharmaceutical residues in the aquatic environment: a review of recent research data." In: Toxicology letters 131, pp. 5-17. DOI: 10.1016/S0378-4274(02)00041-3.

Hebig, K. H. et al. (2014). "Impact of materials used in lab and field experiments on the recovery of organic micropollutants". In: Science of the Total Environment 473-474, pp. 125-131. DOI: $10.1016 /$ j.scitotenv.2013.12.004.

Hernando, M. D. et al. (2006). "Environmental risk assessment of pharmaceutical residues in wastewater effluents, surface waters and sediments". In: Talanta 69.2 SPEC. ISS. Pp. 334-342. DOI: 10.1016/j . talanta.2005.09.037 arXiv: arXiv: $1011.1669 \mathrm{v} 3$ 
Herrero, P. et al. (2014). "An overview of analytical methods and occurrence of benzotriazoles, benzothiazoles and benzenesulfonamides in the environment". In: $\operatorname{Tr} A C$ - Trends in Analytical Chemistry 62.November, pp. 46-55. DOI: 10.1016/j.trac. 2014.06.017.

Herzog, B. et al. (2014). "Monitoring benzotriazoles: a 1 year study on concentrations and removal efficiencies in three different wastewater treatment plants". In: Water Science and Technology 69.4, pp. 710-717. DOI: 10.2166/wst.2013.766.

Hillebrand, O., S. Musallam, et al. (2013). "The challenge of sample-stabilisation in the era of multi-residue analytical methods: A practical guideline for the stabilisation of 46 organic micropollutants in aqueous samples". In: Science of the Total Environment 454-455, pp. 289-298. DOI: 10.1016/j.scitotenv.2013.03.028.

Hillebrand, O., K. Nödler, T. Licha, et al. (2012). "Caffeine as an indicator for the quantification of untreated wastewater in karst systems". In: Water Research 46.2, pp. 395-402. DOI: $10.1016 / j$. watres.2011.11.003.

Hillebrand, O., K. Nödler, M. Sauter, et al. (2015). "Multitracer experiment to evaluate the attenuation of selected organic micropollutants in a karst aquifer". In: Science of the Total Environment 506-507, pp. 338-343. DOI: 10.1016/j.scitotenv. 2014. 10.102 .

Holčapek, M., R. Jirásko, and M. Lísa (2012). "Recent developments in liquid chromatography-mass spectrometry and related techniques". In: Journal of Chromatography A 1259, pp. 3-15. DOI: 10.1016/j.chroma.2012.08.072, arXiv: arXiv:1011.1669v3.

Hrudey, S. E. and E. J. Hrudey (2014). Ensuring safe drinking water: learning from frontline experience with contamination. American Water Works Association Denver $(\mathrm{CO})$.

Huang, C.-H. et al. (2011). "Assessment of potential antibiotic contaminants in water and preliminary occurrence analysis". In: Journal of Contemporary Water Research and Education 120.1, p. 4.

Hühnerfuss, H. and M. R. Shah (2009). "Enantioselective chromatography-A powerful tool for the discrimination of biotic and abiotic transformation processes of chiral environmental pollutants". In: Journal of Chromatography A 1216.3, pp. 481-502. DOI: $10.1016 / \mathrm{j}$.chroma.2008.09.043

James, C. A. et al. (2016). "Evaluating Contaminants of Emerging Concern as tracers of wastewater from septic systems". In: Water Research 101, pp. 241-251. DOI: 10 . $1016 / j$.watres.2016.05.046.

Janna, H. et al. (2011). "From dishwasher to tap? Xenobiotic substances benzotriazole and tolyltriazole in the environment". In: Environmental Science and Technology 45.9, pp. 3858-3864. DOI: $10.1021 /$ es103267g.

Jekel, M. et al. (2015). "Selection of organic process and source indicator substances for the anthropogenically influenced water cycle". In: Chemosphere 125, pp. 155-167. DOI: $10.1016 / \mathrm{j}$. chemosphere.2014.12.025.

Jewell, K., A. Wick, and T. Ternes (2014). "Comparisons between abiotic nitration and biotransformation reactions of phenolic micropollutants in activated sludge". In: Water Research 48.1, pp. 478-489. DOI: 10.1016/j.watres.2013.10.010 
Jiang, J., Z. Zhou, and V. Sharma (2013). "Occurrence, transportation, monitoring and treatment of emerging micro-pollutants in waste water - a review from global views". In: Microchemical Journal 110, pp. 292-300.

Jones, O., N. Voulvoulis, and J. Lester (2001). "Human Pharmaceuticals in the Aquatic Environment a Review." In: Environ. Tech. 22.12, pp. 1383-94. DOI: 10.1080/ 09593332208618186 .

Kahl, S., J. Nivala, et al. (2017). "Effect of design and operational conditions on the performance of subsurface flow treatment wetlands: Emerging organic contaminants as indicators". In: Water Research. DOI: 10.1016/j.watres.2017.09.004

Kahl, S., S. Kleinsteuber, et al. (2018). "Emerging Biodegradation of the Previously Persistent Artificial Sweetener Acesulfame in Biological Wastewater Treatment". In: Environmental Science and Technology 52.5, pp. 2717-2725. DOI: 10.1021 /acs . est.7b05619.

Kahle, M. et al. (2009). "Hydrophilic anthropogenic markers for quantification of wastewater contamination in ground-and surface WATERS". In: Environmental toxicology and chemistry 28.12, pp. 2528-2536.

Kallenborn, R. et al. (2017). "Pharmaceuticals and personal care products (PPCPs) in Arctic environments: indicator contaminants for assessing local and remote anthropogenic sources in a pristine ecosystem in change". In: Environmental Science and Pollution Research, pp. 1-13. DOI: 10.1007/s11356-017-9726-6.

Kasprzyk-Hordern, B. (2010). "Pharmacologically active compounds in the environment and their chirality". In: Chemical Society Reviews 39.11, pp. 4466-4503. DOI: $10.1039 / \mathrm{c} 000408 \mathrm{c}$

Kasprzyk-Hordern, B. and D. Baker (2012). "Estimation of community-wide drugs use via stereoselective profiling of sewage". In: Science of the Total Environment 423, pp. 142-150. DOI: 10.1016/j.scitotenv.2012.02.019.

Kasprzyk-Hordern, B. and Baker (2012). "Enantiomeric profiling of chiral drugs in wastewater and receiving waters". In: Environmental Science and Technology 46.3, pp. 1681-1691. DOI: 10.1021/es203113y.

Khan, K. et al. (2017). "Prevalent fecal contamination in drinking water resources and potential health risks in Swat, Pakistan". In: Journal of Environmental Sciences, pp. 1-12. DOI: $10.1016 / \mathrm{j} \cdot \mathrm{jes} .2017 .12 .008$.

Khazaei, E. and W. Milne-Home (2017). "Applicability of geochemical techniques and artificial sweeteners in discriminating the anthropogenic sources of chloride in shallow groundwater north of Toronto, Canada". In: Environmental Monitoring and Assessment 189.5. DOI: $10.1007 / \mathrm{s} 10661-017-5927-1$.

Kiss, A. and E. Fries (2009). "Occurrence of benzotriazoles in the rivers Main, Hengstbach, and Hegbach (Germany)". In: Environmental Science and Pollution Research 16.6, pp. 702-710. DOI: $10.1007 /$ s11356-009-0179-4.

- (2012). "Seasonal source influence on river mass flows of benzotriazoles". In: Journal of Environmental Monitoring 14.2, p. 697. DOI: 10.1039/c2em10826g.

Knepper, T. (2004). "Analysis and fate of insect repellents". In: Water Science and Technology 50.5, pp. 301-308.

Kohler, H. P. et al. (1997). "Environmental fate of chiral pollutants. The necessity of considering stereochemistry". In: Chimia 51.12, pp. 947-951. 
Kosonen, J. and L. Kronberg (2009). "The occurrence of antihistamines in sewage waters and in recipient rivers". In: Environmental Science and Pollution Research 16.5, pp. 555-564. DOI: $10.1007 / \mathrm{s} 11356-009-0144-2$.

Kümmerer, K. (2009). "Antibiotics in the aquatic environment - A review - Part II". In: Chemosphere 75.4, pp. 435-441. DOI: 10.1016/j.chemosphere.2008.12.006.

Kunkel, U. and M. Radke (2011). "Reactive tracer test to evaluate the fate of pharmaceuticals in rivers". In: Environmental Science and Technology 45.15, pp. 6296-6302. DOI: $10.1021 /$ es104320n.

Kunkel, U. and M. Radke (2012). "Fate of pharmaceuticals in rivers: Deriving a benchmark dataset at favorable attenuation conditions". In: Water Research 46.17, pp. 55515565. DOI: $10.1016 / \mathrm{j}$. watres.2012.07.033.

Kurissery, S. et al. (2012). "Caffeine as an anthropogenic marker of domestic waste: A study from Lake Simcoe watershed". In: Ecological Indicators 23, pp. 501-508. DOI: 10.1016/j.ecolind.2012.05.001.

L., A. G. R., A. Putschew, and T. Nehls (2014). "Littered cigarette butts as a source of nicotine in urban waters". In: Journal of Hydrology 519.PD, pp. 3466-3474. DOI: $10.1016 / \mathrm{j} \cdot \mathrm{jhydrol} .2014 .05 .046$.

Lai, F. et al. (2013). "Using quantitative wastewater analysis to measure daily usage of conventional and emerging illicit drugs at an annual music festival". In: Drug and Alcohol Review 32.6, pp. 594-602. DOI: 10.1111/dar.12061.

Lange, F. T., M. Scheurer, and H. J. Brauch (2012). "Artificial sweeteners-A recently recognized class of emerging environmental contaminants: A review". In: Analytical and Bioanalytical Chemistry 403.9, pp. 2503-2518. DOI: $10.1007 / \mathrm{s} 00216-012-$ 5892-z.

Lapworth, D. J. et al. (2012). "Emerging organic contaminants in groundwater: A review of sources, fate and occurrence". In: Environmental Pollution 163, pp. 287303. DOI: $10.1016 / \mathrm{j}$. envpol.2011.12.034.

Leclerc, H. et al. (2001). "Advances in the Bacteriology of the Coliform Group: Their Suitability as Markers of Microbial Water Safety". In: Annual Review of Microbiology 55.1, pp. 201-234. DOI: 10.1146/annurev.micro.55.1.201.

Lee, E., H. K. Shon, and J. Cho (2014). "Role of wetland organic matters as photosensitizer for degradation of micropollutants and metabolites". In: Journal of Hazardous Materials 276, pp. 1-9. DOI: 10.1016/j.jhazmat.2014.05.001

Lewandowski, J. et al. (2011). "Fate of organic micropollutants in the hyporheic zone of a eutrophic lowland stream: Results of a preliminary field study". In: Science of the Total Environment 409.10, pp. 1824-1835. DOI: 10.1016/j.scitotenv. 2011. 01.028 .

Licha, T., M. Herfort, and M. Sauter (2001). "Phenolindex - ein sinnvoller Parameter für die Altlastenbewertung ?" In: Grundwasser 6.1, pp. 8-14. DOI: $10.1007 /$ PL00010389.

Lim, F., S. Ong, and J. Hu (2017). "Recent Advances in the Use of Chemical Markers for Tracing Wastewater Contamination in Aquatic Environment: A Review". In: Water 9.2 , p. 143 . DOI: $10.3390 /$ w9020143 
Löffler, D. et al. (2005). "Environmental fate of pharmaceuticals in water/sediment systems". In: Environmental Science and Technology 39.14, pp. 5209-5218. DOI: 10 . 1021/es0484146.

Loos, R. et al. (2009). "EU-wide survey of polar organic persistent pollutants in European river waters". In: Environmental Pollution 157.2, pp. 561-568. DoI: http: //dx.doi.org/10.1016/j.envpol.2008.09.020

Loraine, G. A. and M. E. Pettigrove (2006). "Seasonal variations in concentrations of pharmaceuticals and personal care products in drinking water and reclaimed wastewater in Southern California". In: Environmental Science and Technology 40.3, pp. 687-695. DOI: $10.1021 / \mathrm{es} 051380 \mathrm{x}$

Luo, Y. et al. (2014). "A review on the occurrence of micropollutants in the aquatic environment and their fate and removal during wastewater treatment". In: Science of the Total Environment 473-474, pp. 619-641. DOI: 10.1016/j.scitotenv.2013. 12.065 .

MacLeod, S., P. Sudhir, and C. Wong (2007). "Stereoisomer analysis of wastewaterderived $\beta$-blockers, selective serotonin re-uptake inhibitors, and salbutamol by highperformance liquid chromatography-tandem mass spectrometry". In: Journal of Chromatography A 1170.1, pp. 23-33.

Massmann, G. et al. (2006). "The impact of variable temperatures on the redox conditions and the behaviour of pharmaceutical residues during artificial recharge". In: Journal of Hydrology 328.1-2, pp. 141-156. DOI: 10.1016/j . jhydrol.2005.12.009.

Mastroianni, N., M. Lopez de Alda, and D. Barcelo (2014). "Analysis of ethyl sulfate in raw wastewater for estimation of alcohol consumption and its correlation with drugs of abuse in the city of Barcelona". In: Journal of Chromatography A 1360, pp. 93-99. DOI: $10.1016 / \mathrm{j}$.chroma.2014.07.051.

McCance, W. et al. (2018). "Contaminants of Emerging Concern as novel groundwater tracers for delineating wastewater impacts in urban and peri-urban areas". In: Water Research 146, pp. 118-133. DOI: 10.1016/j.watres.2018.09.013.

Müller, B. et al. (2012). "Pharmaceuticals as indictors of sewage-influenced groundwater". In: Hydrogeology Journal 20.6, pp. 1117-1129. DOI: 10.1007/s10040-0120852-4.

Murtaugh, J. and R. Bunch (1967). "Sterols as a measure of fecal pollution". In: Journal (Water Pollution Control Federation), pp. 404-409.

Musolff, A. et al. (2009). "Temporal and spatial patterns of micropollutants in urban receiving waters". In: Environmental Pollution 157.11, pp. 3069-3077. DOI:10.1016/ j.envpol.2009.05.037.

Nödler, K., O. Hillebrand, et al. (2013). "Occurrence and fate of the angiotensin II receptor antagonist transformation product valsartan acid in the water cycle - A comparative study with selected $\beta$-blockers and the persistent anthropogenic wastewater indicators carbamazepine and acesulfame". In: Water Research 47, pp. 6650-6659. DOI: $10.1016 / \mathrm{j}$. watres.2013.08.034.

Nödler, K., T. Licha, K. Bester, et al. (2010). "Development of a multi-residue analytical method, based on liquid chromatography-tandem mass spectrometry, for the simultaneous determination of 46 micro-contaminants in aqueous samples". In: Journal of Chromatography A 1217, pp. 6511-6521. DOI: 10.1016/j.chroma.2010.08.048. 
Nödler, K., T. Licha, S. Fischer, et al. (2011). "A case study on the correlation of micro-contaminants and potassium in the Leine River (Germany)". In: Applied Geochemistry 26, pp. 2172-2180. DOI: 10.1016/j . apgeochem.2011.08.001.

Nödler, K., T. Licha, and D. Voutsa (2013). "Twenty years later - Atrazine concentrations in selected coastal waters of the Mediterranean and the Baltic Sea". In: Marine Pollution Bulletin 70.1-2, pp. 112-118. DOI: 10.1016/j.marpolbul.2013.02.018.

Nödler, K., M. Tsakiri, M. Aloupi, et al. (2016). "Evaluation of polar organic micropollutants as indicators for wastewater-related coastal water quality impairment". In: Environmental Pollution 211, pp. 282-290. DOI: 10.1016/j.envpol.2016.01.014.

Nödler, K., M. Tsakiri, and T. Licha (2014). "The Impact of Different Proportions of a Treated Effluent on the Biotransformation of Selected Micro-Contaminants in River Water Microcosms". In: International Journal of Environmental Research and Public Health 11.10, pp. 10390-10405. DOI: 10.3390/ijerph111010390.

Nuijs, A. L. N. van et al. (2011). "Illicit drug consumption estimations derived from wastewater analysis: A critical review". In: Science of the Total Environment 409.19, pp. 3564-3577. DOI: 10.1016/j.scitotenv.2010.05.030.

O'Brien, J. W. et al. (2014). "A model to estimate the population contributing to the wastewater using samples collected on census day". In: Environmental Science and Technology 48.1, pp. 517-525. DOI: 10.1021/es403251g.

Oliveira, T. S. et al. (2015). "Characterization of Pharmaceuticals and Personal Care products in hospital effluent and waste water influent/effluent by direct-injection LC-MS-MS". In: Science of the Total Environment 518-519, pp. 459-478. DOI: 10. 1016/j.scitotenv.2015.02.104.

Oppenheimer, J. et al. (2011). "Occurrence and suitability of sucralose as an indicator compound of wastewater loading to surface waters in urbanized regions". In: Water Research 45.13, pp. 4019-4027. DOI: 10.1016/j .watres.2011.05.014.

Orlikowska, A., K. Fisch, and D. E. Schulz-Bull (2015). "Organic polar pollutants in surface waters of inland seas". In: Marine Pollution Bulletin 101.2, pp. 860-866. DOI: 10.1016/j.marpolbul.2015.11.018.

Osenbrück, K. et al. (2007). "Sources and transport of selected organic micropollutants in urban groundwater underlying the city of Halle (Saale), Germany". In: Water Research 41.15, pp. 3259-3270. DOI: 10.1016/j.watres.2007.05.014

Parfitt, K. (1999). Martindale: the complete drug reference. Pharmaceutical press.

Petrie, B., R. Barden, and B. Kasprzyk-Hordern (2014). "A review on emerging contaminants in wastewaters and the environment: Current knowledge, understudied areas and recommendations for future monitoring". In: Water Research 72.0, pp. 327. DOI: $10.1016 / \mathrm{j}$.watres.2014.08.053.

Plósz, B. G. et al. (2013). "Biotransformation kinetics and sorption of cocaine and its metabolites and the factors influencing their estimation in wastewater". In: Water Research 47.7, pp. 2129-2140. DOI: 10.1016/j . watres.2012.12.034.

Postigo, C., M. J. López de Alda, and D. Barceló (2010). "Drugs of abuse and their metabolites in the Ebro River basin: Occurrence in sewage and surface water, sewage treatment plants removal efficiency, and collective drug usage estimation". In: Environment International 36.1, pp. 75-84. DOI: 10.1016/j.envint.2009.10.004. 
Proll, G., J. Tschmelak, and G. Gauglitz (2005). "Fully automated biosensors for water analysis". In: Analytical and Bioanalytical Chemistry 381.1, pp. 61-63. DOI: 10 . 1007/s00216-004-2897-2.

Qi, Y., T. C. Zhang, and Y. Ren (2014). "Testosterone sorption and desorption: Effects of soil particle size". In: Journal of Hazardous Materials 279, pp. 493-501. DOI: 10.1016/j.jhazmat.2014.06.077.

Radke, M. et al. (2010). "Dynamics and attenuation of acidic pharmaceuticals along a river stretch". In: Environmental Science and Technology 44.8, pp. 2968-2974. DOI: 10.1021/es903091z

Ravindra, K. et al. (2008). "Atmospheric polycyclic aromatic hydrocarbons: Source attribution, emission factors and regulation". In: Atmospheric Environment 42.13, pp. 2895-2921. DOI: 10.1016/j . atmosenv.2007.12.010

Reemtsma, T., U. Berger, et al. (2016). "Mind the Gap: Persistent and Mobile Organic Compounds - Water Contaminants That Slip Through". In: Environmental Science and Technology 50.19, pp. 10308-10315. DOI: 10.1021/acs.est.6b03338.

Reemtsma, T., L. Alder, and U. Banasiak (2013). "A multimethod for the determination of 150 pesticide metabolites in surface water and groundwater using direct injection liquid chromatography-mass spectrometry". In: Journal of Chromatography A 1271.1, pp. 95-104. DOI: $10.1016 / \mathrm{j}$.chroma.2012.11.023.

Reh, R., O. Hillebrand, et al. (2014). "Charakterisierung zweier Karstsysteme mithilfe organischer Spurenstoffe". In: Grundwasser 19.4, pp. 251-262. DOI: 10.1007/s00767014-0264-6.

Reh, R., T. Licha, T. Geyer, et al. (2013). "Occurrence and spatial distribution of organic micro-pollutants in a complex hydrogeological karst system during low flow and high flow periods, results of a two-year study". In: Science of the Total Environment 443, pp. 438-445. DOI: 10.1016/j.scitotenv.2012.11.005.

Reh, R., T. Licha, K. Nödler, et al. (2015). "Evaluation and application of organic micro-pollutants (OMPs) as indicators in karst system characterization". In: Environmental Science and Pollution Research 22.6, pp. 4631-4643. DOI: 10.1007/ s11356-014-3676-z

Reid et al. (2011). "Analysis and interpretation of specific ethanol metabolites, ethyl sulfate, and ethyl glucuronide in sewage effluent for the quantitative measurement of regional alcohol consumption". In: Alcoholism: Clinical and Experimental Research 35.9, pp. 1593-1599. DOI: $10.1111 / \mathrm{j} .1530-0277.2011 .01505 . \mathrm{x}$.

Renwick, A. G. (1986). "The metabolism of intense sweeteners". In: Xenobiotica 16.1011, pp. 1057-1071. DOI: 10.3109/00498258609038983.

Richardson, S. D. and T. A. Ternes (2018). "Water Analysis: Emerging Contaminants and Current Issues". In: Analytical Chemistry 90.1, pp. 398-428. DOI: 10.1021/acs. analchem.7b04577, arXiv: arXiv:1201.4976v1.

Rivera-Utrilla, J. et al. (2013). "Pharmaceuticals as emerging contaminants and their removal from water. A review". In: Chemosphere 93.7, pp. 1268-1287. DOI: 10.1016/ j.chemosphere.2013.07.059

Robertson, W. D., D. R. Van Stempvoort, Roy, et al. (2016). "Use of an Artificial Sweetener to Identify Sources of Groundwater Nitrate Contamination". In: Groundwater 54.4, pp. 579-587. DOI: 10.1111/gwat.12399. 
Robertson, W. D., D. R. Van Stempvoort, J. Spoelstra, et al. (2016). "Degradation of sucralose in groundwater and implications for age dating contaminated groundwater". In: Water Research 88, pp. 653-660. DOI: 10.1016/j.watres.2015.10.051.

Rodil, R. et al. (2008). "Multiclass determination of sunscreen chemicals in water samples by liquid chromatography-tandem mass spectrometry". In: Analytical Chemistry 80.4, pp. 1307-1315. DOI: $10.1021 /$ ac702240u.

Rodríguez-Álvarez, T. et al. (2015). "Alcohol and cocaine co-consumption in two European cities assessed by wastewater analysis". In: Science of the Total Environment 536, pp. 91-98. DOI: 10.1016/j.scitotenv.2015.07.016

Roy, J., D. R. Van Stempvoort, and G. Bickerton (2014). "Artificial sweeteners as potential tracers of municipal landfill leachate". In: Environmental Pollution 184, pp. 89-93. DOI: $10.1016 / \mathrm{j}$.envpol.2013.08.021.

Roy, S. B. and D. A. Dzombak (1997). "Chemical factors influencing colloid-facilitated transport of contaminants in porous media". In: Environmental Science and Technology 31.3, pp. 656-664. DOI: 10.1021/es9600643

Ryu, Y. et al. (2016). "Comparative measurement and quantitative risk assessment of alcohol consumption through wastewater-based epidemiology: An international study in 20 cities". In: Science of the Total Environment 565, pp. 977-983. DOI: $10.1016 / j$.scitotenv.2016.04.138.

Sauvé, S. et al. (2012). "Fecal coliforms, caffeine and carbamazepine in stormwater collection systems in a large urban area". In: Chemosphere 86.2, pp. 118-123. DOI: 10.1016/j.chemosphere.2011.09.033

Schaffer, M., H. Börnick, et al. (2012). "Role of cation exchange processes on the sorption influenced transport of cationic $\beta$-blockers in aquifer sediments". In: Water Research 46, pp. 5472-5482. DOI: $10.1016 / \mathrm{j}$. watres.2012.07.013.

Schaffer, M. and T. Licha (2015). "A framework for assessing the retardation of organic molecules in groundwater: Implications of the species distribution for the sorptioninfluenced transport". In: Science of The Total Environment 524-525, pp. 187-194. DOI: $10.1016 / \mathrm{j}$. scitotenv.2015.04.006

Schaffer, M., K. F. Kröger, et al. (2015). "Influence of a compost layer on the attenuation of 28 selected organic micropollutants under realistic soil aquifer treatment conditions: Insights from a large scale column experiment". In: Water Research 74, pp. 110-121. DOI: $10.1016 /$ j.watres.2015.02.010.

Schaffer, M., W. Warner, et al. (2017). "Organic molecules as sorbing tracers for the assessment of surface areas in consolidated aquifer systems". In: Journal of Hydrology 546, pp. 370-379. DOI: $10.1016 / \mathrm{j} \cdot \mathrm{jhydrol} .2017 .01 .013$

Schaper, J. L. et al. (2018). "The fate of polar trace organic compounds in the hyporheic zone". In: Water Research 140, pp. 158-166. DOI: 10.1016/j watres.2018.04.040.

Scheurer, M. et al. (2017). "Small, mobile, persistent: Trifluoroacetate in the water cycle - Overlooked sources, pathways, and consequences for drinking water supply". In: Water Research 126, pp. 460-471. DOI: 10.1016/j.watres.2017.09.045.

Schmidt, G. and R. Schoyerer (1966). "Zum Nachweis von Coffein und seinen Metaboliten im Harn". In: Deutsche Zeitschrift für die gesamte gerichtliche Medizin 57.3, pp. 402-409. 
Schmidt, T. (2018). "Recent trends in water analysis triggering future monitoring of organic micropollutants". In: Analytical and Bioanalytical Chemistry 410.17, pp. 39333941. DOI: $10.1007 / \mathrm{s} 00216-018-1015-9$.

Schwarzenbach, R. et al. (2010). "Global Water Pollution and Human Health". In: Annual Review of Environment and Resources 35.1, pp. 109-136. DOI: 10.1146/ annurev-environ-100809-125342.

Seiler, R. L. et al. (1999). "Caffeine and pharmaceuticals as indicators of waste water contamination in wells". In: Ground Water 37.3, pp. 405-410.

Seitz, W. and R. Winzenbacher (2017). "A survey on trace organic chemicals in a German water protection area and the proposal of relevant indicators for anthropogenic influences". In: Environmental Monitoring and Assessment 189.6, p. 244. DOI: $10.1007 / \mathrm{s} 10661-017-5953-\mathrm{z}$.

Sen, T. K. and K. C. Khilar (2006). "Review on subsurface colloids and colloidassociated contaminant transport in saturated porous media". In: Advances in Colloid and Interface Science 119.2-3, pp. 71-96. DOI: 10.1016/j.cis.2005.09.001.

Sheldon, L. and R. Hites (1978). "Organic compounds in the Delaware River". In: Environmental Science \& Technology 12.10, pp. 1188-1194. DOI: 10.1021/es60146a006.

Sidhu, J. et al. (2013). "Sewage pollution in urban stormwater runoff as evident from the widespread presence of multiple microbial and chemical source tracking markers". In: Science of the Total Environment 463-464, pp. 488-496. DOI:10.1016/j.scitotenv. 2013.06 .020

Sievers, R. E. et al. (1977). "Environmental trace analysis of organics in water by glass capillary column chromatography and ancillary techniques: products of ozonolysis". In: Journal of Chromatography A 142, pp. 745-754.

Sjerps, R. M. et al. (2016). "Data-driven prioritization of chemicals for various water types using suspect screening LC-HRMS". In: Water Research 93, pp. 254-264. DOI: $10.1016 / \mathrm{j}$. watres.2016.02.034.

Snider, D. et al. (2017). "Concentrations of Artificial Sweeteners and Their Ratios with Nutrients in Septic System Wastewater". In: Groundwater Monitoring and Remediation, pp. 1-9. DOI: 10.1111/gwmr.12229.

Sodré, F. F. et al. (2018). "Seasonal and spatial distribution of caffeine, atrazine, atenolol and deet in surface and drinking waters from the brazilian federal district". In: Journal of the Brazilian Chemical Society 29.9, pp. 1854-1865. DOI: 10.21577/ 0103-5053.20180061.

Solomon, K. R. et al. (2016). "Sources, fates, toxicity, and risks of trifluoroacetic acid and its salts: Relevance to substances regulated under the Montreal and Kyoto Protocols". In: Journal of Toxicology and Environmental Health - Part B: Critical Reviews 19.7, pp. 289-304. DOI: 10.1080/10937404.2016.1175981.

Sorensen, J. P. R. et al. (2015). "Emerging contaminants in urban groundwater sources in Africa". In: Water Research 72, pp. 51-63. DOI: 10.1016/j .watres.2014.08.002.

Spoelstra, J., N. D. Senger, and S. L. Schiff (2017). "Artificial Sweeteners Reveal Septic System Effluent in Rural Groundwater". In: Journal of Environment Quality 0.0, p. 0. DOI: $10.2134 /$ jeq2017.06.0233 
Stephan, S. et al. (2016). "Contaminant screening of wastewater with HPLC-IM-qTOFMS and LC+LC-IM-qTOF-MS using a CCS database". In: Analytical and Bioanalytical Chemistry 408.24, pp. 6545-6555. DOI: 10.1007/s00216-016-9820-5.

Stuart, M. et al. (2012). "Review of risk from potential emerging contaminants in UK groundwater". In: Science of the Total Environment 416, pp. 1-21. DOI: 10.1016/ j.scitotenv.2011.11.072.

Suárez, S. et al. (2012). "Mass balance of pharmaceutical and personal care products in a pilot-scale single-sludge system: Influence of T, SRT and recirculation ratio". In: Chemosphere 89.2, pp. 164-171. DOI: 10.1016/j.chemosphere.2012.05.094.

Sui, Q. et al. (2015). "Occurrence, sources and fate of pharmaceuticals and personal care products in the groundwater: A review". In: Emerging Contaminants 1.1, pp. 14-24. DOI: $10.1016 /$ j.emcon.2015.07.001.

Sun, F. et al. (2017). "Nitrite-driven abiotic transformation of sulfonamide micropollutants during freezing process". In: Chemical Engineering Journal 327, pp. 11281134. DOI: $10.1016 / j . c e j .2017 .07 .005$.

Tang-Liu, D., R. Williams, and S. Riegelman (1983). "Disposition of caffeine and its metabolites in man." In: Journal of Pharmacology and Experimental Therapeutics 224.1, pp. $180-185$.

Thiebault, T. et al. (2017). "Record of pharmaceutical products in river sediments: A powerful tool to assess the environmental impact of urban management?" In: Anthropocene 18, pp. 47-56. DOI: $10.1016 / \mathrm{j}$. ancene.2017.05.006.

Thomaidis, N. S. et al. (2016). "Reflection of Socioeconomic Changes in Wastewater: Licit and Illicit Drug Use Patterns". In: Environmental Science and Technology 50.18, pp. 10065-10072. DOI: 10.1021 /acs .est.6b02417.

Thomas, K. et al. (2012). "Comparing illicit drug use in 19 European cities through sewage analysis". In: Science of the Total Environment 432, pp. 432-439. DOI: 10 . 1016/j.scitotenv.2012.06.069.

Tran, N. H. et al. (2014). "Occurrence and suitability of pharmaceuticals and personal care products as molecular markers for raw wastewater contamination in surface water and groundwater". In: Environmental Science and Pollution Research 21.6, pp. 4727-4740. DOI: 10.1007/s11356-013-2428-9.

Triebskorn, R. et al. (2004). "Toxic effects of the non-steroidal anti-inflammatory drug diclofenac". In: Aquatic Toxicology 68.2, pp. 141-150. DOI: $10.1016 / \mathrm{j}$. aquatox . 2004.03 .015

Tröger, R. et al. (2018). "Micropollutants in drinking water from source to tap - Method development and application of a multiresidue screening method". In: Science of the Total Environment 627, pp. 1404-1432. DOI: 10.1016/j.scitotenv.2018.01.277.

Valhondo, C. et al. (2015). "Characterizing redox conditions and monitoring attenuation of selected pharmaceuticals during artificial recharge through a reactive layer". In: Science of The Total Environment 512-513, pp. 240-250. DOI: $10.1016 / \mathrm{j}$. scitotenv.2015.01.030.

Van Nuijs, A. et al. (2009). "Can cocaine use be evaluated through analysis of wastewater? A nation-wide approach conducted in Belgium". In: Addiction 104.5, pp. 734741. DOI: $10.1111 / \mathrm{j} .1360-0443.2009 .02523 . \mathrm{x}$. 
Van Stempvoort, D. R. et al. (2013). "An artificial sweetener and pharmaceutical compounds as co-tracers of urban wastewater in groundwater". In: Science of the Total Environment 461-462, pp. 3480-359. DOI: 10.1016/j.scitotenv.2013.05.001.

Vengosh, A. et al. (1994). "Boron Isotope Application for Tracing Sources of Contamination in Groundwater". In: Environmental Science and Technology 28.11, pp. 19681974. DOI: 10.1021/es00060a030.

Verplanck, P. L. et al. (2005). "Aqueous stability of gadolinium in surface waters receiving sewage treatment plant effluent Boulder Creek, Colorado". In: Environmental Science and Technology 39.18, pp. 6923-6929. DOI: 10.1021/es048456u.

Viviano, G. et al. (2017). "Combined Use of Caffeine and Turbidity to Evaluate the Impact of CSOs on River Water Quality". In: Water, Air, \&3 Soil Pollution 228.9, p. 330. DOI: $10.1007 / \mathrm{s} 11270-017-3505-3$

Voutsa, D. et al. (2001). "A Study of Surface Water Quality in Macedonia, Greece: Specification of Nitrogen and Phosphorus". In: Water, Air, and Soil Pollution 129, pp. 13-32.

Wang, P. and A. A. Keller (2008). "Particle-size dependent sorption and desorption of pesticides within a water soil nonionic surfactant system". In: Environmental Science and Technology 42.9, pp. 3381-3387. DOI: 10.1021/es702732g.

Warner, W., H. Ruppert, and T. Licha (2016). "Application of PAH concentration profiles in lake sediments as indicators for smelting activity". In: Science of the Total Environment 563-564, pp. 587-592. DOI: 10.1016/j.scitotenv.2016.04.103.

Wild, S. R. and K. C. Jones (Jan. 1995). "Polynuclear aromatic hydrocarbons in the United Kingdom environment: a preliminary source inventory and budget". In: Environmental Pollution 88.1, pp. 91-108. DOI: 10.1016/0269-7491(95)91052-M.

Wittmer, I. K., H. P. Bader, et al. (2010). "Significance of urban and agricultural land use for biocide and pesticide dynamics in surface waters". In: Water Research 44.9, pp. 2850-2862. DOI: $10.1016 / \mathrm{j}$.watres.2010.01.030.

Wittmer, I. K., R. Scheidegger, et al. (2011). "Loss rates of urban biocides can exceed those of agricultural pesticides". In: Science of the Total Environment 409.5, pp. 920932. DOI: $10.1016 / \mathrm{j}$. scitotenv.2010.11.031.

Wode, F., C. Reilich, et al. (2012). "Multiresidue analytical method for the simultaneous determination of 72 micropollutants in aqueous samples with ultra high performance liquid chromatography-high resolution mass spectrometry". In: Journal of Chromatography A 1270, pp. 118-126. DOI: 10.1016/j.chroma.2012.10.054.

Wode, F., P. van Baar, et al. (2015). "Search for over 2000 current and legacy micropollutants on a wastewater infiltration site with a UPLC-high resolution MS target screening method". In: Water Research 69, pp. 274-283. DOI: 10.1016/j.watres. 2014.11.034

Wolf, L., I. Held, et al. (2004). "Impact of leaky sewers on groundwater quality". In: Acta Hydrochimica et Hydrobiologica 32.4-5, pp. 361-373. DOI: 10.1002/aheh.200400538.

Wolf, L., C. Zwiener, and M. Zemann (2012). "Tracking artificial sweeteners and pharmaceuticals introduced into urban groundwater by leaking sewer networks". In: Science of the Total Environment 430, pp. 8-19. DOI: 10.1016/j.scitotenv. 2012 . 04.059 . 
Wolf, L., M. Eiswirth, and H. Hötzl (2006). "Assessing sewer-groundwater interaction at the city scale based on individual sewer defects and marker species distributions". In: Environmental Geology 49.6, pp. 849-857. DOI: 10.1007/s00254-006-0180-x.

Wong, C. S. (2006). "Environmental fate processes and biochemical transformations of chiral emerging organic pollutants". In: Analytical and Bioanalytical Chemistry 386.3, pp. 544-558. DOI: $10.1007 / \mathrm{s} 00216-006-0424-3$.

Yang, Y., W. Liu, et al. (2017). "Suitability of pharmaceuticals and personal care products (PPCPs) and artificial sweeteners (ASs) as wastewater indicators in the Pearl River Delta, South China". In: Science of The Total Environment 590-591, pp. 611-619. DOI: $10.1016 / \mathrm{j}$. scitotenv.2017.03.001.

Yang, Y., Y. S. Ok, et al. (2017). "Occurrences and removal of pharmaceuticals and personal care products (PPCPs) in drinking water and water/sewage treatment plants: A review". In: Science of the Total Environment 596-597, pp. 303-320. DOI: 10.1016/j.scitotenv.2017.04.102.

Yang, Y.-Y. et al. (2018). "Pharmaceuticals and personal care products (PPCPs) and artificial sweeteners (ASs) in surface and ground waters and their application as indication of wastewater contamination". In: Science of The Total Environment 616617, pp. 816-823. DOI: $10.1016 / \mathrm{j}$. scitotenv.2017.10.241.

Zahn, D., T. Frömel, and T. Knepper (2016). "Halogenated methanesulfonic acids: A new class of organic micropollutants in the water cycle". In: Water Research 101, pp. 292-299. DOI: $10.1016 / \mathrm{j}$.watres.2016.05.082.

Zhang, Y., S. U. Geißen, and C. Gal (2008). "Carbamazepine and diclofenac: Removal in wastewater treatment plants and occurrence in water bodies". In: Chemosphere 73.8, pp. 1151-1161. DOI: 10.1016/j.chemosphere.2008.07.086. arXiv: 1735-1472.

Zipper, C. et al. (1998). "Changes in the enantiomeric ratio of (R)- to (S)-mecoprop indicate in situ biodegradation of this chiral herbicide in a polluted aquifer". In: Environmental Science and Technology 32.14, pp. 2070-2076. DOI: 10.1021/es970880q.

Zirlewagen, J. et al. (2016). "Use of two artificial sweeteners, cyclamate and acesulfame, to identify and quantify wastewater contributions in a karst spring". In: Science of the Total Environment 547, pp. 356-365. DOI: 10.1016/j.scitotenv.2015.12.112. 


\section{Integrated approach for innovative monitoring strategies of reservoirs and lakes}

Wiebke Warner ${ }^{1}$, Karsten Nödler ${ }^{2}$, Alessandro Farinelli ${ }^{3}$, Jason Blum ${ }^{3}$, Tobias Licha $^{1}$

${ }^{1}$ Geoscience Centre, Department of Applied Geology, Hydrochemistry Group, University of Göttingen, Goldschmidtstr. 3, 37077 Göttingen, Germany

${ }^{2}$ Water Technology Center Karlsruhe (TZW), Karlsruher Straße 84, 76139 Karlsruhe, Germany

${ }^{3}$ Computer Science Department, University of Verona, Verona CAP 37134, Italy

Citation: W. Warner, K. Nödler, et al. (2018). "Integrated Approach for innovative Monitoring Strategies of Reservoirs an Lakes". In: Environmental Engineering and Management Journal 17.10, pp. 2497-2505

http://www.eemj.icpm.tuiasi.ro/pdfs/vol17/no10/Full/22_121_Warner_18. pdf 


\subsection{Abstract}

An innovative strategy significantly increasing data density by introducing a flexible, problem-orientated, and cost-effective water quality monitoring approach is presented. Most current monitoring strategies produce water quality data based on fixed stations conducted on fixed dates throughout a defined period of time and, thus, often give a biased and insufficient picture of the water quality. Establishing a refined picture of water quality while not increasing monitoring costs clearly needs a change in monitoring strategy. The complexity of social-economic needs, environmental aspects and evolving legislative guideline values makes the design of a suitable innovative strategy challenging. The combination of investigative and risk based monitoring with real-time monitoring of proxies (e. g., electrical conductivity (EC)) is a vital asset within this here proposed innovative strategy. For the former, organic micropollutants (e. g., pesticides, pharmaceuticals) are suggested here to be a powerful tool for source apportionment as they allow to determine and quantify the cause and impact of water quality impairments. This strategy was tested in a field campaign, in which an area of elevated EC was investigated at Lake Garda, Italy. A radio-controlled boat was used for EC mapping and sampling. As no chemical indicators for significant anthropogenic sources could be detected, the elevated EC could be assigned to natural sources.

Keywords: water quality monitoring, innovative monitoring strategy, micropollutants, proxy mapping, indicator concept

\subsection{Introduction}

On account of modern analytical techniques, the number of detected anthropogenic micropollutants in the water cycle steadily increases (Amare 2017; Brumovský et al. 2017; Petrie, Barden, and Kasprzyk-Hordern 2014; Reemtsma et al. 2016; Scheurer et al. 2017; Yang et al. 2018). According to the water framework directive (2000/60/EC, WFD) all member states of the European Union (EU) have to ensure a good chemical and ecological status of all surface water bod- 
ies by the year of 2027. Furthermore, within the precautionary principle article 7 (3) of the WFD states that "Member States shall ensure the necessary protection for the bodies of water identified with the aim of avoiding deterioration in their quality in order to reduce the level of purification treatment required in the production of drinking water." Besides the EU framework directive, the water safety plans derived by the World Health Organisation (WHO, 2005) give new directions towards water quality monitoring by compromising the management of drinking water "from catchment to consumer". As a novelty compared to previous and established monitoring strategies this includes a preventive risk elimination and recurrent quality control. State-of-the-art monitoring stands for a water quality assessment based on data derived from fixed station on fixed dates with regular frequencies. This bears substantial drawbacks as no information on system's dynamics is given and hence this insufficiently reflects the real status of the water quality on catchment scale. This strategy is highly susceptible to discontinuous and/or unpredictable hazardous events, such as direct discharge of sewage, combined sewer overflows or surface run-off from agricultural areas into drinking water resources or water bodies used for recreational purposes. Such events occur occasionally and are usually not reflected by fixed date measurements and the results of those investigations are often rather poor in terms of data density, predictive power and for deriving effective countermeasures. This points out the great importance of an improved monitoring strategy leading to more reliable datasets and hence allowing the prediction of water quality on catchment scale as well as paving the way to water quality improvements (Voulvoulis, Arpon, and Giakoumis 2017). In the view of the current water quality monitoring strategy at many sites the demand for more reliable data would require a larger number of sampling points with significantly higher sampling frequencies in order to gain temporally and spatially better resolved data. This is remarkably time and cost intensive, not feasible and often leads to the so called "data-rich but information-poor" syndrome (Ward, Loftis, and McBride 1986). Thus, an innovative monitoring strategy will be a shift from mainly static sampling to dynamic real-time monitoring, which leads to an optimum water quality monitoring frequency for individual water bodies and hence an increase in information density without increasing costs, especially caused by non-focused sampling. Nearly three decades ago scientist and stakeholders already called for 
more reliable and meaningful data by a strategic change in water quality monitoring and a more holistic approach by including the catchment information into monitoring strategies (Ward 1997; Ward, Loftis, and McBride 1986). Especially with the implementation of the WFD and recent developments of new monitoring tools such as remote sensing, automated sampling devices and effect-based tools, new strategies for water quality monitoring are needed (Behmel et al. 2016). But most tools are either too general or too site-specific and there is no "one-sizefits-all" solution serving every catchment (Behmel et al. 2016). Newly developed mathematical models are more generic and enable to predict meaningful sampling points along a catchment: Thus, the implementation of decision support systems (DSS) can help decision makers to establish a monitoring network with optimum information density (Alilou et al. 2018; Behmel et al. 2016). Additionally to surveillance (long-term changes) and operational monitoring (asses success measures), especially investigative water quality monitoring is needed, because accidental pollution or areas with unknown problems in water quality are often overseen and can significantly harm water safety (Milano, Chèvre, and Reynard 2018; Premazzi et al. 2003). This publication aims to present a highly promising and target-oriented approach into investigative water quality monitoring leading into long-term real-time water quality monitoring using proxies. The first application of the investigative aspect of innovative strategy from an exemplarily short field campaign on Lake Garda in autumn 2017 using a platypus boat equipped with an electrical conductivity (EC) probe for real-time mapping and an automatic sampling device is presented.

\subsection{Aspects of an innovative monitoring strategy}

The variety of climatic, topographical, geomorphological, hydrological, physical and cultural factors influencing water quality (X. Hu 1999) creates numerous factors influencing water quality and makes finding a suitable strategy for water quality monitoring on catchment scale highly complex. Improving data quality and density without increasing the monetary effort in these complex systems therefore needs a shift into innovative information driven monitoring strategies. Considering the whole catchment in water quality management concepts allows identifying substantial sources for water quality deterioration as well as detecting 
hot spots and areas of higher risks than others. At these locations, highly spatially and/or temporally resolved or even real-time data can significantly better describe a potential risk, while at points of low potential risk monitoring efforts and, thus, costs can be minimised. Another important key element is investigative monitoring and, thus, assigning the appropriate best fit and problem oriented long-term monitoring strategy based on the area's vulnerability. This can be best achieved by using source and process specific indicator compounds (e. g., organic micropollutants) to identify the cause of water quality deterioration, differentiate between multiple sources or even quantify their impact accordingly. The idea of considering the whole catchment in water quality management strategies was developed in the early 1990s but to the authors' knowledge there is only one successful case study in Australia published (Bennett and Lawrence 2002; Mitchell and Hollick 1993) and a further publication on the transfer of the Australian study to China (X. Hu 1999). All these publications mainly focus on the sociological and organisational aspects between stakeholders and citizens but not on a strategic technical approach as this publication aims to deliver. An innovative monitoring strategy must include the reliable identification of the water quality status and must allow the detection of pollution sources and their impact. It should further allow the monitoring of the effect of management measures taken in the catchment in order to improve water quality selectively (e. g., elimination of misconnections, improvement of combined sewer overflows (CSO)). At the same time, it needs to be capable to capture single pollution events such as accidents or spillages, the release of combined sewage overflows or wash off during rain events. Furthermore, it must allow the prioritization of catchment measures based on their efficiencies in improving water quality on catchment scale. Finally, it is important that the strategy is flexible and applicable to a large variety of different water bodies and catchments across Europe and the entire world. Recently, a shift from the static state-of-the-art water quality monitoring into a dynamic risk-based strategy found application in a draft for a novel drinking water act in Germany, based on changes in the annexes of the European drinking water guideline 98/83/EG (EU: 31998L0083), which emphasizes the need for novel strategies also for surface water bodies. 


\subsubsection{First step: Composing existing data and defining problems and needs for water quality}

A crucial point in setting up an innovative monitoring strategy for a catchment is to re-analyse existing data and to re-evaluate the current monitoring program. This includes the evaluation of the number and locations of existing observation points and monitoring parameters, the frequency of data collection and the water quality development on the basis of historic datasets. This will give a first impression on water quality issues and allows to judge on the meaningfulness and significance of the existing strategy. Initially, a catchment assessment which includes morphological information (e. g., estimation of run-off flow direction), land uses to identify possible pollution sources and especially locations which are very vulnerable to hazardous events (e. g., areas used for drinking water production) needs to be carried out. Additional information can be gathered from historical data, local stakeholders (e. g., farmers), and from citizens. Within this context existing numerical models can be used and, if required, extended. If the existing data base is not sufficient in its resolution, more information needs to be gathered and individual initial monitoring campaigns with focus on investigative monitoring might be useful to close these gaps. A further crucial factor is that the requirements on the water quality together with standards are clearly defined. Initially, legislative guideline values (in agreement with WFD, national guidelines or bathing water guidelines) should be identified. Then, socio-economic needs, such as the apparent water quality (e. g., odour, colour or turbidity), the requirements for fishing, bathing and tourism must be considered. These water quality demands can be diverse and strongly dependent on the individual requirements of the end users.

\subsubsection{Second step: Investigative real-time water quality mapping, sampling and identification of an appropriate set of source and process specific indicators}

A key element of the presented strategy is the investigative real-time mapping of areas with either real or suspected water quality issues by using universal sensors prior to collecting samples for laboratory analysis. As EC is a general parameter which comprises the simultaneous detection of numerous ionic substances 
it can be used to identify water quality changes or issues easily. Using such a probe in tracking contamination from, e. g., wastewater is well established. Bonvin et al. 2011 demonstrated the linear correlation of elevated EC with elevated source specific micropollutants, especially benzotriazoles (corrosion inhibitors) and paracetamol (analgesic). They could assign this water quality impairment to the effluent of a wastewater treatment plant discharging $30 \mathrm{~m}$ below the water table of Lake Geneva. Besides natural sources (e. g., caused by geological processes) EC can also be correlated to nitrate contaminations (K. Hu et al. 2005), pesticides (Castilho et al. 2000) and even to mining activities (Olías et al. 2004). Covering the most common pollution sources known for aquatic systems EC is a powerful parameter to detect any hot spots within the system. In combination with temperature $(\mathrm{T})$ it may even be a more powerful tool within investigative monitoring strategies for water quality impairment detection. Mapping can be conducted manually (if accessible) by simple field measurements with handheld probes or via automated robotic systems, such as boats or drones equipped with a sensor and a positioning system. Manual samples should only be taken wherever anomalies in form of a deviation from the mean background (baseline) value of the system are detected. At these locations water quality impairments are very likely.

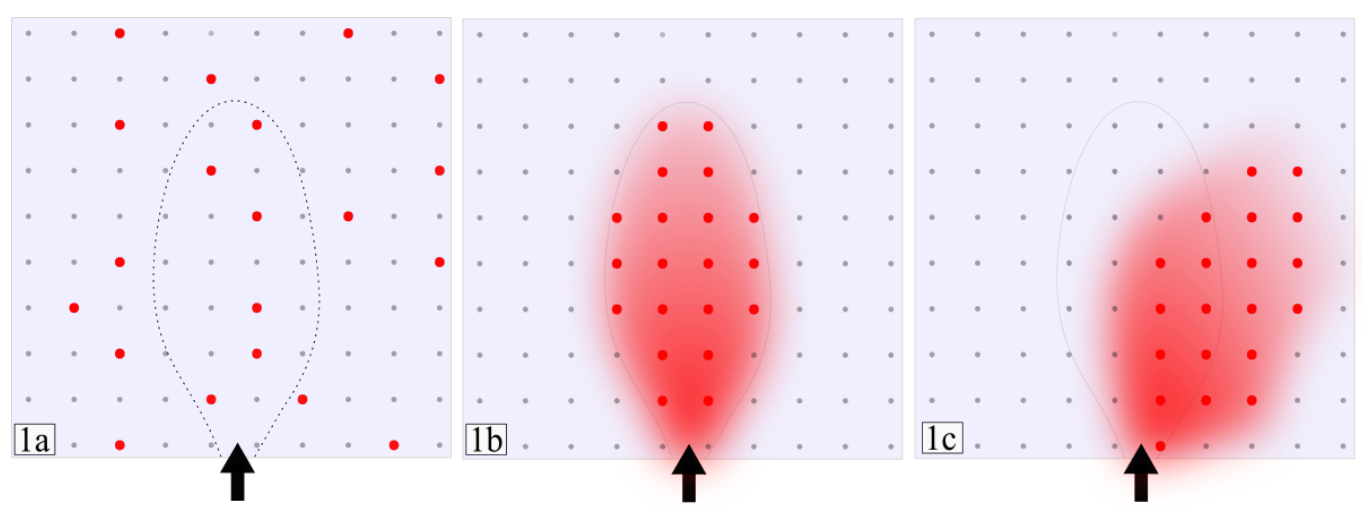

Figure 3.1.: All three figures show a potential plume (dotted line) originating from a hypothetic point source. The fixed number of twenty samples are marked as red dots. The proxy map (e. g., EC) is marked in red. By allocating all samples according to the mapped plume the information density increases remarkably and becomes independent from plume dynamics. In (a) all are samples distributed equally over the water body, in (b) they are distributed within the plume and in (c) accordingly to the drifted plume. 
As shown in Figure 3.1, mapping can increase data density significantly: Figure 3.19 all hypothetic samples are distributed equally over the water body and randomly six out of twenty samples were collected within the actual plume (dotted line). After mapping (red coloured) all sampling points were located in the area of the plume and information density increases from $30 \%$ to $100 \%$ without increasing the total number of samples (Figure 3.1p) and thus, cost. If the plume drifts (Figure 3.1k), for example due to changing weather conditions, real-time mapping is able to visualise this change and sampling locations can be reallocated accordingly without any information loss and avoids non-focused sampling. Water bodies are highly dynamic systems. Contamination plumes, flow directions or the impact of water quality impairing sources are highly variable. Initial mapping reduces cost for sampling and laboratory analysis because only meaningful samples are taken. In order to assign the observed anomaly (e. g., increased EC) to the induced causes in an investigative monitoring strategy samples are then screened for a variety of chemical source and process indicators with a cost-effective multi-residue analytical method. Here, micropollutants such as life-style products, pharmaceuticals, personal care products or pesticides and their respective transformation products are well established (Barbosa et al. 2016; Glassmeyer and Meyer 2005; Jekel, Ruhl, et al. 2013; Lapworth et al. 2012, Lim, Ong, and J. Hu 2017). According to their negligible natural background and often unique transformation products, they are highly selective compared to classical inorganic tracers, which allows them to be very source specific (Khazaei and Milne-Home 2017). Their wide range of physicochemical properties let them interact in numerous ways with the environment (e. g., during transport processes) and thus can help to estimate residence times or flow paths (Clara, Strenn, and Kreuzinger 2004; Gasser et al. 2010, Warner, Ruppert, and Licha 2016). Some prominent and established examples are briefly given in Table 3.1. For most catchments, a standard set of indicators is already established and can be easily adapted to specific catchment requirements (Jekel, Dott, et al. 2015 Lim, Ong, and J. Hu 2017; Seitz and Winzenbacher 2017; Zirlewagen et al. 2016). Chemical analysis for these indicators is often conducted using modern techniques such as liquid-chromatography coupled with tandem mass spectrometry (LC-MS/MS). A strategy for method development can, for example, be found in Gago-Ferrero, Schymanski, et al. 2015, Nödler, Licha, Bester, et al. 2010; Reemtsma et al. 2016. 


\begin{tabular}{lll}
\hline Source & Indicators & Reference \\
\hline Untreated effluent & $\begin{array}{l}\text { Caffeine and its human } \\
\text { metabolites }\end{array}$ & $\begin{array}{l}\text { Seiler et al. 1999, Hille- } \\
\text { brand et al. 2012 }\end{array}$ \\
\cline { 2 - 3 } & $\begin{array}{l}\text { Cyclamat (artificial } \\
\text { sweetener) }\end{array}$ & Zirlewagen et al. 2016 \\
\hline Treated effluent & Valsartan acid & Nödler, Tsakiri, et al. \\
& Selected pesticides & $\begin{array}{l}\text { e.g., Nödler, Hillebrand, } \\
\text { et al. 2013 }\end{array}$ \\
\hline Agriculture & Selected veterinary an- & $\begin{array}{l}\text { e.g., Kay, Blackwell, } \\
\text { and Boxall 2005 }\end{array}$ \\
\cline { 2 - 3 } & tibiotics (livestock) & $\begin{array}{l}\text { e.g., Gago-Ferrero, } \\
\text { Díaz-Cruz, and Barceló }\end{array}$ \\
\hline Tourism & Selected UV blocker & 2013 \\
\hline
\end{tabular}

Table 3.1.: Examples of typical indicators used in the last decades.

Wode et al. 2015. Recent analytical developments allow simplified methods with small sample volumes, direct injections of water samples, and short analysis and processing times, which significantly decreases costs (Oliveira et al. 2015). The high sensitivity of modern analytical instruments also simplified the sampling procedure and logistics, as sample volumes $<50 \mathrm{~mL}$ are rather the rule than the exception.

Once contamination sources, their impact, location and point of discharge are identified by the aforementioned indicators, the overall number of analytes can be limited to a few meaningful and problem-orientated key indicators to even further reduce laboratory costs in future investigative monitoring strategies. Building a correlation function between a real-time parameter collected by a sensor such as temperature or EC and the source of deterioration, e. g., wastewater, using the chemical indicators will now allow the continuous and cost-efficient quantification of the individual amount of discharge and to reflect the dynamics of the impact. For mainly site-specific problems individual specific problem oriented tools, e. g., nitrate sensors or even biosensors (Proll, Tschmelak, and Gauglitz 2005) are possible options. Some established proxies are potassium as a proxy to quantify the impact of effluents from wastewater treatment plants (Nödler, Licha, Fischer, 
et al. 2011) and turbidity as a proxy for E. coli and for CSO overflow (Nnane, Ebdon, and Taylor 2011; Viviano et al. 2017). Another well-established proxy for eutrophication is chlorophyll- $\alpha$, which can be easily detected by remote sensing techniques (Barrett and Frazier 2016; Duan et al. 2007).

\subsubsection{Third step: Real-time monitoring by using proxies}

Once the proxy-source-relationship is established and a suitable proxy sensor type or sensor array is selected, the amount and source(s) of the water quality impairment become quantifiable by the proxy(ies) in real-time. The proxies can serve in long-term, cost-efficient monitoring programs generating real-time monitoring data and contribute to the understanding of water quality on catchment scale. Thus, they are important within a risk-based monitoring strategy. Within this context threshold values need to be defined for indicating a potential risk for water quality deterioration. These should not be mistaken with legislative guideline values. When just a single source for water quality impairment was detected during the investigative strategy it may be sufficient to solely monitor one proxy parameter and directly associate it to that specific source. If there are multiple sources such as leakage from waste-water pipes and run-off from agriculture causing water quality deterioration in the same catchment, more proxies are needed. Possible powerful ways are building ratios of proxies to differentiate between sources, e. g., temperature and EC or using combination of them as sampling or monitoring criterion. If only one proxy is available because of limited probe availability, this general proxy is still useful in investigative and long-term monitoring to give a warning signal and for triggering meaningful manual sampling. These samples must later be screened for the specific key indicators as defined in step two. After screening, all sources and their impact can be differentiated with greater confidence and the appropriate and most efficient catchment management measures even preventative ones can be implemented. A crucial point is to regularly verify the proxy-source-relationship as catchments are dynamic systems in space and time. When demands, water/land uses within the catchment or sources and their impact change, new proxies or indicators might need to be included or need to be changed to reflect the sources and their impact and, thus, to ensure a safe monitoring strategy. By using this innovative monitoring concept samples are limited to source identification and apportionment or 
within the validation of the proxy-water-quality-impairment relationship. This significantly saves resources and costs. A graphical summary can be found in form of a flowchart in Figure 3.2. In order to demonstrate the applicability of the investigative aspect of the presented monitoring strategy under field conditions data from a test site at Lake Garda, Italy, is presented in the following.

\subsection{Application of the investigative monitoring aspects within the innovative monitoring strategy}

\subsubsection{Field site}

With a total surface area of $368 \mathrm{~km}^{2}$ and a catchment area of $2.350 \mathrm{~km}^{2}$ Lake Garda is the largest lake in Italy. The main tributary of Lake Garda is the River Sarca (North), but it is also served by smaller streams. In the northern part of the lake the catchment is dominated by woodlands, mountains and agriculture, while the southern part functions as popular touristic area with amusement parks, campsites, hotels and marinas. As Lake Garda is dominated by tourisms it has a summer population estimated to be more than 400.000 and in contrast less than 80.000 people during winter months. A circular pipeline collects wastewater from all municipalities around the lake and serves a centralised WWTP (330.000 PE) in Peschiera del Garda, which discharges into the River Mincio.

Routine water quality monitoring at Lake Garda is accordingly to the WFD and comprises four samples per year to define the ecological status and twelve samples to evaluate the chemical status of the water body. For bathing water quality 65 sampling points on the Eastern shore are tested monthly from May to September for the detection of two microbiological parameters (E. coli and intestinal Enterococci). Further, the lake water serves as raw water resource for $6 \%$ of the population. Therefore, four locations around the lake are tested according to national guideline values. Key challenges for the catchment of Lake Garda include ensuring a good bathing water quality and evaluating the impact of combined sewage overflows (CSO).

During a short field campaign in autumn 2016 at Lake Garda near the village Ronchi (20 km West of Verona, Italy) significantly elevated EC values of up to 


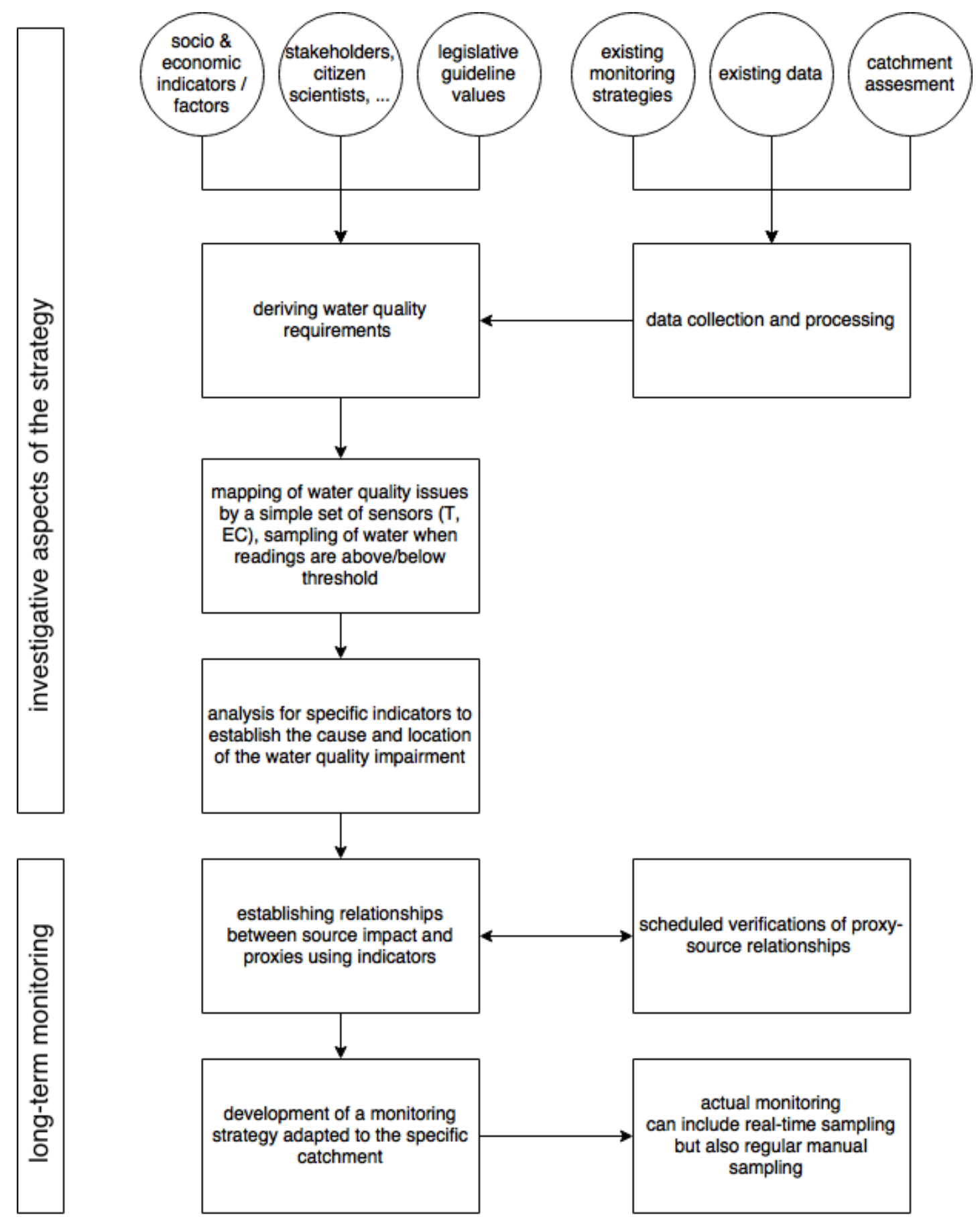

Figure 3.2.: Graphical overview over the different steps of the described innovative monitoring strategy. 
$1348 \mathrm{\mu S} / \mathrm{cm}$ were observed in a small tributary of Lake Garda. This elevated EC (five times higher than the background value of lake Garda, $250 \mu \mathrm{S} / \mathrm{cm}$ ) can be caused by either natural or anthropogenic sources. Possible causes for elevated EC include misconnections in the sewage system of the amusement park nearby or the stream might be connected to saline hot springs in Colà, a small town a few kilometers upstream. Additionally, nearby sampling points for bathing water quality occasionally show impairments in the microbiological parameter. As this area is used for recreational activities and is a natural reserve for birds a contamination by wastewater would be a significant impairment despite the low flow rate of the tributary.

\subsubsection{Materials and methods}

Initial EC-mapping was conducted by a robotic in-water propeller boat produced by Platypus engineered for the INTCATCH project (EU, Horizon 2020). This boat is equipped with an automated sampling system for four water samples and an EC/T-probe. Automated sampling was triggered by an exceeded EC value three times higher $(800 \mu \mathrm{S} / \mathrm{cm})$ than the background EC value of Lake Garda $(250 \mathrm{\mu S} / \mathrm{cm})$. Samples were carefully transferred into glass storage vials for transport and stored under cool and dark conditions until analysis via LC-MS/MS (Sciex Qtrap 6500+ equipped with a Shimadzu Nexera X2 liquid chromatography system) by direct injection. In total 76 organic contaminants as indicators were analysed. Additionally to analytes in Nödler, Licha, Bester, et al. 2010 samples were screened for 4-nitro-sulfamethoxazole, acesulfame, atenolol acid, bentazone, benzenesulfonic acid, benzimidazole, benzocaine, fluorescent brightener 28, chloridazon, desphenyl-chloridazon, desphenyl-methyl-chloridazon, ethyl sulfate, famotidine, furosemide, gabapentin, haloperidol, irbesartan, losartan, melamine, metaldehyd, primidone, propranolol, ritalinic acid, sulfamic acid, valsartan and valsartan acid. Method quantitation limits varied between $0.3 \mathrm{ng} \mathrm{\textrm {L } ^ { - 1 }}$ (isoproturon) and $34.5 \mathrm{ng} \mathrm{L}^{-1}$ (fluorescent brightener 28).

\subsubsection{Results}

An additional field campaign in October 2017 with the aim of testing the proposed monitoring strategy was conducted. On both days, a distinct plume of elevated 
EC around the area where the tributary meets the lake was observed. As can be seen in Figure 3.3 the location and extend of the plume significantly changed between both days. This clearly points out how dynamic surface water bodies may be and, hence, the importance of real-time-mapping supported sampling.
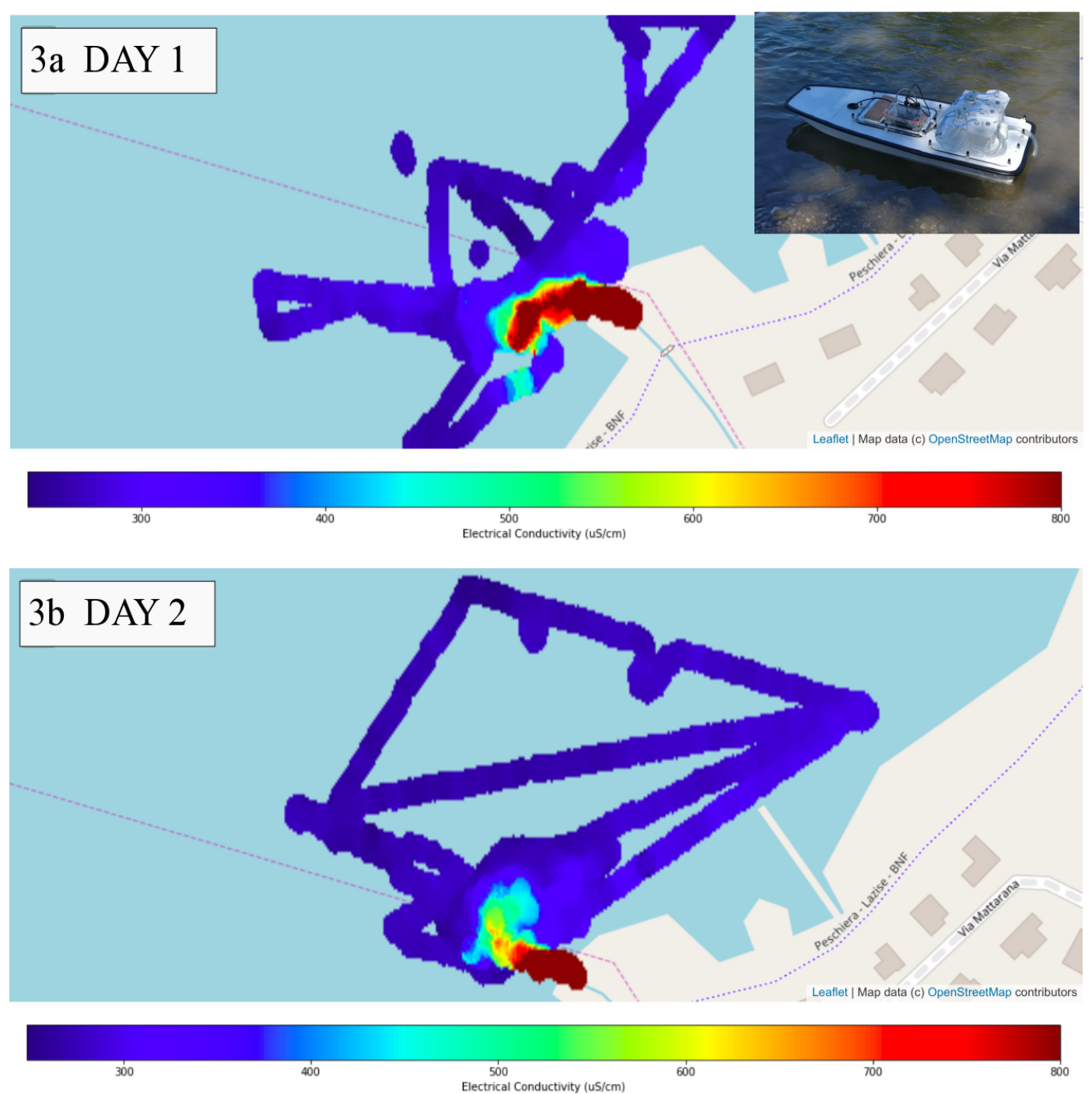

Figure 3.3.: Picture of a proxy mapping campaign by using an automated boat during a mapping and sampling campaign in October 2017 in Italy / Lake Garda near Ronchi. As can be seen in: (a) on the first day the plume drifts southwards, while one day later the plume changed directions (b).

No micropollutants which would indicate a possible anthropogenic influence of, e. g., domestic wastewater were detected. Besides, constantly increasing 
EC values of up to $1410 \mu \mathrm{S} / \mathrm{cm}$ and temperatures of up to $25.9{ }^{\circ} \mathrm{C}$ near Colà (hot springs) were observed by manual measurements upstream using a handheld probe. Beyond the area of hot springs, decreasing EC values and lower temperatures were observed. As a result, it can be concluded that the elevated EC values are predominately caused by a natural source most likely from hot springs upstream. Based on this, no immediate catchment measures need to be taken, because the risk that pathogens are connected to natural hot springs is assumed to be low. Further investigative monitoring can rule out anthropogenic influences completely. Moreover, in this area of Lake Garda EC can serve as a proxy for compounds introduced by tributaries. This information can be implemented within emergency plans: In case of substantial contamination within a tributary (e. g., accidents, spillages, etc.) the application of the here proposed monitoring strategy will allow for straightforward and focused determination of the distribution of associated pollutants.

\subsection{Conclusions}

The field campaign at Lake Garda clearly demonstrated the superiority of the suggested water monitoring strategy over state-of-the-art approaches. Mapping by using general parameters, such as EC and T, before actual sampling increases information density significantly and greatly reduces costs. Especially for highly dynamic systems, such as plumes, this approach is highly effective. Source and process specific chemical indicators allow to differentiate between different sources, such as anthropogenic and natural sources and enable to derive most efficient catchment management measures. A promising micropollutant-based indicator set for the described test site is caffeine to detect untreated wastewater, valsartan acid for treated wastewater, a dermal UV blocker for tourism and a corrosion inhibitor, e. g., tolyltriazol, for industry or facilities from the amusement park nearby. As a proxy for long-term monitoring at Lake Garda we suggest EC to cover all possible source of water quality impairments even though this is supportive rather than directive.

Finding a suitable relationship between a proxy and the source makes even real-time monitoring affordable and informative, which can significantly reduce potential risks in highly vulnerable areas. This demonstrated the effectiveness 
of the investigative aspects of the here suggested innovative monitoring strategy. Even with a small budget and little time it was possible to differentiate between the two potential sources with completely different risk potentials. How transferable this monitoring strategy is to river systems may depend on flow velocity, river size and morphology.

\subsection{Acknowledgments}

This study was funded by the European Commission (contract number 689341), INTCATCH, "Development and application of Novel, Integrated Tools for monitoring and managing Catchments". The catchment information for Lake Garda has been kindly provided by Instituto Di Santia (ISS) and Azienda Gardesana Servizi Spa (AGS). 


\section{References}

Alilou, H. et al. (2018). "A cost-effective and efficient framework to determine water quality monitoring network locations". In: Science of the Total Environment 624, pp. 283-293. DOI: 10.1016/j.scitotenv.2017.12.121.

Amare, E. (2017). "Wastewater Confronting Realities for Sustainable Livelihood in Developing Countries : Case Study Mekelle University, Ethiopia”. In: Water Conservation Science and Engineering, pp. 21-30. DOI: 10.1007/s41101-017-0021-7.

Barbosa, M. et al. (2016). "Occurrence and removal of organic micropollutants: An overview of the watch list of EU Decision 2015/495". In: Water Research 94, pp. 257279. DOI: $10.1016 / \mathrm{j}$.watres.2016.02.047.

Barrett, D. and A. Frazier (2016). "Automated Method for Monitoring Water Quality Using Landsat Imagery". In: Water 8.6, p. 257. DoI: 10.3390/w8060257.

Behmel, S. et al. (2016). "Water quality monitoring strategies - A review and future perspectives". In: Science of the Total Environment 571, pp. 1312-1329. DOI: 10 . 1016/j.scitotenv.2016.06.235.

Bennett, J. and P. Lawrence (2002). "Adaptive management framework for catchment and coastal management and decision making". In: Coastal $\{C R C\}$ conference 1994, pp. 24-27.

Bonvin, F. et al. (2011). "Spatial and temporal presence of a wastewater-derived micropollutant plume in Lake Geneva". In: Environmental Science and Technology 45.11, pp. 4702-4709. DOI: 10.1021/es2003588.

Brumovský, M. et al. (2017). "Contaminants of emerging concern in the open sea waters of the Western Mediterranean". In: Environmental Pollution 229, pp. 976-983. DOI: 10.1016/j.envpol.2017.07.082.

Castilho, J. A. A. et al. (2000). "Organochlorine and organophosphorus pesticide residues in the Atoya river basin, Chinandega, Nicaragua". In: Environmental Pollution 110.3, pp. 523-533. DOI: 10.1016/S0269-7491(99)00277-8.

Clara, M., B. Strenn, and N. Kreuzinger (2004). "Carbamazepine as a possible anthropogenic marker in the aquatic environment: Investigations on the behaviour of Carbamazepine in wastewater treatment and during groundwater infiltration". In: Water Research 38.4, pp. 947-954. DOI: $10.1016 /$ j.watres.2003.10.058.

Duan, H. et al. (2007). "Assessment of chlorophyll-a concentration and trophic state for lake chagan using landsat TM and field spectral data". In: Environmental Monitoring and Assessment 129.1-3, pp. 295-308. DOI: 10.1007/s10661-006-9362-y.

Gago-Ferrero, P., M. Díaz-Cruz, and D. Barceló (2013). "Liquid chromatographytandem mass spectrometry for the multi-residue analysis of organic UV filters and their transformation products in the aquatic environment". In: Rapid communications in mass spectrometry : RCM 5.6, pp. 722-30. DOI: $10.1002 / \mathrm{rcm} .6507$.

Gago-Ferrero, P., E. L. Schymanski, et al. (2015). "Extended Suspect and Non-Target Strategies to Characterize Emerging Polar Organic Contaminants in Raw Wastewater with LC-HRMS/MS". In: Environmental Science and Technology 49.20, pp. 1233312341. DOI: $10.1021 /$ acs.est.5b03454. 
Gasser, G. et al. (2010). "Quantitative evaluation of tracers for quantification of wastewater contamination of potable water sources". In: Environmental Science and Technology 44.10, pp. 3919-3925. DOI: 10.1021/es100604c.

Glassmeyer, S. and M. Meyer (2005). "Transport of Chemical and Microbial Compounds from Known Wastewater Discharges : Potential for Use as Indicators of $\mathrm{Hu}$ man Fecal Contamination". In: Environmental Science and Technology 39, pp. 51575169.

Hillebrand, O. et al. (2012). "Identification of the attenuation potential of a karst aquifer by an artificial dualtracer experiment with caffeine". In: Water Research 46, pp. 5381-5388. DOI: $10.1016 / \mathrm{j}$.watres.2012.07.032.

$\mathrm{Hu}$, K. et al. (2005). "Spatial variability of shallow groundwater level, electrical conductivity and nitrate concentration, and risk assessment of nitrate contamination in North China Plain". In: Environment International 31.6, pp. 896-903. DOI: 10 . 1016/j.envint.2005.05.028.

$\mathrm{Hu}, \mathrm{X}$. (1999). "Integrated catchment management in china: Application of the australian experience". In: Water International 24.4, pp. 323-328. DOI: $10.1080 /$ 02508069908692184

Jekel, M., W. Dott, et al. (2015). "Selection of organic process and source indicator substances for the anthropogenically influenced water cycle". In: Chemosphere 125, pp. 155-167. DOI: 10.1016/j.chemosphere.2014.12.025.

Jekel, M., A. Ruhl, et al. (2013). "Anthropogenic organic micro-pollutants and pathogens in the urban water cycle : assessment, barriers and risk communication ( ASKURIS )". In: Environmental Science Europe, pp. 1-8. DoI: 10.1186/2190-4715-25-20.

Kay, P., P. a. Blackwell, and A. B. a. Boxall (2005). "Column studies to investigate the fate of veterinary antibiotics in clay soils following slurry application to agricultural land". In: Chemosphere 60.4, pp. 497-507. DOI: 10.1016/j . chemosphere.2005.01. 028 .

Khazaei, E. and W. Milne-Home (2017). "Applicability of geochemical techniques and artificial sweeteners in discriminating the anthropogenic sources of chloride in shallow groundwater north of Toronto, Canada". In: Environmental Monitoring and Assessment 189.5. DOI: $10.1007 / \mathrm{s} 10661-017-5927-1$.

Lapworth, D. J. et al. (2012). "Emerging organic contaminants in groundwater: A review of sources, fate and occurrence". In: Environmental Pollution 163, pp. 287303. DOI: $10.1016 / \mathrm{j}$.envpol.2011.12.034.

Lim, F., S. Ong, and J. Hu (2017). "Recent Advances in the Use of Chemical Markers for Tracing Wastewater Contamination in Aquatic Environment: A Review". In: Water 9.2, p. 143 . DOI: $10.3390 /$ w9020143

Milano, M., N. Chèvre, and E. Reynard (2018). "Assessing watercourse quality: challenges in implementing European and Swiss legal frameworks". In: Environmental Science and Pollution Research 25.1, pp. 805-823.

Mitchell, B. and M. Hollick (1993). "Integrated catchment management in Western Australia: Transition from concept to implementation". In: Environmental Management 17.6, pp. $735-743$. DOI: $10.1007 /$ BF02393894 
Nnane, D. E., J. E. Ebdon, and H. D. Taylor (2011). "Integrated analysis of water quality parameters for cost-effective faecal pollution management in river catchments". In: Water Research 45.6, pp. 2235-2246. DOI: 10.1016/j .watres.2011.01.018.

Nödler, K., O. Hillebrand, et al. (2013). "Occurrence and fate of the angiotensin II receptor antagonist transformation product valsartan acid in the water cycle - A comparative study with selected $\beta$-blockers and the persistent anthropogenic wastewater indicators carbamazepine and acesulfame". In: Water Research 47, pp. 6650-6659. DOI: $10.1016 / j$.watres.2013.08.034.

Nödler, K., T. Licha, K. Bester, et al. (2010). "Development of a multi-residue analytical method, based on liquid chromatography-tandem mass spectrometry, for the simultaneous determination of 46 micro-contaminants in aqueous samples". In: Journal of Chromatography A 1217, pp. 6511-6521. DOI: 10.1016/j.chroma.2010.08.048.

Nödler, K., T. Licha, S. Fischer, et al. (2011). "A case study on the correlation of micro-contaminants and potassium in the Leine River (Germany)". In: Applied Geochemistry 26, pp. 2172-2180. DOI: 10.1016/j . apgeochem.2011.08.001.

Nödler, K., M. Tsakiri, et al. (2016). "Evaluation of polar organic micropollutants as indicators for wastewater-related coastal water quality impairment". In: Environmental Pollution 211, pp. 282-290. DOI: 10.1016/j.envpol.2016.01.014.

Olías, M. et al. (2004). "Seasonal water quality variations in a river affected by acid mine drainage: The Odiel River (South West Spain)". In: Science of the Total Environment 333.1-3, pp. 267-281. DOI: $10.1016 /$ j.scitotenv.2004.05.012.

Oliveira, T. S. et al. (2015). "Characterization of Pharmaceuticals and Personal Care products in hospital effluent and waste water influent/effluent by direct-injection LC-MS-MS". In: Science of the Total Environment 518-519, pp. 459-478. DOI: 10 . 1016/j.scitotenv.2015.02.104.

Petrie, B., R. Barden, and B. Kasprzyk-Hordern (2014). "A review on emerging contaminants in wastewaters and the environment: Current knowledge, understudied areas and recommendations for future monitoring". In: Water Research 72.0, pp. 327. DOI: $10.1016 / \mathrm{j}$.watres.2014.08.053.

Premazzi, G. et al. (2003). "Lake management in Italy: The implications of the water framework directive". In: Lakes and Reservoirs: Research and Management 8.1, pp. 41-59. DOI: $10.1046 / \mathrm{j} .1440-1770.2003 .00210 . \mathrm{x}$.

Proll, G., J. Tschmelak, and G. Gauglitz (2005). "Fully automated biosensors for water analysis". In: Analytical and Bioanalytical Chemistry 381.1, pp. 61-63. DOI: 10 . 1007/s00216-004-2897-2.

Reemtsma, T. et al. (2016). "Mind the Gap: Persistent and Mobile Organic Compounds - Water Contaminants That Slip Through". In: Environmental Science and Technology 50.19, pp. 10308-10315. DOI: 10.1021/acs.est.6b03338.

Scheurer, M. et al. (2017). "Small, mobile, persistent: Trifluoroacetate in the water cycle - Overlooked sources, pathways, and consequences for drinking water supply". In: Water Research 126, pp. 460-471. DOI: 10.1016/j.watres.2017.09.045.

Seiler, R. L. et al. (1999). "Caffeine and pharmaceuticals as indicators of waste water contamination in wells". In: Ground Water 37.3, pp. 405-410.

Seitz, W. and R. Winzenbacher (2017). "A survey on trace organic chemicals in a German water protection area and the proposal of relevant indicators for anthro- 
pogenic influences". In: Environmental Monitoring and Assessment 189.6, p. 244. DOI: $10.1007 / \mathrm{s} 10661-017-5953-\mathrm{z}$.

Viviano, G. et al. (2017). "Combined Use of Caffeine and Turbidity to Evaluate the Impact of CSOs on River Water Quality". In: Water, Air, E3 Soil Pollution 228.9, p. 330. DOI: $10.1007 / \mathrm{s} 11270-017-3505-3$.

Voulvoulis, N., K. D. Arpon, and T. Giakoumis (2017). "The EU Water Framework Directive: From great expectations to problems with implementation". In: Science of the Total Environment 575, pp. 358-366. DOI: 10.1016/j.scitotenv.2016.09.228

Ward, R. C. (1997). "WATER QUALITY MONITORING : WHERE' S THE BEEF ?' nation 's water quality is in terrible condition and the resulting data, in many ways, are comparable Current, and popular , efforts to curtail public monitoring programs will be unable to document grou". In: Water Resources Bulletin 32.4.

Ward, R. C., J. C. Loftis, and G. B. McBride (1986). "The "data-rich but informationpoor" syndrome in water quality monitoring". In: Environmental Management 10.3, pp. 291-297. DOI: 10.1007/BF01867251.

Warner, W., H. Ruppert, and T. Licha (2016). "Application of PAH concentration profiles in lake sediments as indicators for smelting activity". In: Science of the Total Environment 563-564, pp. 587-592. DOI: 10.1016/j.scitotenv.2016.04.103.

Wode, F. et al. (2015). "Search for over 2000 current and legacy micropollutants on a wastewater infiltration site with a UPLC-high resolution MS target screening method". In: Water Research 69, pp. 274-283. DOI: 10.1016/j . watres . 2014 . 11.034 .

Yang, Y.-Y. et al. (2018). "Pharmaceuticals and personal care products (PPCPs) and artificial sweeteners (ASs) in surface and ground waters and their application as indication of wastewater contamination". In: Science of The Total Environment 616617, pp. 816-823. DOI: $10.1016 /$ j.scitotenv.2017.10.241.

Zirlewagen, J. et al. (2016). "Use of two artificial sweeteners, cyclamate and acesulfame, to identify and quantify wastewater contributions in a karst spring". In: Science of the Total Environment 547, pp. 356-365. DOI: 10.1016/j.scitotenv.2015.12.112. 


\section{Application of PAH concentration profiles in lake sediments as indicators for smelting activity}

Wiebke Warner ${ }^{1}$, Hans Ruppert ${ }^{2}$, Tobias Licha $^{1}$

\footnotetext{
${ }^{1}$ Geoscience Centre, Department of Applied Geology, Hydrochemistry Group, University of Göttingen, Goldschmidtstr. 3, 37077 Göttingen, Germany

${ }^{2}$ Geoscience Centre, Department of Sedimentology and Environmental Geology, University of Göttingen, Goldschmidtstr. 3, 37077 Göttingen, Germany
}

Citation: W. Warner, H. Ruppert, and T. Licha (2016). "Application of PAH concentration profiles in lake sediments as indicators for smelting activity". In: Science of the Total Environment 563-564, pp. 587-592. DOI: $10.1016 / \mathrm{j}$. scitotenv.2016.04.103

https://www.sciencedirect.com/science/article/pii/S0048969716307835 


\section{Abstract}

The ability of lake sediment cores to store long-term anthropogenic pollution establish them as natural archives. In this study, we focus on the influence of copper shale mining and smelting in the Mansfeld area of Germany, using the depth profiles of two sediment cores from Lake Süßer See. The sediment cores provide a detailed chronological deposition history of polycyclic aromatic hydrocarbons (PAHs) and heavy metals in the studied area. Theisen sludge, a fine-grained residue from copper shale smelting, reaches the lake via deflation by wind or through riverine input; it is assumed to be the main source of pollution. To achieve the comparability of absolute contaminant concentrations, we calculated the influx of contaminants based on the sedimentation rate. Compared to the natural background concentrations, PAHs are significantly more enriched than heavy metals. They are therefore more sensitive and selective for source apportionment. We suggest two diagnostic ratios of PAHs to distinguish between Theisen sludge and its leachate: the ratio fluoranthene to pyrene $\sim 2$ and the ratio of $\mathrm{PAH}$ with $\log \mathrm{K}_{\mathrm{OW}}<5.7$ to $\mathrm{PAH}$ with a $\log \mathrm{K}_{\mathrm{OW}}>5.7$ converging to an even lower value than 2.3 (the characteristic of Theisen sludge) to identify the particulate input in lake environments

Keywords: PAH, heavy metals, indicators, diagnostic ratios, lake sediments, environmental archives

\subsection{Introduction}

Policyclic aromatic hydrocarbons (PAHs) and heavy metals are ubiquitous environmental toxics (Sverdrup, Nielsen, and Krogh 2002). Haykiri-Acma et al. 2011, Erlenkeuser, Suess, and Willkomm 1974 and Bertine and Goldberg 1971 proposed that increasing coal/lignite combustion, and the resulting fly ash, will increase the mobilization of heavy metals. PAHs are the most stable form of hydrocarbons due to their low hydrogen to carbon ratio (Manahan 2010). They are typically of anthropogenic origin, formed during the incomplete combustion of mobile, domestic, industrial and fossil energy sources (Ravindra, Sokhi, et al. 2008). Natural 
sources of PAHs, such as volcanic eruptions or non-anthropogenic wildfires, are difficult to quantify (Wild and Jones 1995). Low molecular weight PAHs undergo a worldwide atmospheric dispersion, while PAHs with higher molecular weight are mainly associated with particulate matter (Subramanyam et al. 1994). Very low biodegradation of PAHs under nutrient-low and anoxic conditions was observed, especially for those with high molecular weight (Breedveld and Sparrevik 2000 ).

Due to their persistence (Schneider et al. 2001) and low mobility (Malawska, Ekonomiuk, and Wilkomirski 2006), PAHs have been used as environmental archives (Thuens, Blodau, and Radke 2013). With their high temporal resolution, sediment cores can be successfully utilized for the reconstruction of historical PAH deposition (Hites et al. 1980; Simcik et al. 1996). The sediment cores of lakes not only show atmospheric contamination, but also the contamination history of the catchment area; even single fire events can be detected (Denis et al. 2012).

Therefore, in the last two decades the PAH distribution in sediment cores from rivers, lakes and estuary/marine profiles have been increasingly studied. In order to predict the historical atmospheric input of PAHs and to quantify a specific source, such as the PAH content in fly ash particles, PAH studies are typically conducted on sediment cores taken from lakes in remote areas with low anthropogenic influence (Denis et al. 2012, Rose and Rippey 2002).

Few studies have investigated sediment cores taken from lakes that are supplemented by rivers with several anthropogenic sources of input (Vrana, Paschke, and Popp 2001). Studies which compare PAH data to heavy metals on lake sediments are rare (Müller, Grimmer, and Böhnke 1977). Exact source apportionment of PAHs is difficult, but the application of diagnostic ratios is a common method and can be usefully applied (Grimmer, Jacob, and Naujack 1981; Oda et al. 2001; Ravindra, Bencs, et al. 2006, Ravindra, Wauters, et al. 2006). The majority of studies on the distribution patterns of PAHs deal with their occurrence in the atmosphere in order to predict air quality and health risks in metropolitan areas (Dvorská et al. 2012 Menichini 1992, Zhang and Tao 2009).

In order to exploit PAHs and extend their applicability in environmental archives, we investigated sediment cores from Lake Süßer See in the Mansfeld area (Germany), which was influenced by centuries of copper shale mining and smelting. 
Due to the fact that both PAHs and heavy metals were emitted in high amounts from different sources, this site is ideal for deriving diagnostic ratios as indicators and for comparing the enrichment factors of PAHs relative to heavy metals. Additionally this study aims to check the sensitivity of PAH enrichment relative to metals and organic matter.

\subsection{Materials and methods}

\subsubsection{Description of sampling site}

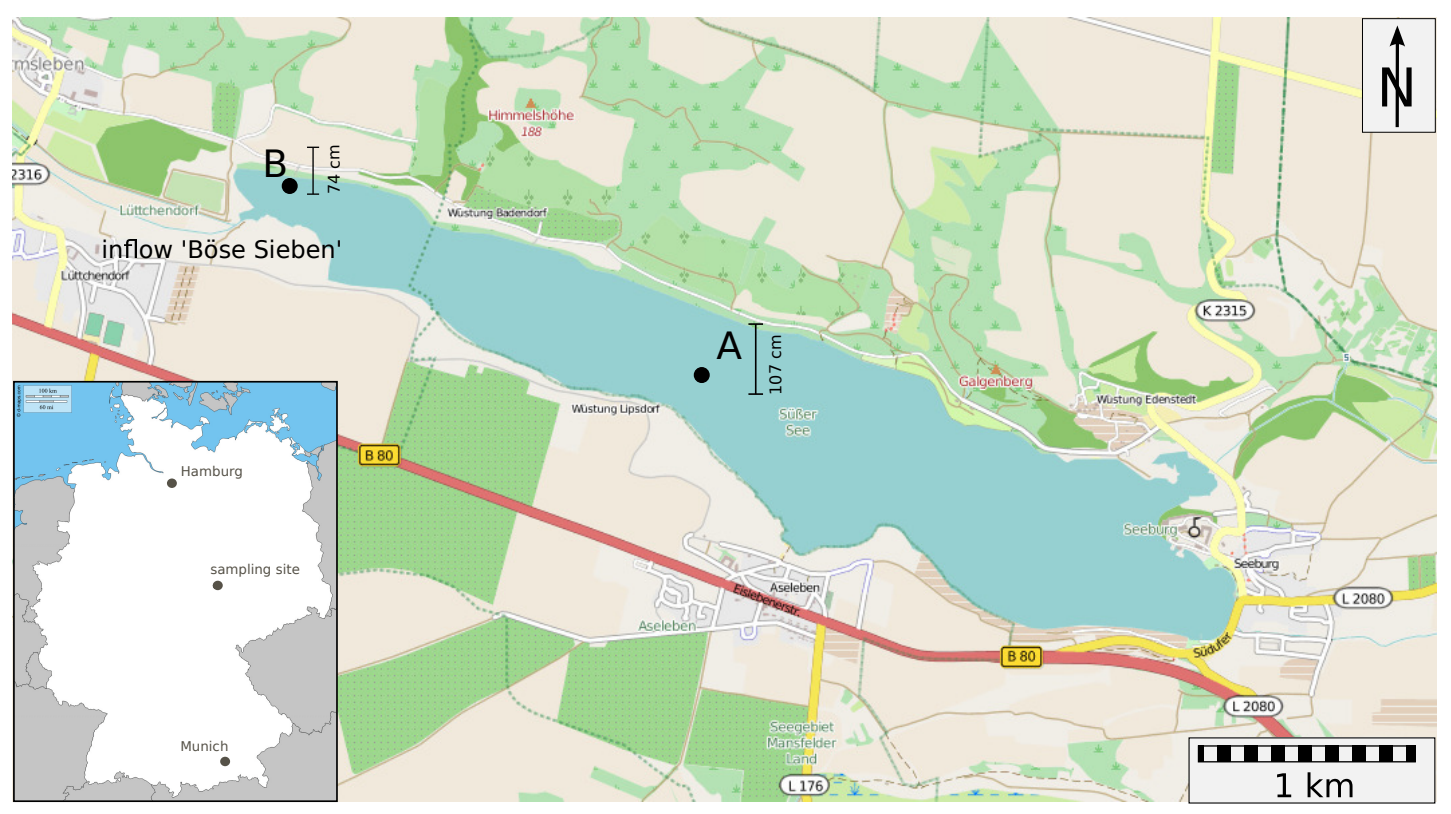

Figure 4.1.: Location of Lake Süßer See in Mansfeld area in the East of Germany (black point on the small map). A and B indicate the location of the sediment. The length of sediment core is $107 \mathrm{~cm}$ and the length of sediment core B is $74 \mathrm{~cm}$. Smelters were located in the river catchment and are closed today, for details see Wennrich et al. 2004. Maps from http://www.openstreetmap.de/ and http://www.d-maps.com/index.php?lang=de.

\subsubsection{Sampling}

Core A was taken from the center of Lake Süßer See, whilst core B was collected from the litoral zone close to the main contributor of River Böse Sieben, Fig- 
ure 4.1. Core samples were taken in June 2013 using blank free tools and were stored in an oxygen-free environment at $4{ }^{\circ} \mathrm{C}$. The extraction was carried out within four weeks. One half of each core was used for multi-element analysis and the other half for PAH analysis.

\subsubsection{Chemicals}

For ICP-OES analysis subboiled Hydrofluoric acid (40\%) (P.A. qualility), nitric acid (65\%), hydrochloric acid (37\%), sodium hydroxide (for sodium hydroxide solution) and sodium sulfate were purchased from Merck (Darmstadt, Germany) and Hydrochloric acid (70 \%) from Carl Roth (Karlsruhe, Germany). For sulphur and carbon analysis, tungsten and iron from Eltra (Haan, Germany) were used. As an internal standard for organic analysis a mixture of acenaphthene D10, benzo(g,h,i)perylene D12, chrysene D12, naphthalene D8, perylene D10, phenanthrene D10 and pyrene D10 was from Dr. Ehrensdorfer (Augsburg, Germany) (concentration $15 \mathrm{ng} \mathrm{LL}^{-1}$ ). Isohexane was purchased from Fischer Scientific (Schwerte, Germany) and ultrapure water was obtained from a combined water purification system consisting of Elix 5 and Milli-Q Gradient A10, both from Merck Millipore (Schwalbach, Germany).

\subsubsection{Sample preparation and analysis}

Sediment cores were divided into $2 \mathrm{~cm}$ segments. For zinc, lead and copper analysis, samples were dried at $105{ }^{\circ} \mathrm{C}$ until a constant weight was reached. Digestion of samples was carried out as follows: $200 \mathrm{mg}$ of homogenized dried sample were weighed into teflon vessels and treated with a mixture of $3 \mathrm{~mL}$ hydrofluoric acid, $3 \mathrm{~mL}$ perchloric acid, and $2 \mathrm{~mL}$ nitric acid at $150{ }^{\circ} \mathrm{C}$ for $15 \mathrm{~h}$ under pressure. During the following vaporization phase, vessels were heated at $180{ }^{\circ} \mathrm{C}$ for $10 \mathrm{~h}$. The residue was dissolved in a dilute mixture of nitric and hydrochloric acid and further treated at $150{ }^{\circ} \mathrm{C}$ for $3 \mathrm{~h}$ in sealed teflon vessels. For more detail see Ruppert, Kappas, and Ibendorf 2013.

For PAH analysis, 500-1000 mg of a wet sample were used. Its water was captured using sodium sulfate in order to avoid incompatibility with the extraction solvent. The samples were transferred into teflon vessels, $5 \mu \mathrm{L}$ internal standard and $3 \mathrm{~mL}$ isohexane added, closed tightly. The vessels were closed tightly and 
heated in a CEM Mars Express microwave at $1600 \mathrm{~W}$ (10 min preheating to $130{ }^{\circ} \mathrm{C}, 20$ min extracting at $130{ }^{\circ} \mathrm{C}$ ). The microwave extraction was repeated three times. The extracts were then combined and stored at $-18{ }^{\circ} \mathrm{C}$ until analysis.

Element analysis for zinc, lead and copper was carried out on the digested sample by using ICP-OES Fissions Maxim I 109 ARL. All results were drift and blank corrected. Sulphur and Carbon analysis was performed on an Eltra Metalyt CS 100 RF by adding elementary tungsten and iron to 20-100 mg of each sample and heating to $1400{ }^{\circ} \mathrm{C}$. PAHs were analyzed using gas chromatography with mass spectrometric detection (GC-MS) using an Agilent 7890A- 5975E System, with an Agilent autosampler 120 and multimode inlet and large volume injection $(100 \mu \mathrm{L})$. Separation of PAHs was achieved with an Agilent DB-XLB column (30x250x0.25). Data was recorded in the single ion monitoring mode (quantifier in $\mathrm{m} / \mathrm{z}$ and internal standard in paranthesis) of at least $100 \mathrm{~ms}$ per amu for the following analytes: acenaphthylene (152, acenaphthene D10), fluorene (166, acenaphthene D10), phenanthrene (178, phenanthrene D10), anthracene (178, phenanthrene D10 ), pyrene (202, pyrene D10), 7h-benz(c)-fluorene (216, phenanthrene D10), cyclopenta(c,d)-pyrene (226, chrysene D10), benzo(a)-anthracene (288, chrysene D10), chrysene (288, chrysene D10), 5-methylchrysene (242, chrysene D10), benzo(b,j,k)-fluoranthene (252, perylene D10), benzo(a)pyrene (250, perylene D10), dibenzo(a,h)-anthracene (278, benzo (g,h,i)-perylene D10), ideno(1,2,3-c,d)-anthracene (276, benzo(g,h,i)-perylene D10), benzo(g,h,i)-perylene (278, benzo(g,h,i)-perylene D10) to dibenzo(a,i),(a,e), (a,i) and (a,h)-pyrene (302, benzo(g,h,i)-perylene D10). Peak purity was assured by simultaneous scanning of 50$350 \mathrm{amu}$. The method quantification limit was $5 \mu \mathrm{g} \mathrm{kg} \mathrm{kg}^{-1}$ and the mean of two replicates was used. For more details, please see Graue et al. 2013.

The sediment cores were dated with a Canberra 7229PW borehole crystal detector (active volume: $70 \mathrm{cc}$, coaxial detector, diameter: $49 \mathrm{~mm}$, length $53 \mathrm{~mm}$, well depth: $42 \mathrm{~mm}$, well diameter: $19 \mathrm{~mm}$, depletion voltage $230 \mathrm{~V}$ ) three days per sample. ${ }^{137}$ Cs-Dating was adjusted to the Chernobyl Disaster in 1986 and the significant decrease of ${ }^{137} \mathrm{Cs}$ activity with the Limited Test Ban Treaty in the fall of 1963, which prohibits all test detonations of nuclear weapons except underground. The Sedimentation rates of both sediment cores were approximated and interpolated according to Becker et al. 2001. 


\subsection{Results and discussion}

Due to varying sedimentation rates within different lakes, absolute contaminant concentrations of contaminants are not comparable. The input of each contaminant is therefore calculated by

$$
\begin{aligned}
& \text { flux }\left[m g a^{-1} m^{-2}\right] \\
& =\text { sedimentation rate }\left[m a^{-1}\right] \cdot \text { dry density }\left[\mathrm{kg} \mathrm{m}^{-3}\right] \cdot \text { concentration }\left[\mathrm{mg} \mathrm{kg}^{-1}\right]
\end{aligned}
$$

with Loess bulk density of $1.4 \mathrm{~g} \mathrm{~m}^{-3}$ according to Schmidt and Skowronek 1994. A higher sediment flux can lead to the dilution of contaminants and thus a decrease in the contaminant flux. quantify due to the high range of influencing factors like oxygen-supply and associated burning temperature or moisture content (Denis et al. 2012). The assumed correlation of both can therefore not be assured. Only sediment core A shows a peak influx of both heavy metals in and PAHs with a $\log \mathrm{K}_{\mathrm{OW}}>5.7$ in the mid to end of $1980 \mathrm{~s}$. Unlike sediment core A, core B does not show any enrichment pattern, most due to its location in the lake. Sediment core $\mathrm{B}$ is located at the litoral zone of the lake, near to the inflow of the River Böse Sieben. Processes like riverine delta formation, where the river enters the lake, resuspension and redistribution, and mixing (Hilton, Lishman, and Allen 1986) disturb a uniform sedimentation. As a consequence, we propose that sediment cores located at the inflow of rivers or at the litoral zone of lakes are not suitable for reliable environmental archives. With its relatively constant sedimentation rate, sediment core $\mathrm{A}$ is located in the center of the lake and reflects a reliable and undisturbed archive for environmental contaminants.

\subsubsection{Time and space resolved correlation of heavy metals and PAH fluxes}

Both sediment cores are significantly dominated by smelting associated heavy metals such as zinc, copper and lead, (Wennrich et al. 2004), with a peak concentration in the early 1990s and a significant decrease up until then. The flux of heavy metals, as calculated in Equation 4.1, is higher in core B than in core A, coincides with Becker et al. 2001, who predicted a general decrease of contami- 
nants from west to east in Lake Süßer See. The same pattern can be observed with the distribution of PAHs in the lake. In total, sediment core B contains four times more PAHs (sum of all detected PAHs $23206 \mathrm{mg} \mathrm{a}^{-1} \mathrm{~m}^{-2}$ in the second half 1988) than sediment core A (sum of all detected PAHs $5329 \mathrm{mg} \mathrm{a}^{-1} \mathrm{~m}^{-2}$ in 1987), see compared PAHs to the content of organic carbon in Figure 4.2 .

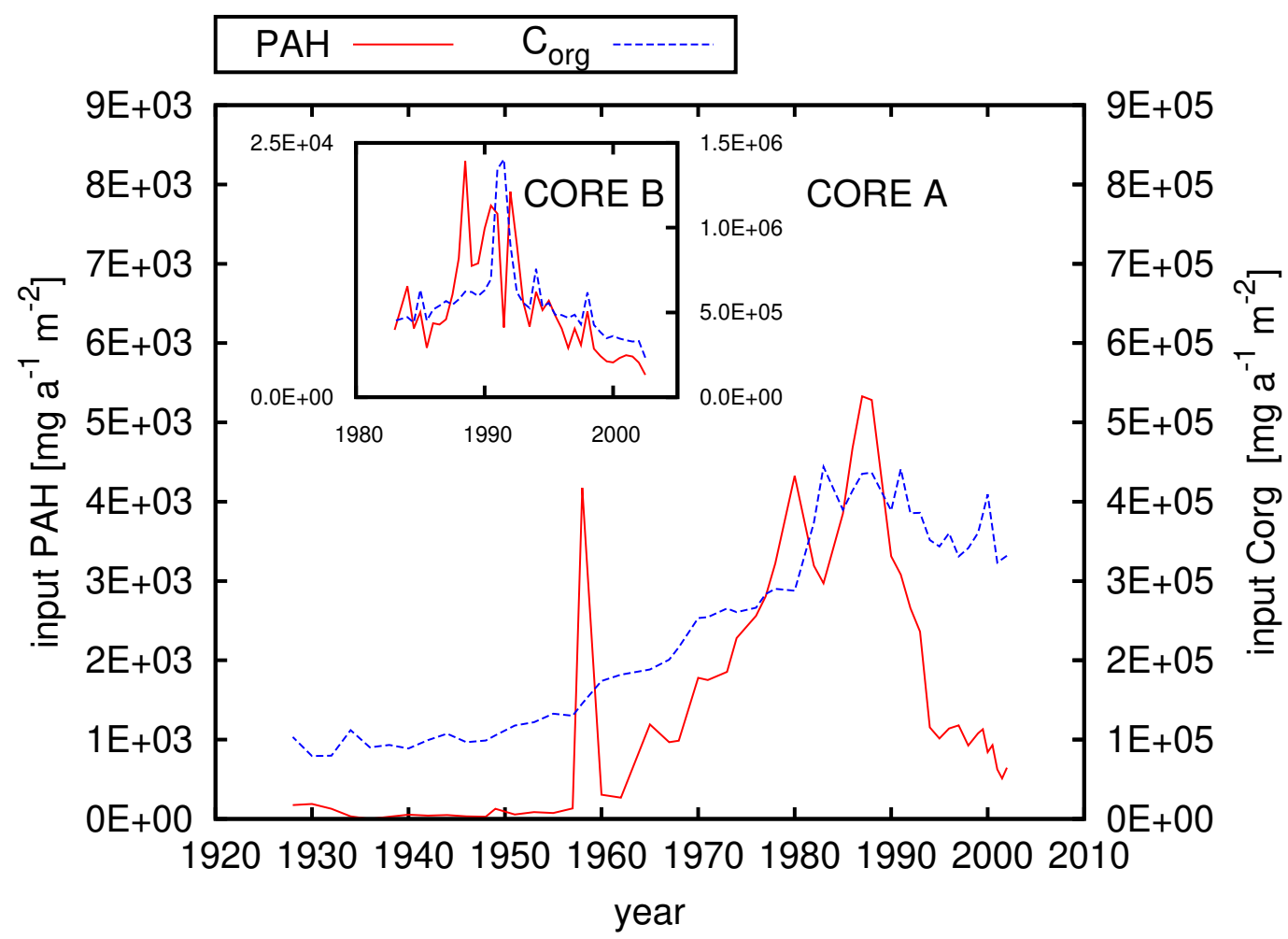

Figure 4.2.: Input of PAHs compared to input of $\mathrm{C}_{\text {org }}$ of sediment core $\mathrm{A}$ and $\mathrm{B}$. The input of $\mathrm{C}_{\text {org }}$ is about 100 times higher than input of PAHs. The peak in 1980 indicates the maximum of smelter production.

Both sediment cores are dominated by fluoranthene and PAHs with four aromatic rings. Compared to sediment core B, core A shows a slight enrichment in PAHs with a higher molecular weight. Based on the higher time resolution of sediment A, an additional peak dominated by high molecular weight PAHs in absence of an elevated input of heavy metals in 1958 can be detected, see Figure 4.3. This peak may be associated with the fire in a malt factory in Eisleben that occurred near the lake in the same year. PAH patterns as a result of fires in factories and households are difficult to quantify due to the high range of influencing factors like oxygen-supply and associated burning temperature or moisture con- 
tent (Denis et al. 2012). The assumed correlation of both can therefore not be assured. Only sediment core A shows a peak influx of both heavy metals in and PAHs with a $\log K_{\mathrm{OW}}>5.7$ in the mid to end of 1980s. Unlike sediment core A, core $\mathrm{B}$ does not show any enrichment pattern, most due to its location in the lake. Sediment core B is located at the litoral zone of the lake, near to the inflow of the River Böse Sieben. Processes like riverine delta formation, where the river enters the lake, resuspension and redistribution, and mixing (Hilton, Lishman, and Allen 1986) disturb a uniform sedimentation. As a consequence, we propose that sediment cores located at the inflow of rivers or at the litoral zone of lakes are not suitable for reliable environmental archives. With its relatively constant sedimentation rate, sediment core A is located in the center of the lake and reflects a reliable and undisturbed archive for environmental contaminants.

$\mathrm{PAH}=\mathrm{Cu}-\mathrm{Pb} \cdots \cdots \cdots \cdot \quad \mathrm{Zn} \cdots \cdots \cdots \cdots$

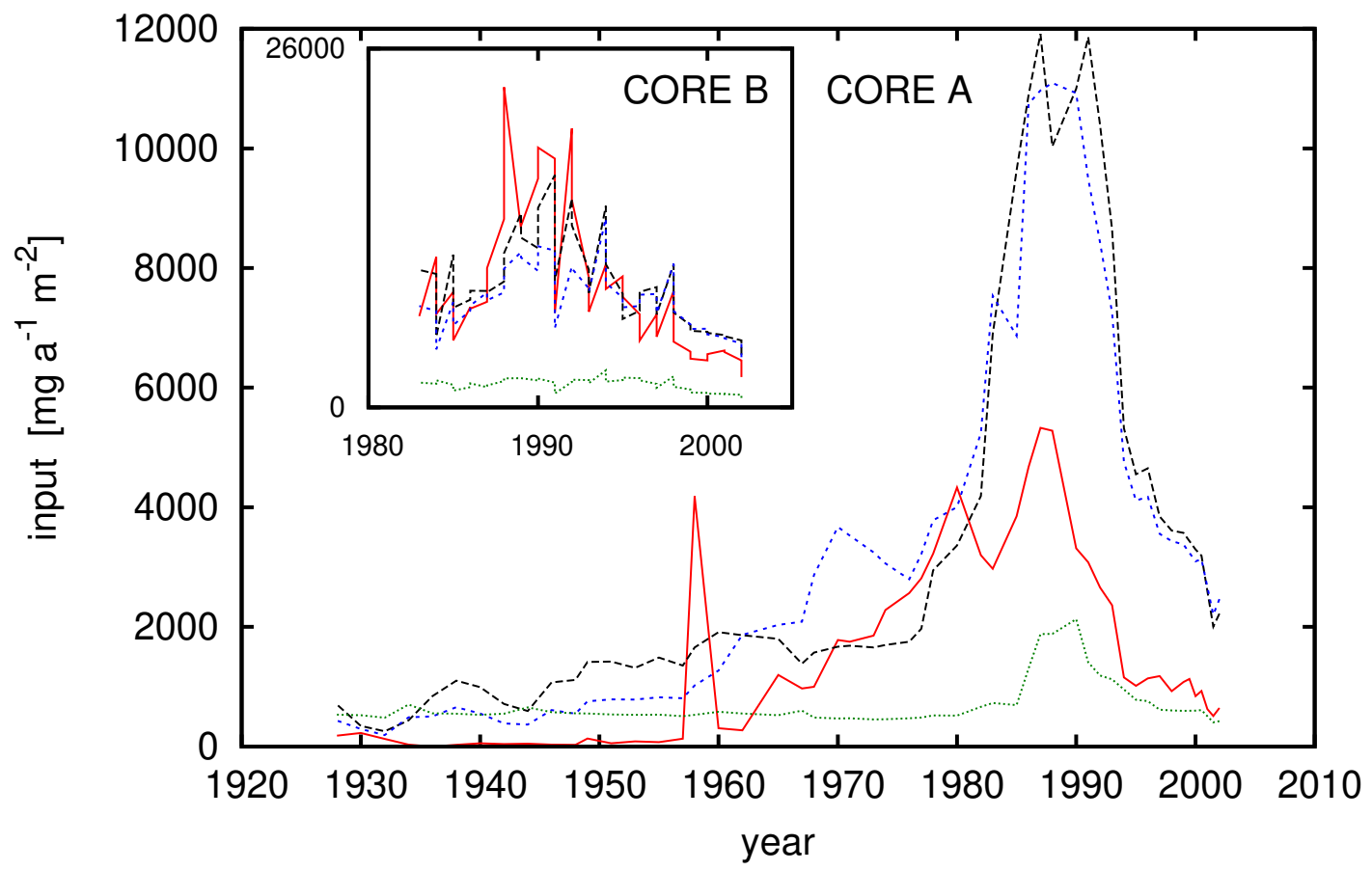

Figure 4.3.: Distribution of PAHs and heavy metals in sediment core A and B with an additional maximum input of PAH in the early 1960s in absence of an elevated input of heavy metals. 


\subsubsection{Enrichment of heavy metals and PAHs connected to copper smelting activity}

To evaluate the contaminant enrichment from coppershale mining and smelting activities, the heavy metal input of the Lake Süßer See is compared to that of other lakes and to the geogenic background. For the Mansfeld area the geogenic background is assumed to be Loess (Schnetger 1992). Copper (maximum flux: A: $11913 \mathrm{mg} \mathrm{a}^{-1} \mathrm{~m}^{-2}$ in 1986 and B: $16843 \mathrm{mg} \mathrm{a}^{-1} \mathrm{~m}^{-2}$ in 1991), lead (A:11 $092 \mathrm{mg}$ $\mathrm{a}^{-1} \mathrm{~m}^{-2}$ in 1985 and B: $13694 \mathrm{mg} \mathrm{a}^{-1} \mathrm{~m}^{-2}$ in 1994), and zinc (A: $262045 \mathrm{mg} \mathrm{a}^{-1}$ $\mathrm{m}^{-2}$ in 1985 and B: $55305 \mathrm{mg} \mathrm{a}^{-1} \mathrm{~m}^{-2}$ in 1994) are of environmental relevance again due to the intensive use of mineral fertilizer over the last few decades (Czarnecki and Düring 2015). In Lake Süßer See these elements are enriched in the range of $10-10^{2}$, see Table 4.1, compared to the lake's geogenic background and Lake Tussjön, an exemplary remote lake in Sweden with small anthropogenic influence. Due to numerous anthropogenic (Yang et al.2015) and geogenic sources in the catchment of Lake Süßer See this factor of enrichment may not be sensitive and selective enough to identify direct pollution caused by copper shale smelting, its residue Theisen sludge or distinguish the source of contamination. With an enrichment factor of $10^{5}-10^{7}$, compared to remote lakes and air as background values, PAHs are significantly more enriched than heavy metals. This yields a higher sensitivity, and enables the detection of anthropogenic influence within environmental archives, see Table 4.2. Furthermore, PAHs are more selective as no significant natural background concentrations exist (Ravindra, Sokhi, et al. 2008) that could cause such a high enrichment in lake sediments. Evaluating the PAH pattern of Lake Süßer See, both sediment cores are extremely dominated by fluoranthene and pyrene. This cannot be observed in other lakes, but matches the composition of Theisen sludge provided by Weiss et al. 1997 and Popp et al. 1997. Fluoranthene and pyrene correlate well with each other $\left(\mathrm{r}_{\mathrm{COREA} A}=0.9918\right.$ and $\left.\mathrm{r}_{\mathrm{COREB}}=0.9985\right)$ and show a relatively constant ratio of fluoranthene to pyrene beginning in the $1960 \mathrm{~s}$, see Figure 4.4 .

We propose that these two compounds are characteristic for this type of sludge. Furthermore, we assume the ratio of fluoranthene/pyrene $\sim 2$ diagnostic to identify the influence of Theisen sludge in lake environments. Vrana, Paschke, and Popp 2001 proposed a diagnostic ratio of benzo(a)anthracene to chrysene for Theisen sludge; this could not be confirmed by our study. The ratio of fluoran- 


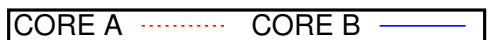

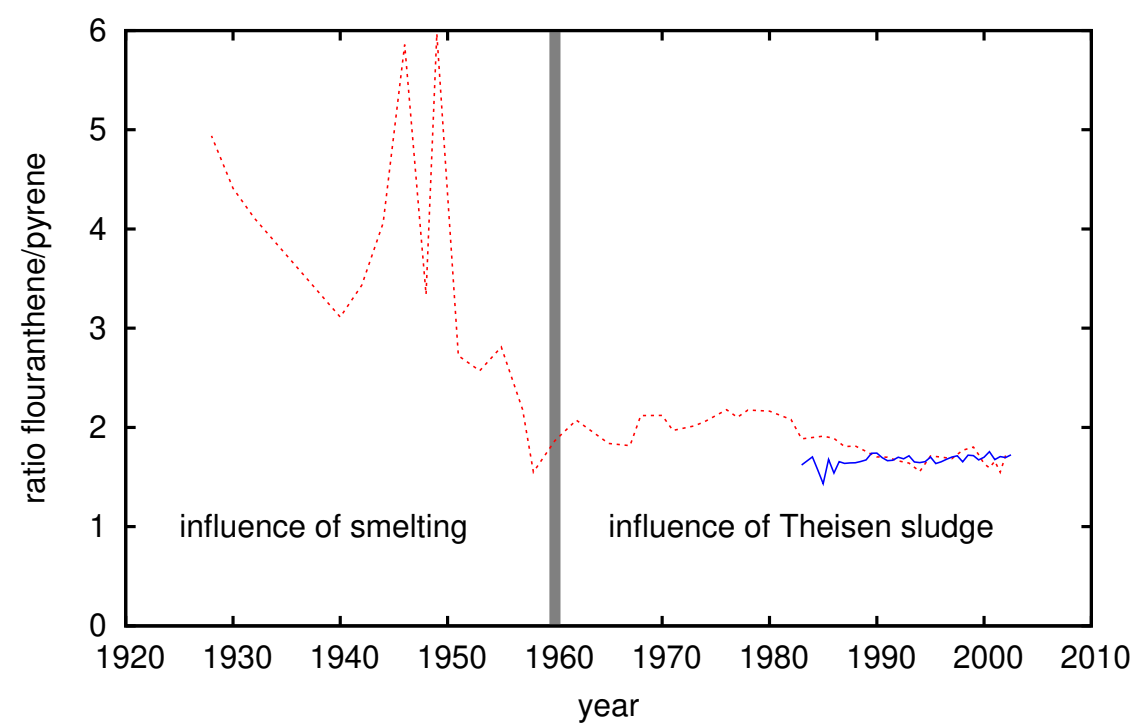

Figure 4.4.: Ratio of fluoranthene to pyrene stabilizes after 1960 and converges to 2. We assume an increasing influence for Theisen sluge beginning in 1960s in contrast to the direct influence of coppershale smelting process itself before 1960 indicated by ratio $>2$.

thene to pyrene remains constant in time. Even the additional PAHs maxima in the 1960s, which is assumed to be a result of the fire in Eisleben. This confirms the robustness against non-smelting related processes. Figure 4.5 demonstrates the ratio of PAHs with a $\log \mathrm{K}_{\mathrm{OW}}<5.7$ to PAHs with a $\log \mathrm{K}_{\mathrm{OW}}>5.7\left(\log \mathrm{K}_{\mathrm{OW}}\right.$ calculated using Advanced Chemistry Development (ACD/Labs) Software V11.02 (C1994-2015 ACD/Labs) retrieved via SciFinder).

The ratio of PAHs with $\log \mathrm{K}_{\mathrm{OW}}<5.7$ to $\mathrm{PAHs} \log \mathrm{K}_{\mathrm{OW}}>5.7$ of both sediment cores converges to the even lower value than Theisen sludge (ratio $\log \mathrm{K}_{\mathrm{OW}}<5.7$ / PAHs $\log \mathrm{K}_{\mathrm{OW}}>5.7=2.3$ ) over time. Theisen sludge as the main contaminant source represents a particulate input of contaminants into the lake, by deflation or particulate transport in the water column. So its leachate product can be eliminated as the most significant contaminant source. The particulate input of Theisen sludge further lowers the ratio of PAHs with $\log \mathrm{K}_{\mathrm{OW}}<5.7$ to PAHs $\log \mathrm{K}_{\mathrm{OW}}>5.7$. Dominating atmospheric PAH input would not undergo any fractionation and would lead to higher values of the $\log K_{\mathrm{OW}}$ ratio.

An influence of brown coal combustion is probable, but could not be verified with the proposed diagnostic ratios of Park, Kim, and Kang 2002 and Oros and 


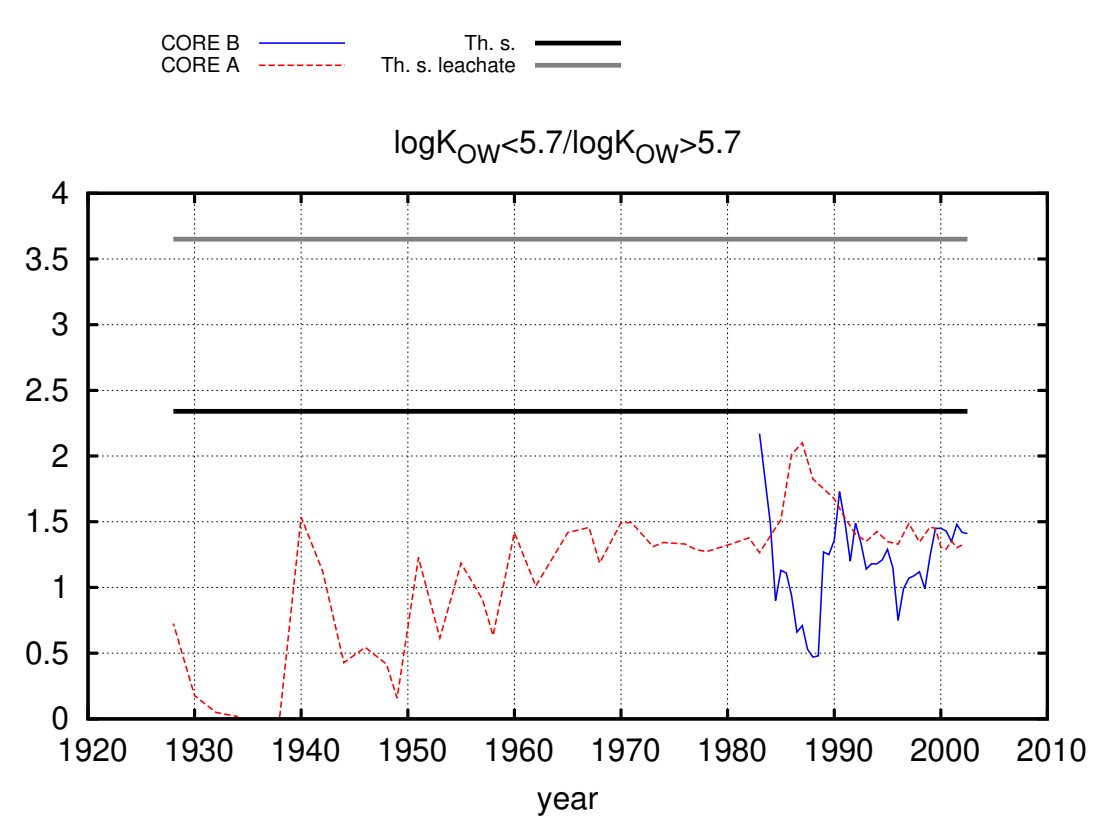

Figure 4.5.: $\log \mathrm{K}_{\mathrm{OW}}<5.7 / \log \mathrm{K}_{\mathrm{OW}}>5.7$ compared with Theisen sludge $(\mathrm{Th}$. s.) and Theisen sludge leachate calculated with data from Vrana, Paschke, and Popp 2001. The ratio of $\log \mathrm{K}_{\mathrm{OW}}<5.7 / \log \mathrm{K}_{\mathrm{OW}}>5.7$ of both sediment cores converge to an even lower the value of Theisen: 1.5 over time, which represents a particulate input of Theisen sludge.

Simoneit 2000.

In summary, we assume a significant change in the early 1960s, which could be a result of the rearrangement of the open dumps. We assume the particulate input of Theisen sludge to be responsible for such high enrichment factors, especially of PAHs. This study showed that organic contaminants, such as PAHs, are more sensitive and selective than inorganic contaminants for smelting related processes. Additionally, we were able to distinguish between contamination originating from Theisen sludge itself and that of its leachate.

\subsection{Conclusion}

To obtain knowledge related to the past contamination history of an area, environmental archives, like sediment cores from lakes, have the ability to provide reliable environmental archives that can offer a detailed time correlation. When using sediment cores from lakes for environmental archives, their location within the lake is important. Sediment cores should be sampled from relatively 
undisturbed areas with undisturbed sedimentation. Additionally, the influx of compounds should be calculated instead of comparing absolute concentrations in order to compensate for different sedimentation rates. This study demonstrated that PAHs are several magnitudes more selective and sensitive than heavy metals due to the absence of a significant natural background concentration. PAH patterns and diagnostic ratios can help us to identify the major source of contamination and to distinguish between the input of Theisen sludge and its leachate. We propose a ratio of fluoranthene to pyrene of $\sim 2$ combined with a ratio of PAHs with $\log \mathrm{K}_{\mathrm{OW}}<5.7$ to PAHs with a $\log \mathrm{K}_{\mathrm{OW}}>5.7$ converging to a ratio lower than 2.3 to identify the particulate input of Theisen sludge in lake environments. Furthermore, this study emphasized the benefits of combining the analysis of a selected group of inorganic contaminants and PAHs and comparing them.

\subsection{Acknowledgment}

We thank Prof. Jürgen Schneider and Prof. Hans Ruppert for providing both sediment cores. Additionally we thank Christina Heller and Irene Schimmelpfennig for sampling and heavy metal analysis and Mechthild Rittmeier for helping with sample preparation and analysis of PAHs. 


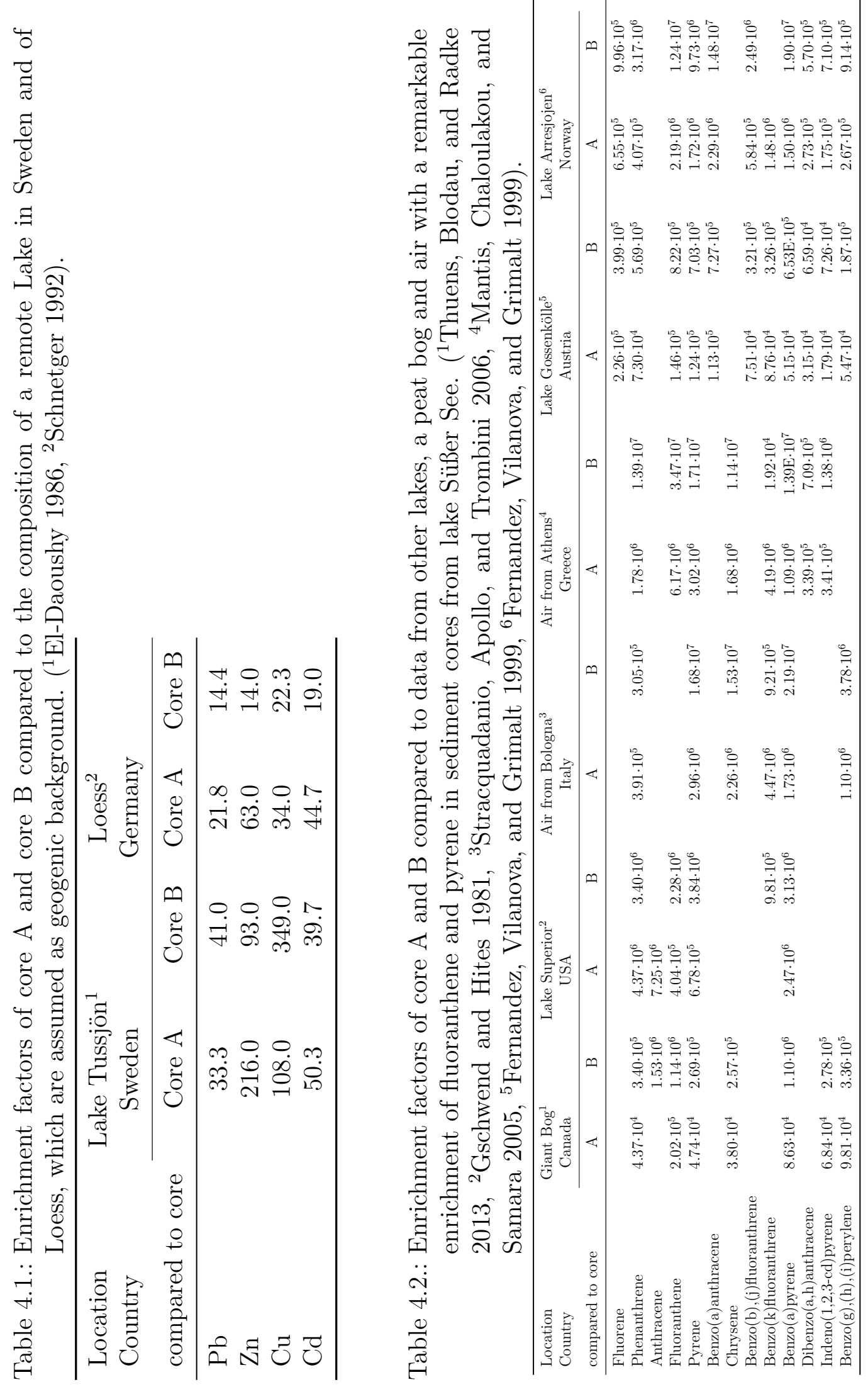




\section{References}

Becker, A. et al. (2001). "Lake Süßer See as a natural sink for heavy metals from copper mining". In: Journal of Geochemical Exploration 74.1, pp. 205-217.

Bertine, K. K. and E. D. Goldberg (1971). "Fossil fuel combustion and the major sedimentary cycle". In: Science 173.3993 , pp. 233-235.

Breedveld, G. G. D. and M. Sparrevik (2000). "Nutrient-limited biodegradation of $\mathrm{PAH}$ in various soil strata at a creosote contaminated site". In: Biodegradation 11.6, pp. 391-399.

Czarnecki, S. and R. Düring (2015). "Influence of long-term mineral fertilization on metal contents and properties of soil samples taken from different locations in Hesse, Germany". In: Soil 1.1, pp. 23-33.

El-Daoushy, F. (1986). "Scandinavian limnochronology of sediments and heavy metals". In: Hydrobiologia 143.1, pp. 267-276.

Denis, E. H. et al. (2012). "Polycyclic aromatic hydrocarbons (PAHs) in lake sediments record historic fire events: Validation using HPLC-fluorescence detection". In: Organic Geochemistry 45, pp. 7-17.

Dvorská, A. et al. (2012). "Polycyclic aromatic hydrocarbons in background air in central Europe - Seasonal levels and limitations for source apportionment". In: Atmospheric Environment 46, pp. 147-154. DOI: 10.1016/j . atmosenv.2011.10.007.

Erlenkeuser, H., E. Suess, and H. Willkomm (1974). "Industrialization affects heavy metal and carbon isotope concentrations in recent Baltic Sea sediments". In: Geochimica et Cosmochimica Acta 38.6, pp. 823-842.

Graue, B. et al. (2013). "The effect of air pollution on stone decay: the decay of the Drachenfels trachyte in industrial, urban, and rural environments - a case study of the Cologne, Altenberg and Xanten cathedrals". In: Environmental Earth Sciences 69.4, pp. 1095-1124.

Grimmer, G., J. Jacob, and K.-W. Naujack (1981). "Profile of the polycyclic aromatic hydrocarbons from lubricating oils inventory by GCGC/MS - PAH in environmental materials, part 1". In: Fresenius' Zeitschrift f\{̈̈\}r Analytische Chemie 306.5, pp. 347355.

Haykiri-Acma, H. et al. (2011). "Mobilization of some trace elements from ashes of Turkish lignites in rain water". In: Fuel 90.11, pp. 3447-3455.

Hilton, J., J. Lishman, and P. Allen (1986). "The dominant processes of sediment distribution and focusing in a small, eutrophic, monomictic lake". In: Limnology and Oceanography 31.1, pp. 125-133.

Hites, R. et al. (1980). "Polycyclic aromatic hydrocarbons in an anoxic sediment core from the Pettaquamscutt River (Rhode Island, USA)". In: Geochimica et Cosmochimica Acta 44.6, pp. 873-878.

Malawska, M., A. Ekonomiuk, and B. Wilkomirski (2006). "Polycyclic aromatic hydrocarbons in peat cores from southern Poland : distribution in stratigraphic profiles as an indicator of PAH sources". In: Society 1, pp. 1-14.

Manahan, S. E. (2010). Environmental chemistry. CRC press.

Menichini, E. (1992). "Urban air pollution by polycyclic aromatic hydrocarbons: levels and sources of variability". In: Science of the total environment 116.1, pp. 109-135. 
Müller, G., G. Grimmer, and H. Böhnke (1977). "Sedimentary record of heavy metals and polycyclic aromatic hydrocarbons in Lake Constance". In: Naturwissenschaften 431.8, pp. 427-431.

Oda, J. et al. (2001). "Mobile sources of atmospheric polycyclic aromatic hydrocarbons in a roadway tunnel". In: Atmospheric Environment 35.28, pp. 4819-4827. DOI: 10 . 1016/S1352-2310(01)00262-X.

Oros, D. and B. Simoneit (2000). "Identification and emission rates of molecular tracers in coal smoke particulate matter". In: Fuel 79.5, pp. 515-536.

Park, S. S., Y. J. Kim, and C. H. Kang (2002). "Atmospheric polycyclic aromatic hydrocarbons in Seoul, Korea". In: Atmospheric Environment 36.17, pp. 2917-2924. DOI: $10.1016 / \mathrm{S} 1352-2310(02) 00206-6$.

Popp, P. et al. (1997). "Application of accelerated solvent extraction followed by gas chromatography, high-performance liquid chromatography and gas chromatographymass spectrometry for the determination of polycyclic aromatic hydrocarbons, chlorinated pesticides and polychlorin". In: Journal of Chromatography A 774, pp. 203211.

Ravindra, K., L. Bencs, et al. (Feb. 2006). "Seasonal and site-specific variation in vapour and aerosol phase PAHs over Flanders (Belgium) and their relation with anthropogenic activities". In: Atmospheric Environment 40.4, pp. 771-785. DOI: 10 . 1016/j.atmosenv.2005.10.011.

Ravindra, K., R. Sokhi, et al. (2008). "Atmospheric polycyclic aromatic hydrocarbons: Source attribution, emission factors and regulation". In: Atmospheric Environment 42.13, pp. 2895-2921. DOI: 10.1016/j . atmosenv.2007.12.010.

Ravindra, K., E. Wauters, et al. (2006). "Assessment of air quality after the implementation of compressed natural gas (CNG) as fuel in public transport in Delhi, India". In: Environmental monitoring and assessment 115.1-3, pp. 405-417.

Rose, N. L. and B. Rippey (2002). "The historical record of PAH, PCB, trace metal and fly-ash particle deposition at a remote lake in north-west Scotland". In: Environmental Pollution 117.1, pp. 121-132.

Ruppert, H., M. Kappas, and J. Ibendorf (2013). Sustainable Bioenergy Production: An Integrated Approach. Springer.

Schmidt, R. and A. Skowronek (1994). "Weichselzeitlicher Löß als Rohstoff für die landwirtschaftliche Rekultivierung im Rheinischen Braunkohlentagebau". In: Eiszeitalter und Gegenwart, pp. 20-27.

Schneider, A. R. et al. (2001). "Recent Declines in PAH, PCB, and Toxaphene Levels in the Northern Great Lakes As Determined from High Resolution Sediment Cores". In: Environmental Science \&3 Technology 35.19, pp. 3809-3815. DOI: 10 . 1021/es002044d.

Schnetger, B. (1992). "Chemical-composition of loess from a local and worldwide view". In: Neues Jahrbuch für Mineralogie-Monatshefte 1, pp. 29-47.

Simcik, M. et al. (1996). "Atmospheric Loading of Polycyclic Aromatic Hydrocarbons to Lake Michigan as Recorded in the Sediments". In: Environmental Science $\&$ Technology 30.10, pp. 3039-3046. 
Subramanyam, V. et al. (1994). "Gas-to-particle partitioning of polycyclic aromatic hydrocarbons in an urban atmosphere". In: Atmospheric Environment 28.19, pp. 30833091.

Sverdrup, L., T. Nielsen, and P. Krogh (2002). "Soil ecotoxicity of polycyclic aromatic hydrocarbons in relation to soil sorption, lipophilicity, and water solubility". In: Environmental science \& technology 36.11, pp. 2429-2435.

Thuens, S., C. Blodau, and M. Radke (2013). "How suitable are peat cores to study historical deposition of PAHs?" In: Science of the Total Environment 450, pp. 271279.

Vrana, B., A. Paschke, and P. Popp (2001). "Polyaromatic hydrocarbon concentrations and patterns in sediments and surface water of the Mansfeld region, Saxony-Anhalt, Germany". In: Journal of Environmental Monitoring, pp. 602-609.

Weiss, H. et al. (1997). "Physical and chemical characterization of a complexly contaminated scrubber dust-a by-product of copper smelting in Sachsen-Anhalt, Germany". In: Science of the total environment 203.1, pp. 65-78.

Wennrich, R. et al. (2004). "Characterization of sediments in an abandoned mining area; a case study of Mansfeld region, Germany". In: Environmental Geology 45.6, pp. 818-833. DOI: 10.1007/s00254-003-0942-7.

Wild, S. R. and K. C. Jones (Jan. 1995). "Polynuclear aromatic hydrocarbons in the United Kingdom environment: a preliminary source inventory and budget". In: Environmental Pollution 88.1, pp. 91-108. DOI: 10.1016/0269-7491(95)91052-M.

Yang, K. et al. (2015). "Characteristics of heavy metal contamination by anthropogenic sources in artificial lakes of urban environment". In: KSCE Journal of Civil Engineering 00.0000 , pp. $1-8$.

Zhang, Y. and S. Tao (2009). "Global atmospheric emission inventory of polycyclic aromatic hydrocarbons (PAHs) for 2004". In: Atmospheric Environment 43.4, pp. 812819. DOI: $10.1016 / \mathrm{j}$. atmosenv.2008.10.050. 


\section{General conclusions and perspectives}

Criticisms of the WFD and its implementation are various, but engaging multiple countries and designing monitoring strategies for their individual water quality issues is undoubtedly a difficult challenge. To date the exiting monitoring strategy has apparently only resulted in minimal improvements in water quality. Therefore, a key challenge for the future of water quality monitoring should be to create more meaningful water quality data rather than just create more data. Meaningful data provide the necessary evidence to effect change and promote better decision making concerning the monitoring and management of water quality and catchments.

\subsection{Implementation of integrated monitoring strategies}

Catchment needs and their respective requirements for water quality vary widely. The uptake of interest amongst local communities and citizen scientists in water quality issues is rising and is often emotionally charged. Many examples in the past have shown that socio and economic requirements for water, e.g. tourism and recreational activities such as river bathing, have become increasingly important amongst the population and voluntary citizen scientists are willing and able to be increasingly engaged into water quality assessments.

Consequently, there is potential to create a more flexible approach to water quality monitoring, both in terms of widening participation in who can carry out the monitoring and also what is monitored. This would be a move away from the traditional, inflexible approach of static sampling points, fixed sampling days conducted by governmental staff and screening for a standardised list of 
pollutants. As budgets for environmental monitoring are relatively tight, a new monitoring strategy should come at lower costs or be at least cost-neutral, but with a significantly higher meaningful output. Breaking the huge variety of water quality indicators down into a set of a few selected meaningful indicators, which are relevant for the respective catchment, lowers analytical costs through a reduction in the number of analytes. Universal signals, such as electrical conductivity or temperature, serving as proxies are easily accessible and enable the engagement of both citizen scientists and innovative tools, e.g. real-time data streams from boats and drones. Nevertheless, a regular verification with indicators is always mandatory as well as a regular verification of the relationship between the indicators and proxies.

Another key element for a successful and innovative monitoring strategy is the selection of meaningful sampling spots (high information density). This must be driven by observations such as misconnected outfalls, or such as fish kills or benthic invertebrate counts (the riverfly monitoring initiative, RMI). This is already successfully applied in the River Thames system (London, UK), where citizens regularly contribute with so-called outfall safaris, helping to identify areas with potential water quality threats. Nevertheless, deciding for the right indicator sets and sampling spots, data interpretation and management and mitigation actions for catchment-scale water quality improvements still requires a lot of knowledge. This might be one of the reasons that the application of an integrated monitoring approach is still rare, besides one pilot study in Australia from the 1990s (Bennett and Lawrence 2002; Mitchell and Hollick 1993). Decision support systems (DSS) might simplify this process and can help stakeholders and decision makers during the implementation of a monitoring strategy and also with management decisions. This might help to lift novel monitoring concepts out from academia and into real field application for routine water quality monitoring.

Environmental water quality monitoring has now been carried out for several decades and, as stated many times, generates a lot of data. A future task could be to exploit and process existing water quality data to gain more systems information. For example, metabolites of the herbicide chloridazon (used since 1960s) are persistent and ubiquitous in the aquatic environment and are only removed to a minor extent by waste water treatment plants (WWTPs) or drinking water treatment (Buttiglieri et al. 2009). Consequently, they are present in drinking 
water resources and already pose a problem for drinking water supply. Exploiting exiting data might help to find correlation between pesticide/metabolite concentrations and other parameters such as nitrate and soil or rock type. This might also allow forecasting of whether rising concentrations can be expected, or how other pesticides and their respective metabolites may behave in future. Even though WFD aims to standardise water quality data to make them comparable, there are still major differences, such as different analytical techniques, limits of detection and varying compound inventories in data sets. This is a major obstacle in processing existing water quality data.

\subsection{New indicators and future problems}

Currently the WFD does not include micropollutants, such as pharmaceutically active compounds, in their priority substance list, but their appearance in water bodies will be an upcoming challenge for the future. Recognition of this can be found in specific WFD provisions for pharmaceutical substances with the aim of assessing possible environmental impacts (Directive 2013/39/EU). For priority substances the WFD amendments from 2013 include a so called watch list of "substances for which Union-wide monitoring are to be gathered for the purpose of supporting future prioritization" (art. 8b (2013/39/EU)), to be updated every two years (Kallenborn et al. 2017). An example is diclofenac which causes cytological alterations in the liver, kidney and gills of rainbow trouts even at low concentrations (Triebskorn et al. 2004) and was included into the WFD watch list in 2013, but is not yet incorporated into routine monitoring.

LC-MS/MS is often the method of choice for the determination of micropollutants. Rapid technological development in this field during the last decade allows for the simultaneous determination of an increased number of analytes per analytical run with a broader polarity spectrum in significantly shorter run times. Developments in high resolution mass spectrometry (HRMS) applications are now sufficiently sensitive to permit screening of multiple target compounds simultaneously with non-target specific screening, which allows detection of a broad spectrum of previously unknown environmentally relevant substances (Čelić et al. 2017; Richardson and Ternes 2018; Schmidt 2018). An extended polarity range is often reached by hydrophilic interaction liquid chromatography and supercritical 
fluid chromatography (SFC) (Bieber et al. 2017; Reemtsma et al. 2016). This can be an advantage for the analysis of transformation products of micropollutants as they often are more polar than their parent compounds (Boxall et al. 2012). Transformation products are often very source and process specific and allow new applications such as wastewater-based epidemiology (Andrés-Costa, Andreu, and Picó 2017; Choi et al. 2018; Lai et al. 2018). Furthermore, an extended polarity range also allows the quantification of whole new compound groups, such as highly polar persistent mobile organic compounds (PMOCs) to be exploited as indicators. PMOCs are often of emerging concern because they can easily pass selected barriers or even originate from treatment in WWTPs and hence can be a potential risk for drinking water (Reemtsma et al. 2016; Scheurer et al. 2017; Solomon et al. 2016, Tröger et al. 2018). Prominent examples for PMOCs are methyl-terbutylether (MTBE), ethylenediaminetetraacetic acid (EDTA) shortchain perfluoroalkyl acids (PFAAs) and tris(2-chloroethyl)phosphate (TCEP). They may be used as indicators to evaluate the efficiency of barriers.

Compounds such as oxamic acid, melamine and sufamic acid are PMOCs which can be found in high concentrations in the aquatic environment and this may make them useful indictors. However, their indicator quality has not been exploited yet. A source of oxamic acid seems to be ozonation of unidentified Ncontaining compounds during drinking water treatment. In particular, the main metabolites of chloridazon, desphenyl chloridazon and desphenyl methyl chloridazon can be found in high concentrations in surface water, ground and even in drinking water (Moschet et al. 2014, Tröger et al. 2018) and hence can be sources of oxamic acid during drinking water treatment (Fleischer et al. 2015).

Also melamine is increasingly detected in surface waters (Moschet et al. 2014, Seitz and Winzenbacher 2017). Melamine is routinely analysed for food quality assurance, especially in milk products, because melamine enhances the overall nitrogen content of products which increases the apparent protein content. Potential sources of melamine include rinsing off of melamine resins derived from kitchen utensils, furniture and as construction material. Additionally melamine is in the core structures of some drugs such as altretamine (hexalen, cancer treatment, not used in Germany) and ethylhexyl triazone (UVB absorber used in sunscreens). Melamine also is a metabolite of cyromazin (Sancho et al. 2005), a triazine insect growth regulator mainly used in manure, but is also approved 
as an antiparasitic drug in veterinary medicine. Sulfamic acid is predominantly used for descaling and cleaning in a variety of industrial and household cleaners (Motamedi, Tehrani-Bagha, and Mahdavian 2013), but is also identified as a transformation product of the artificial sweetener acesulfame (Castronovo et al. 2017 ). It is environmentally persistent because it does not undergo any considerable degradation so it can be found in high concentrations in surface and drinking water. As melamine, oxamic and sulfamic acid might build up to high concentrations in the water cycle and might be a problem in the future they therefore deserve special observation. However, as they have many sources and no specific parent compounds, they are obviously not very source specific and useful as indicators. Nevertheless, they might function as long-term, highly stable and nearly conservative anthropogenic indicators in general.

Most micropollutants such as pharmaceuticals, lifestyle products or pesticides are of predominantly anthropogenic origin and can even be found in remote areas with very low anthropogenic impact (Kallenborn et al. 2017). So far, compounds indicating processes, such as residence times and connectivities between water bodies, even in pristine areas with no anthropogenic impact, are still missing. A relatively new field of research is the detection of small active molecules, e.g. plant hormones (phytohormones), which regulate complex processes such as plant growth and development, defence signalling and crosstalk among them (Per et al. 2018). These may have great potential to be exploited as natural indicators in the future.

Some plant species are able to distinguish between neighbours of different genetic identity and closely related individuals (kins) to avoid competition (Semchenko, Saar, and Lepik 2014). Jasmonic acid and its conjugates play an important role in plant response to abiotic stress such as heavy metals (Maksymiec et al. 2005), drought (Brossa et al. 2011), salt (Dong et al. 2013; Zhao et al. 2014) and heat stress (Clarke et al. 2009). Organic acids such as citrate, malate and oxalate are root exudates which mobilize phosphorus in soil (Khorassani et al. 2011; Kidd et al. 2018). While citrate and malate can be found of all species, citramalate was only found in sugar beets and lotus species (Khorassani et al. 2011). While these compounds might be used as indicators to qualify abiotic stress for plants, they may well also bear a potential to be used as indicators on land use. 
Micropollutants in the environment are a double-edged sword, on the one hand more and more compounds are introduced into the environment and one parent compound can result in numerous transformation products or metabolites in the environment. Assessing the health and environmental risks for humans and biota of being exposed to so many anthropogenic compounds and synergies of compounds is nearly impossible today and their routes into the environment should be limited wherever possible. On the other hand, they allow us to build up powerful monitoring systems for water quality. 


\section{References}

Andrés-Costa, M. J., V. Andreu, and Y. Picó (2017). "Liquid chromatography-mass spectrometry as a tool for wastewater-based epidemiology: Assessing new psychoactive substances and other human biomarkers". In: $\operatorname{Tr} A C$ - Trends in Analytical Chemistry 94, pp. 21-38. DOI: 10.1016/j.trac.2017.06.012.

Bennett, J. and P. Lawrence (2002). "Adaptive management framework for catchment and coastal management and decision making". In: Coastal $\{C R C\}$ conference 1994, pp. $24-27$.

Bieber, S. et al. (2017). "RPLC-HILIC and SFC with mass spectrometry: Polarityextended organic molecule screening in environmental (water) samples". In: Analytical Chemistry, acs.analchem.7b00859. DOI: 10.1021/acs.analchem.7b00859.

Boxall, A. B. A. et al. (2012). "Pharmaceuticals and personal care products in the environment: what are the big questions?" In: Environment Health Perspectives 120.9, pp. 1221-1229. DOI: http://dx.doi.org/10.1016/j.envint.2013.06.012

Brossa, R. et al. (2011). "Interplay Between Abscisic Acid and Jasmonic Acid and its Role in Water-oxidative Stress in Wild-type, ABA-deficient, JA-deficient, and Ascorbate-deficient Arabidopsis Plants". In: Journal of Plant Growth Regulation 30.3, pp. 322-333. DOI: 10.1007/s00344-011-9194-z.

Buttiglieri, G. et al. (2009). "Environmental occurrence and degradation of the herbicide n-chloridazon". In: Water Research 43.11, pp. 2865-2873. Dor: $10.1016 / \mathrm{j}$. watres.2009.03.035,

Castronovo, S. et al. (2017). "Biodegradation of the artificial sweetener acesulfame in biological wastewater treatment and sandfilters". In: Water Research 110, pp. 342353. DOI: $10.1016 / \mathrm{j}$.watres.2016.11.041.

Čelić, M. et al. (2017). "Environmental analysis: Emerging pollutants". In: Liquid Chromatography: Applications: Second Edition 2, pp. 451-477. DOI: 10.1016/B978-012-805392-8.00015-3

Choi, P. M. et al. (2018). "Wastewater-based epidemiology biomarkers: Past, present and future". In: TrAC - Trends in Analytical Chemistry 105, pp. 453-469. DOI: 10. $1016 /$ j.trac. 2018.06 .004 .

Clarke, S. M. et al. (2009). "Jasmonates act with salicylic acid to confer basal thermotolerance in Arabidopsis thaliana". In: New Phytologist 182.1, pp. 175-187. DOI: $10.1111 / \mathrm{j} .1469-8137.2008 .02735 \cdot \mathrm{x}$.

Dong, W. et al. (2013). "Wheat Oxophytodienoate Reductase Gene TaOPR1 Confers Salinity Tolerance via Enhancement of Abscisic Acid Signaling and Reactive Oxygen Species Scavenging". In: Plant Physiology 161.3, pp. 1217-1228. DOI: 10.1104/pp. 112.211854.

Fleischer, S. et al. (2015). "Formation of Oxamic Acid During Drinking Water Treatment". In: Ozone: Science and Engineering 37.5, pp. 441-449. DOI: $10.1080 /$ 01919512.2015 .1040911$.

Kallenborn, R. et al. (2017). "Pharmaceuticals and personal care products (PPCPs) in Arctic environments: indicator contaminants for assessing local and remote anthropogenic sources in a pristine ecosystem in change". In: Environmental Science and Pollution Research, pp. 1-13. DOI: 10.1007/s11356-017-9726-6. 
Khorassani, R. et al. (2011). "Citramalic acid and salicylic acid in sugar beet root exudates solubilize soil phosphorus". In: BMC Plant Biology 11.1, p. 121. DOI: 10 . 1186/1471-2229-11-121.

Kidd, D. R. et al. (2018). "The carboxylate composition of rhizosheath and root exudates from twelve species of grassland and crop legumes with special reference to the occurrence of citramalate". In: Plant and Soil 424.1-2, pp. 389-403. DOI: $10.1007 / \mathrm{s} 11104-017-3534-0$

Lai, F. Y. et al. (2018). "Measuring spatial and temporal trends of nicotine and alcohol consumption in Australia using wastewater-based epidemiology". In: Addiction. DOI: 10.1111/add.14157

Maksymiec, W. et al. (2005). "The level of jasmonic acid in Arabidopsis thaliana and Phaseolus coccineus plants under heavy metal stress". In: Journal of Plant Physiology 162.12, pp. 1338-1346. DOI: 10.1016/j.jplph.2005.01.013.

Mitchell, B. and M. Hollick (1993). "Integrated catchment management in Western Australia: Transition from concept to implementation". In: Environmental Management 17.6 , pp. $735-743$. DOI: $10.1007 /$ BF02393894.

Moschet, C. et al. (2014). "How a complete pesticide screening changes the assessment of surface water quality". In: Environmental Science and Technology 48.10, pp. 54235432. DOI: 10.1021/es500371t

Motamedi, M., A. R. Tehrani-Bagha, and M. Mahdavian (2013). "Effect of aging time on corrosion inhibition of cationic surfactant on mild steel in sulfamic acid cleaning solution". In: Corrosion Science 70, pp. 46-54. DOI: 10.1016/j.corsci.2013.01. 007.

Per, T. S. et al. (2018). "Jasmonates in plants under abiotic stresses: Crosstalk with other phytohormones matters". In: Environmental and Experimental Botany 145.Sep. 2017, pp. 104-120. DOI: 10.1016/j .envexpbot.2017.11.004.

Reemtsma, T. et al. (2016). "Mind the Gap: Persistent and Mobile Organic Compounds - Water Contaminants That Slip Through". In: Environmental Science and Technology 50.19, pp. 10308-10315. DOI: 10.1021/acs.est.6b03338.

Richardson, S. D. and T. A. Ternes (2018). "Water Analysis: Emerging Contaminants and Current Issues". In: Analytical Chemistry 90.1, pp. 398-428. DOI: 10.1021/acs. analchem.7b04577, arXiv: arXiv:1201.4976v1,

Sancho, J. V. et al. (2005). "Residue determination of cyromazine and its metabolite melamine in chard samples by ion-pair liquid chromatography coupled to electrospray tandem mass spectrometry". In: Analytica Chimica Acta 530.2, pp. 237-243. DOI: $10.1016 / \mathrm{j}$.aca.2004.09.038

Scheurer, M. et al. (2017). "Small, mobile, persistent: Trifluoroacetate in the water cycle - Overlooked sources, pathways, and consequences for drinking water supply". In: Water Research 126, pp. 460-471. DOI: 10.1016/j.watres.2017.09.045.

Schmidt, T. (2018). "Recent trends in water analysis triggering future monitoring of organic micropollutants". In: Analytical and Bioanalytical Chemistry 410.17, pp. 39333941. DOI: $10.1007 / \mathrm{s} 00216-018-1015-9$.

Seitz, W. and R. Winzenbacher (2017). "A survey on trace organic chemicals in a German water protection area and the proposal of relevant indicators for anthro- 
pogenic influences". In: Environmental Monitoring and Assessment 189.6, p. 244. DOI: $10.1007 / \mathrm{s} 10661-017-5953-\mathrm{z}$.

Semchenko, M., S. Saar, and A. Lepik (2014). "Plant root exudates mediate neighbour recognition and trigger complex behavioural changes". In: New Phytologist 204.3, pp. 631-637. DOI: $10.1111 / \mathrm{nph} .12930$.

Solomon, K. R. et al. (2016). "Sources, fates, toxicity, and risks of trifluoroacetic acid and its salts: Relevance to substances regulated under the Montreal and Kyoto Protocols". In: Journal of Toxicology and Environmental Health - Part B: Critical Reviews 19.7, pp. 289-304. DOI: 10.1080/10937404.2016.1175981.

Triebskorn, R. et al. (2004). "Toxic effects of the non-steroidal anti-inflammatory drug diclofenac". In: Aquatic Toxicology 68.2, pp. 141-150. DOI: $10.1016 / \mathrm{j}$. aquatox . 2004.03.015.

Tröger, R. et al. (2018). "Micropollutants in drinking water from source to tap - Method development and application of a multiresidue screening method". In: Science of the Total Environment 627, pp. 1404-1432. DOI: 10.1016/j.scitotenv.2018.01.277.

Zhao, Y. et al. (2014). "A Wheat Allene Oxide Cyclase Gene Enhances Salinity Tolerance via Jasmonate Signaling". In: Plant Physiology 164.February, pp. 1068-1076. DOI: $10.1104 / \mathrm{pp} .113 .227595$ 


\section{A. Conference contributions and Co-authorship}

List of all journal articles, conference abstracts, and miscellaneous publications authored or co-authored by me and related to the presented work (latest update: June 2018).

Anwendung von Proxy-Indikator-Beziehungen als Strategie für eine effizientere Gewässerqualitätsüberwachung.

Wiebke Warner ${ }^{1}$, Karsten Nödler ${ }^{2}$, Tobias Licha ${ }^{1}$

Tagungsband Umwelt 2018, 09.-12. September 2018, Münster

${ }^{1}$ Geoscience Centre, Department of Applied Geology, Hydrochemistry Group, University of Göttingen, Goldschmidtstr. 3, 37077 Göttingen, Germany

${ }^{2}$ Water Technology Center Karlsruhe (TZW), Karlsruher Straße 84, 76139 Karlsruhe, Germany

Integrated approach for innovative monitoring strategies of reservoirs and lakes

Wiebke Warner ${ }^{1}$, Karsten Nödler ${ }^{2}$, Alessandro Farinelli ${ }^{3}$, Jason Blum ${ }^{3}$, Tobias Licha $^{1}$

International Conference Smarter Catchment Monitoring, Cleaner Waters 04.-06. September 2019 London UK (submitted)

${ }^{1}$ Geoscience Centre, Department of Applied Geology, Hydrochemistry Group, University of Göttingen, Goldschmidtstr. 3, 37077 Göttingen, Germany

${ }^{2}$ Water Technology Center Karlsruhe (TZW), Karlsruher Straße 84, 76139 Karlsruhe, Germany

${ }^{3}$ Computer Science Department, University of Verona, Verona CAP 37134, Italy 


\section{Co-authorship}

M. Ibenthal et al. (2018). "Determination of governing processes that drive groundwater flow between a coastal peatland and the Baltic Sea". In: Poster - 25th Salt Water Intrusion Meeting, Gdansk Poland

S. Schmidt et al. (2018). "Kontaminationsdynamik eines urban beeinflussten semiariden Karstaquifersystems - Empfehlungen für Monitoring und Rohwassermanagement". In: FH-DGGV-Tagung Bochum

M. Schaffer, W. Warner, and T. Licha (2016). "Organic Molecules as Sorbing Tracers for the Characterization of Fracture Surface Areas in Enhanced Geothermal Systems (EGS)". in: PROCEEDINGS, 41st Workshop on Geothermal Reservoir Engineering. Vol. February 2

\section{Co-authorship peer-reviewed journals}

M. Schaffer, W. Warner, S. Kutzner, et al. (2017). "Organic molecules as sorbing tracers for the assessment of surface areas in consolidated aquifer systems". In: Journal of Hydrology 546, pp. 370-379. DOI: 10.1016/j.jhydrol.2017.01.013 